PNL-7700

UC-510

$5 c$

\title{
Chemical Evaluations of John F. Baldwin Ship Channel Sediment Phase II
}

N. P. Kohn

L. F. Lefkovitz
K. O. Barton

J. Q. Word

Battelle/Marine Sciences Laboratory

Sequim, Washington

May 1991

Prepared for the U.S. Army Corps of Engineers

under a Related Services Agreement

with the U.S. Department of Energy

under Contract DE-AC06-76RLO 1830

Pacific Northwest Laboratory

Operated for the U.S. Department of Energy

by Battelle Memorial Institute 


\title{
DISCLAIMER
}

This report was prepared as an account of work sponsored by an agency of the United States Government. Neither the United States Government nor any agency thereof, nor Battelle Memorial Institute, nor any of their employees, makes any warranty, expressed or implied, or assumes any legal liability or responsibility for the accuracy, completeness, or usefulness of any information, apparatus, product, or process disclosed, or represents that its use would not infringe privately owned rights. Reference herein to any specific commercial product, process, or service by trade name, trademark, manufacturer, or otherwise does not necessarily constitute

or imply its endorsement, recommendation, or favoring by the United States Government or any agency thereof, or Battelle Memorial Instituie. The views and opinions of authors expressed herein do not necessarify state or reflect those of the United States Government or any agency thereof.

\author{
PACIFIC NORTHWEST LABORATORY \\ operated by \\ BATTELIE MEMORIAL INSTITUTE \\ for the \\ UNITED STATES DEPARTMENT OF ENERGY \\ under Contract DE-ACO6-76RLO 1830
}

Printed in the United States of America

Available to DOE and DOE contractors from the

Office of Scientific and Technical Information, P.O. Box 62, Oak Ridge, TN 37831; prices available from (615) 576-8401. FTS 626-8401.

Available to the public from the National Technical Information Service, U.S. Department of Commerce, 5285 Port Royal Rd., Springfield, VA 22161. 
PNL -7700

UC -510

CHEMICAL EVALUATIONS OF

JOHN F. BALDWIN

SHIP CHANNEL SEDIMENT

PHASE II
N. P. Kohn
L. F. Lefkovitz
K. 0. Barton
J. Q. Word

Battelle/Marine Sciences Laboratory

Sequin, Washington

May 1991

\begin{abstract}
Prepared for the U.S. Army Corps of Engineers under a Related Services Agreenent with the U.S. Department of Energy under Contract DE-ACO6-76RLO 1830
\end{abstract}

Pacific Northwest Laboratory Richland, Washington 99352 



\section{EXECUTIVE SUMMARY}

In August of 1990, the Battelle/Marine Sciences Laboratory (MSL) conducted a program of sampling, geologic characterization, and chemical analysis of sediments from five sites in the West Richmond reach of the John $F$. Baldwin Ship Channel in San Francisco Bay. The study was conducted for the U.S. Army Corps of Engineers (USACE), San Francisco District. Additional sediment samples were collected for the USACE Waterways Experiment Station (WES) Wetlands and Uplands testing programs.

The objective of the MSL study of the five West Richmond sites was to determine the physical characteristics and chemical contaminant levels in sediments proposed for dredging. One core sample from each site was collected to the dredging project depth of $-45 \mathrm{ft}$ relative to mean lower low water (MLLW) plus $2 \mathrm{ft}$ of overdepth for a total sampling depth of $-47 \mathrm{ft}$ MLLW. Cores from the Phase II West Richmond stations ranged in length from 4.7 to $12.8 \mathrm{ft}$. Each core was split longitudinally so that one half was used for geologic characterization and the other half for chemical analysis. Sediment samples for chemical analysis were prepared by homogenizing the sediment between the sediment surface (mudline) to $-47 \mathrm{ft} \mathrm{MLLW.} \mathrm{These} \mathrm{samples} \mathrm{were}$ analyzed for trace metals, butyltins, polynuclear aromatic hydrocarbons (PAH), polychlorinated bipheny?s (PCB), chiorinated pesticides, and sediment conventionals (grain size, total organic carbon, total volatile solids, oil and grease, and petroleum hydrocarbons).

The sediments were described as predominantly dark olive-gray sands with interstratified layers of silt and/or clay. Grain size analysis bore this out as all five sediment samples contained more than 50\% sand and less than $20 \%$ clay. Contaminant levels in the Phase II West Richmond sediments were very low. Metals concentrations were comparable to or lower than those measured in Phase 1 samples. Butyltin concentrations were very low, with no sample containing more than $2 \mu \mathrm{g} / \mathrm{kg}$ total butyltin. Organic contaminants (PAH, PCB, and pesticides) were not detected in any of the Phase II West Richmond samples. The absence of PAH compounds at three Phase II stations (WR-C, WR-D, and WR-E) was in contrast to total PAH concentrations of $474-3075 \mu \mathrm{g} / \mathrm{kg}$ measured at three nearby Phase I stations (WR V L, WR IV.5 C, and WR IV R). The differences may be explained by the fact that the Phase II stations were located outside the existing channel, $1-2000 \mathrm{ft}$ east of the Phase I stations. 
. 


\section{ACKNOWLEOGMENTS}

The authors thank the following people for their assistance on the John F. Baldwin Phase II project: Bruce Bjornstad for his assistance on and review of the geological core descriptions; Mike Hamilton and Maureen Kilpatrick for chemistry data entry; Lyle Hibler and Ray Bienert for Macintosh computer training and support.

The Battelle/Marine Sciences Laboratory is part of the Pacific Northwest Laboratory, which is operated for the U.S. Oepartment of Energy by Battelle Memorial Institute under Contract DE-AC06-76RLO 1830. 
.

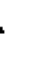

. 


\section{CONTENTS}

EXECUTIVE SUMMARY ....................... . . . . . .

ACKNOWLEDGMENTS ....................

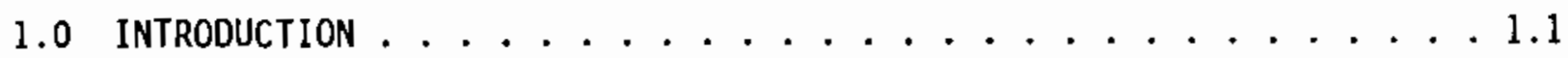

2.0 MATERIALS AND METHODS $\ldots \ldots \ldots \ldots \ldots$

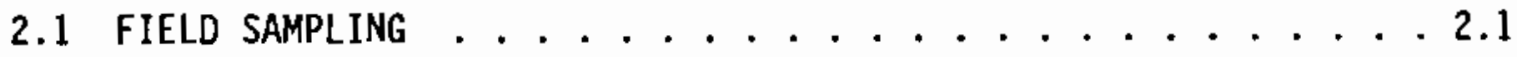

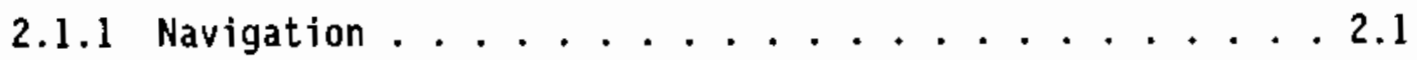

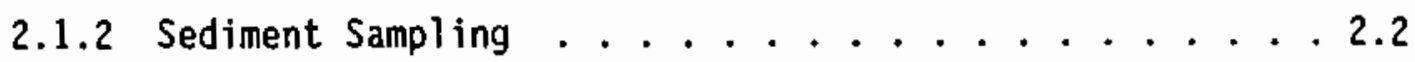

2.2 SEDIMENT SAMPLE PREPARATION AND Geologic

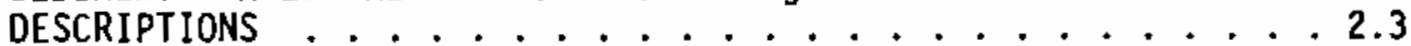

2.3 ANALYTICAL CHEMISTRY . . . . . . . . . . 2.4

2.3.1 Sediment Conventionals . . . . . . . . . 2.6

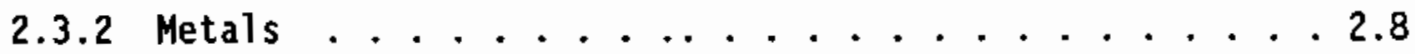

2.3.3 Butyltins . . . . . . . . . . . . 2.8

2.3.4 Semivolatile Organic Compounds . . . . . . . . 2.9

2.3.5 Chlorinated Pesticides and Polychlorinated

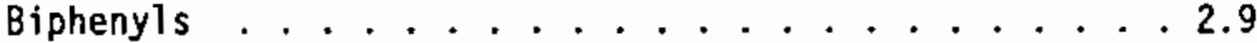

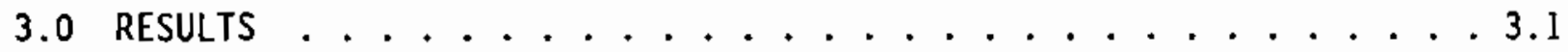

3.1 SEDIMENT SAMPLING FOR MSL ANALYSIS OF WEST

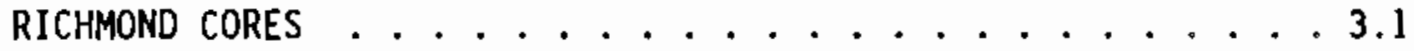

3.2 SEDIMENT SAMPLING FOR WES WETLANDS/UPLANDS TESTING $\ldots \ldots .3$

3.3 ANALYSIS OF WEST RICHMOND 4 -IN CORES $\ldots \ldots \ldots . . \ldots . . . \ldots$

3.3.1 Geologic Descriptions . . . . . . . . . . 3.7

3.3.2 Analytical Chemistry . . . . . . . . . 3.10

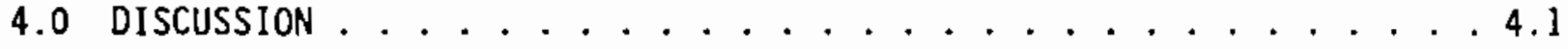

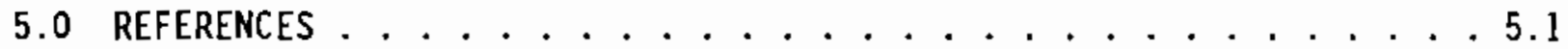




\section{CONTENTS (Cont)}

APPENDIX A - MATERIALS AND METHODS USED FOR THE OESCRIPTION OF

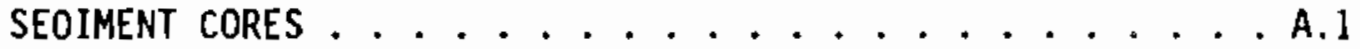

APPENOIX B - JOHN F. BALDWIN SHIP CHANNEL PHASE II GEOTOgic CORE LOGS OF WEST RICHMOND CORES .................... 


\section{FIGURES}

1.1 John F. Baldwin Ship Channel Study Area . . . . . . . . . 1.2

3.1 West Richmond Sampling Sites, John F. BaIdwin Ship ChanneT Showing Both Phase I \& Phase II Stations .......... 3.2

3.2 Pinole Shoal Sampling Sites, John F. Baldwin Ship Channel

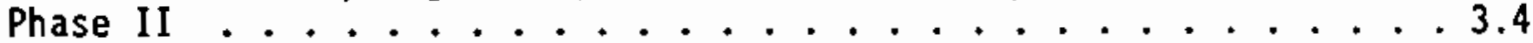

3.3 Sediment Lithology in the West Richmond Reach of John F. Baldwin Ship Channel

\section{TABLES}

2.1 Analytical Chemistry Requirements for John F. Baldwin Ship Channel Sediment Samples ................. 2.5

3.1 Sampling Information for Phase II West Richmond Stations . . . . 3.1

3.2 West Richmond and Pinole Shoal Stations Sampled for WES Uplands and Wetlands Testing ..................... 3.5

3.3 Summary of Grain Size Analysis, Phase II West Richmond Cores . . . 3.11

3.4 Results of Grain Size Analysis, Phase II West Richmond Cores . . . 3.12

3.5 Total Volatile Solids, Total Organic Carbon, $0 i 1$ and Grease, Total Petroleum Hydrocarbons, and Petroleum Fraction as a Percentage of $0 \mathrm{il}$ and Grease in West Richmond Sediment ..... . . 3.14

3.6 Quality Control Data for Metals Analysis, West Richmond

Sediment, John F. Baldwin Ship Channel Phase II . . . . . 3.15

3.7 Metals in Phase II West Richmond Cores . . . . . . . . . . 3.17

3.8 Butyltins in West Richmond Sediment . . . . . . . . . . . 3.19

3.9 Polychlorinated Biphenyls in West Richmond Sediment . . . . . 3.21

3.10 Pesticides in West Richmond Cores . . . . . . . . . . . . 3.22

3.11 Results of Sediment Matrix Spikes ............... 3.23

3.12 Polynuclear Aromatic Hydrocarbons in Phase II West Richmond Cores .................. . . 3.24

3.13 Matrix Spike Data for PAH Analysis . . . . . . . . . . . 3.25

3.14 Standard Reference Material PAH Results . . . . . . . . . . 3.26

4.1 Comparison of PAH, Core Length, Percent $\mathrm{Clay}$, and TOC in West Richmond Sediments, John F. Baldwin Phases I and II . . . . . 4.2 


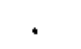

. 


\subsection{INTRODUCTION}

The John F. Baldwin Ship Channel is the major shipping channel in San Pablo Bay that connects San Francisco Bay with Suisun Bay (Figure 1.1). The San Francisco District of the U.S. Army Corps of Engineers (USACE) is responsible for construction and improvement of the John F. Baldwin Ship Channe1, authorized by Congress in the Rivers and Harbors Act of 1965 (Public Law B9-298). The John F. Baldwin Channel is approximately $2 B$ miles long, and will be maintained at a project depth of $-45 \mathrm{ft}$ relative to mean lower low water (MLLW). To this end, it is estimated that 800,000 cubic yards (cy) of sediment from the West Richmond reach, 7,000,000 cy from the Pinole Shoal reach, and 800,000 cy from Carquinez Strait will be dredged and removed from the Channel.

In order to evaluate alternative disposal methods for the dredged sediment, USACE requested Battelle's Marine Sciences Laboratory (MSL) to provide information on chemical and physical characteristics of the sediment. Phase I of MSL's John F. Baldwin Program, conducted in 1989-1990, included sampling, geologic description, and chemical analysis of sediment cores collected from 47 sites. The results are published in Chemical Evaluations of John F. Baldwin Ship Channel Sediment (Word and Kohn 1990). The Phase I study showed little sediment contamination in the John F. Baldwin Channel, except for elevated levels of polynuclear aromatic hydrocarbons (PAH) in the West Richmond Reach and possible elevated levels of trace metals in both Central Pinole Shoal and Carquinez Strait. These Phase I sediment data were used to plan the next phase of John F. Baldwin Ship Channel sediment evaluations.

Phase II of the John F. Baldwin Ship Channel Program was planned with two major objectives in mind. The first was to collect sediment from the relatively uncontaminated northern and western portions of the Pinole Shoal. This sediment would be sent to USACE's Waterways Experiment Station (WES) in Vicksburg, Mississippi, where tests would be conducted to determine acceptability of sediment for the creation of marshes and also evaluated for use in uplands disposal. The second objective was to further examine the 


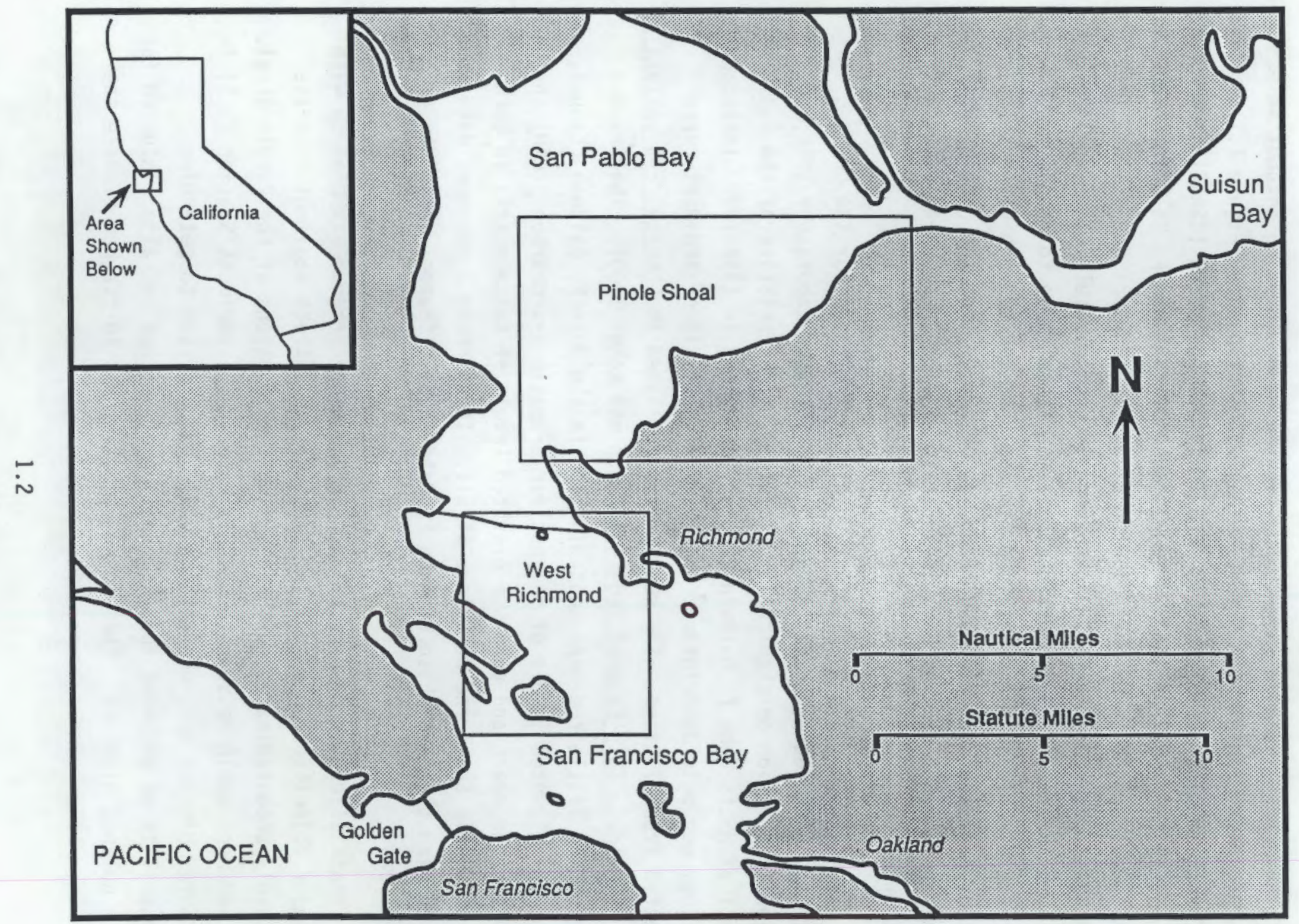

FIGURE 1.1. John F. Baldwin Ship Channel Study Area 
characteristics of sediments in the West Richmond area by collecting and analyzing core samples from five new sites from this reach. The data from the new sites were then compared to data from the West Richmond sites that were sampled in 1989 during Phase I. The materials and methods used during Phase II sampling, the results of sampling, and the analysis of West Richmond core samples are presented in this report. 


\subsection{MATERIALS AND METHODS}

\subsection{EIELD SAMPLING}

The objectives of the field sampling program were to collect sediment and water samples for uplands and wetlands testing to be performed by USACEWES, and to collect sediment for Battelle's geologic and chemical analysis. The WES testing programs required 15 55-gal drums of sediment for each of the testing composites, and 20 gal of water to be used for mixing with these sediments from the relatively uncontaminated areas in the West Richmond and Pinole Shoal reaches of the John F. Baldwin Ship Channel. Because of these large quantities of required sediment, the WES material was collected in the 12-in.-diameter split core sampler designed specifically for these types of programs and described below. The testing program performed by MSL required relatively undisturbed core samples contained in a noncontaminating tube to maintain the stratigraphy and chemical integrity of the sediment. The coring tool used for this purpose was a 4-in diameter vibratory-hammer core, originally designed to sample Merritt Sand formations in 0akland Harbor (Word et al. 1990). All core sampling was conducted from the derrick barge (DB) Hagar, a marine construction platform owned and operated by Manson construction. The barge platform was maneuvered into position by the tugboat Betty $L$ of Westar Marine Services.

\subsubsection{Navigation}

Navigational services were provided by Land and Sea Surveyors of Ventura, California, using a Miniranger transceiver/receiver system. Five shore control sites were used to assure horizontal accuracy $( \pm 2 \mathrm{~m})$. The ranges to each of the planned sampling sites were entered into a computer system set up on the tugboat, which generated a plot of each point on a monitor in the wheelhouse. The skipper of the tugboat would maneuver the barge to the sampling point by watching the movement of the tug and barge on the monitor. When the winds and currents prevented efficient maneuvering by this method, the barge would be anchored so the tug could locate and mark the sampling sites with buoys. Water depths were measured from the barge deck using a handheld fathometer. Tide corrections were made using daily tide book 
predictions for the closest appropriate point to the sampling site. West Richmond stations were corrected to the Chevron pier, while Pinole Shoal stations were corrected to the nearest control point of Hercules, Mare Island, or Pinole Point. If, within a $25-\mathrm{ft}$ radius of any station, there were no depths shallower than $-47 \mathrm{ft}$ MLLW, the station was repositioned.

\subsubsection{Sediment Sampling}

Two types of core samplers, a 12-in.-diameter split core and a 4-in.diameter lexan-lined push tube, both designed by Battelle, were used to meet the sediment sampling requirements for Phase II. Both samplers were deployed from D/B Hagar in a similar manner. To collect a sample, the core sampler was suspended from the crane on the derrick barge, and the crane lowered the sampler to the surface of the sediment. If the mass of the sampler itself did not penetrate the sediment to $-47 \mathrm{ft}$ MLLW (project depth of $-45 \mathrm{ft}$ MLLW plus $2 \mathrm{ft}$ overdepth), the core sampler was driven to depth by a 6-ton electric vibratory hammer. The core barrel was then lifted from the sediment by the crane, decoupled from the vibratory hammer, and lowered onto the deck of the barge.

The 12-in split core sampler yield is approximately 5.8 gal of sediment per running foot, so it was used to collect the large volumes of sediment needed for the WES uplands and wetlands testing programs. The sampler consists of a 12-in.-diameter pipe that is split for approximately $30 \mathrm{ft}$. This $30-\mathrm{ft}$ opening is separated into two hinged door areas that are each $10 \mathrm{ft}$ long. The upper door of this split core was welded shut most of the time, but was cut open when a longer core was needed. The lower door was held shut by chain binders during sampling. Sediment was retained in the 12-in split core either by the plugging the bottom of the core with compact sands or silts whose strength of compaction was sufficient to retain the core in the tube or by a specialiy designed flapper valve. When a 12-in core was brought on deck,

the lower door was unchained and pried open to expose the sediment. The length of the core was measured and recorded. If sufficient sediment was collected, the sediment from the appropriate depth fraction (mudline to $-47 \mathrm{ft}$ MLLW) was shoveled into a labeled, epoxy-coated 55-gal drum. The drums were 
kept covered at all times unless actively being filled. The core sampler was thoroughly rinsed with seawater between stations.

The 4-in.-diameter sampler was used to collect cores from the West Richmond sites for geologic description and chemical analysis. The quantity of sediment provided per foot in this core is approximately $1.9 \mathrm{~L}$. The 4 -in core barrel was lined with a length of steam-cleaned non-contaminating lexan polycarbonate tubing, which protected the sediment from disturbance and contamination. Sediment was retained in the LEXAN core liner either by specially designed ball valves and core catchers or a flapper valve. When the sampler was brought onto the barge, the lexan liner containing the sediment was pulled from the sampler and measured to confirm that sufficient depth was reached. The core was then capped at both ends and labeled. If necessary, samples were cut and capped in shorter sections to fit inside the storage freezer on board the D/B Hagar, where all core samples were stored at approximately $4^{\circ} \mathrm{C}$.

At the end of each day of sampling, samples were loaded into a refrigerated truck maintained at approximately $4^{\circ} \mathrm{C}$. When all sampling was completed, samples for WES were shipped to Vicksburg, Mississippi, in one refrigerated truck. Samples for Battelle were shipped to the MSL in Sequim, washington, using another truck.

\subsection{SEDIMENT SAMPLE PREPARATION AND GEOLOGIC DESCRIPTIONS}

After the 4 -in core samples arrived at the MSL, they were stored in a walk-in cold room at $4^{\circ} \mathrm{C}$ until processed. Each core was cut in half longitudinally, and measured from the top to the $-47-\mathrm{ft}$. MLLW point, where it was marked. Sediment between the mudline and $-47-\mathrm{ft}$. MLLW was removed from one half of the core, using a clean, solvent-rinsed stainless-steel spoon, and taking care to avoid removal of sediment that was in contact with the lexan liner. Sediment was placed in a clean, solvent-rinsed stainless-steel bowl and was homogenized with the spoon until consistent in color and texture. Aliquots of homogenized sediment were removed to appropriately labeled containers for analysis of metals, butyltins, organics, and grain size.

Sediment sample containers were logged in at MSL's chemistry laboratory, and 
distributed for appropriate analyses. The other half of the core was wrapped in sheet Teflon secured with tape, labeled, and stored in the $4^{\circ} \mathrm{C}$ cold room until a geologic description could be done. The geologic descriptions were performed according to the American Society for Testing and Materials (ASTM) Procedure D2488-84, Standard Practice for Description and Identification of Soils (Visual-Manual Procedure) (ASTM 1984). This procedure is detailed in Appendix A.

\subsection{ANALYTICAL CHEMISTRY}

The following sections briefly describe the methods used for analysis of West Richmond sediment for the required chemical and physical parameters. A total of five sediment samples were analyzed for conventional parameters such as total organic carbon (TOC), total volatile solids (TVS), $0 i 1$ and grease, total petroleum hydrocarbons (TPH), and grain size. These samples were also analyzed for 11 metals, butyltins, polychlorinated biphenyls (PCBs), chlorinated pesticides, and polynuclear aromatic hydrocarbons (PAHs). Analyses followed established U.S. Environmental Protection Agency (EPA) procedures where applicable. References are given for those methods not provided by EPA.

Analyses were performed at different laboratories. TVS, metals and butyltins were analyzed at MSL. TOC was performed at Global Geochemistry in Canoga Park, California. PCBs, pesticides, PAHs, oil and grease, and TPH were analyzed at Twin City Testing, St. Paul, Minnesota. Grain size analyses were performed at Soil Technologies, Bainbridge Island, Washington.

Table 2.1 presents a list of the analytes and their detection limit goals. Quality control samples included a set of analytical triplicates, matrix spike and matrix spike duplicate analyses, surrogates and method bTanks. 
TABLE 2.1. Analytical Chemistry Requirements for John F. Baldwin Ship Channel Sediment Samples

Parameters

Conventionals

Total Organic Carbon

Total 0 il and Grease

Total Petroleum HCs

Total Volatile Solids

Grain Size
Detection Limits (a) (mg/kg)

Metals

$\begin{array}{ll}\mathrm{Ag} & 0.1 \\ \mathrm{As} & 2 \\ \mathrm{Cd} & 0.1 \\ \mathrm{Cr} & 2 \\ \mathrm{Cu} & 2 \\ \mathrm{Hg} & 0.02 \\ \mathrm{Ni} & 2 \\ \mathrm{~Pb} & 2 \\ \mathrm{Se} & 1 \\ \mathrm{Tl} & 10.1 \\ \mathrm{Zn} & 2\end{array}$

Organics
Buty $($ B
0.01
PAHs (c)
0.02
Pesticides (d)
0.02
0.002
$0.1 \%$
20
20
$0.1 \%$
N/A

0.1

0.1

0.02

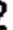

10.

\footnotetext{
(a) Target detection 1 imits; all efforts were made to reach lowest practical detection limits.

(b) Reported as aroclor equivalents 1242, 124B, 1254, and 1260 and total PCB.

(c) A11 compounds on EPA Method 610 1 ist.

(d) All compounds on EPA Method 608 list.
} 


\subsubsection{Sediment Conventionals}

\section{Grain Size}

Grain size of sediment samples was determined by a combination of sieve and pipet techniques following the Puget Sound Estuary Program (PSEP) Protocols for Measuring Selected Environmental Variables in Puget Sound (PSEP 1986). These methods are consistent with ASTM D421 (ASTM 1978) and D422 (ASTM 1972). Approximately $25 \mathrm{~g}$ of sediment were removed for analysis of total solids while another 10 - to $100-\mathrm{g}$ aliquot was weighed for grain size analysis. To separate the coarser sand and gravel fraction from the silt/clay fraction,

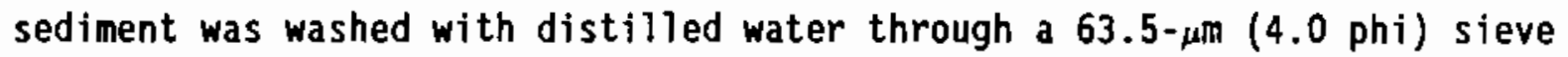
into a 1-L graduated cylinder. The coarse fraction was dried, weighed, and shaken through a nest of sieves to yield the required seven coarse subfractions. Any material still passing the final 63.5- $\mu \mathrm{m}$ sieve was added to the previous fines in the $1-L$ graduated cylinder. The silt/clay fraction was then subdivided by a pipet technique based on Stoke's Law of differential settling velocities for different sized particles. The silt/clay fraction was disassociated by a dispersant in distilled water in a $1-L$ graduated cylinder. At specified time intervals and specified depths below the surface, 20-mL aliquots of suspension were withdrawn from the graduated cylinder, delivered to a preweighed container, and dried to constant weight at $90 \pm 2^{\circ} \mathrm{C}$. Quality control measures included triplicate analysis of one sample. Spikes, standard reference materials, or minimum detection limits do not apply to grain size.

\section{Total Organic Carbon}

The TOC measurement includes the amount of non-volatile, partially volatile, volatile, and particulate organic compounds in a sample. The TOC in sediment was determined by measuring the carbon dioxide released during combustion of the sample (PSEP 1986; SW846 Method 9060, EPA 1986). The sediment sample was dried and ball milled. Before combustion, inorganic carbonate was removed by acidification. TOC was analyzed by combusting samples at $800^{\circ} \mathrm{C}$ and using a DC-80 Total Carbon Analyzer with a Sludge and Sediment Sampler accessory. Quality control measures included a matrix spike and triplicate analysis of one sample. Results are reported as percent of dry weight. 


\section{Total Volatile Solids}

TVS is a measure of the fraction of total solids that are lost on ignition at a higher temperature than that used to determine total solids. Total volatile solids is used as an estimate of the amount of organic matter in the total solids. TVS is operationally defined by the combustion temperature. TVS does not always represent the organic content of a sample because some organic material may be lost at the drying temperature and some inorganic material may be lost at the ignition temperature.

The method used to determine TVS in John F. Baldwin Ship Channel sediments followed that defined in the Puget Sound Protocols (PSEP 1986). The sample was dried to constant weight by freeze-drying and was ball milled to a fine powder. A portion was removed, weighed, and combusted at $550^{\circ} \mathrm{C}$. The sample was cooled in a desiccator and then reweighed. The amount of sample lost during ignition was defined as the volatile fraction and expressed as a percent of the dry weight of the total solids.

\section{0 i] and Grease and Petroleum Hydrocarbons}

Total oil and grease includes vegetable oils, animal fats, soaps, waxes, and any other carbon-hydrogen material extractable by the solvent FREON. Total petroleum hydrocarbons are the mineral fraction of total oil and grease. Infrared (IR) spectrophotometry is used to determine concentrations of $0 i 1$ and grease (Method 413.2, EPA 1979) and petroleum hydrocarbons (Method 418.1, EPA 1979). A 20-g aliquot of sample was dried with anhydrous sodium sulfate, then extracted with Freon.

For total oil and grease, sample extracts were scanned from 4000 to 600 $\mathrm{cm}^{-1}$ on an IR spectrophotometer and the peak height measured at $2930 \mathrm{~cm}^{-1}$. $0 i 1$ and grease and total petroleum hydrocarbons (TPH) were extracted from sediment with Freon, diluted, and split into two aliquots. The TPH aliquot was treated with silica gel to remove non-petroleum oils. Each aliquot was analyzed using an IBM IR/42 IR spectrometer. This wavelength represents the $-\mathrm{CH}_{2}$ configurations of hydrocarbons and was the standard used to determine oil and grease. 
For TBHs, silica gel was added to the extract to remove the animal-and vegetable-based oils. The extract was then shaken and allowed to settle, and an aliquot was removed and scanned the same way as for oil and grease. The relationship of peak height to oil concentration was determined by regressing the peak height versus a known concentration of fuel oil.

\subsubsection{Metals}

Eleven metals were measured in John F. Baldwin Ship Channel sediments: silver (Ag), arsenic (As), cadmium (Cd), chromium ( $\mathrm{Cr}$ ), copper (Cu), mercury $(\mathrm{Hg})$, nickel (Ni), lead (Pb), selenium (Se), thallium (Tl), and zinc ( $\mathrm{Zn}$ ). $\mathrm{Six}$ of these metals ( $\mathrm{As}, \mathrm{Cr}, \mathrm{Cu}, \mathrm{Ni}, \mathrm{Pb}$, and $\mathrm{Zn}$ ) were measured by energydiffusive X-ray fluorescence (XRF) following the method of Nielson and Sanders (1983). Mercury was analyzed by cold-vapor atomic absorption spectroscopy (CVAA) (SW846 Method 7471, EPA 1986a; Bloom and Crecelius 1983), while Ag, Cd, Se, and T) were analyzed by Zeeman graphite-furnace atomic absorption spectroscopy (GFAA) (SW846 7000 series, EPA 1986; Bloom and Crecelius 19B4).

To prepare sediments for analysis, samples were freeze-dried, then blended in a mixer-mill. Approximately $5 \mathrm{~g}$ of mixed sediment was ground in a ceramic ball mill. The XRF analysis was performed on a $0.5-\mathrm{g}$ aliquot of dried, ground sediment pressed into a pellet of $2 \mathrm{~cm}$ diameter. For GFAA and CVAA analysis, $0.2-\mathrm{g}$ aliquots of dried homogenate went through an acid digestion process to separate and isolate the metals from the sediment. Quality control measures for metals determination included analysis of blanks (not applicable to XRF technique), one set of triplicate analyses, and analysis of two SRM samples: National Bureau of Standards (NBS) SRM 1646 and National Research Council of Canada (NRCC) SRM MESS-1.

\subsubsection{Butyltins}

Butylt in compounds were analyzed using gas chromatography with flame photometric detection (GC-FPD) following the methods of Unger et al. (1986). Approximately $10 \mathrm{~g}$ of wet sediment was weighed into a solvent-rinsed jar, dried with anhydrous sodium sulfate, then extracted from sediment with $110 \mathrm{~mL}$ methylene $\mathrm{chloride}\left(\mathrm{MeCl}_{2}\right)$ and $0.25 \mathrm{~g}$ tropolone. Propyltin was added before extraction as a surrogate compound to assess extraction efficiency. The 
extract was decanted through silanized glass wool to remove particles, and the container rinsed three times with $\mathrm{MeCl}_{2}$ to ensure that all extracted material was recovered. The mono-, di-, and tributyltin compounds extracted from the sediment were derivatized with $n$-hexyl magnesium bromide to a less volatile, more thermally stable (nonionic $n$-hexyl derivatives).

The extracts were passed through a fluoracil liquid chromatography column for cleanup and the butyltins quantified by GC-FPD. Concentrations were reported in $\mu \mathrm{g} / \mathrm{kg}$ dry weight of mono-, di-, and tributyltin species as tin. Total butyltins were calculated by adding the concentrations of detected species (as opposed to a measured total). The recently certified NRCC SRM PACS-1 for butyltins was analyzed along with John F. Baldwin Ship Channel sediments.

\subsubsection{Semivolatile Organic Compounds}

The semivolatile organic compounds analyzed in John $F$. Baldwin Ship Channel sediments were the 16 polynuclear aromatic hydrocarbons (PAHs) 1 isted in EPA Method 610. These compounds were extracted from sediments and analyzed by gas chromatography/mass spectroscopy in the Selective Ion Mode (GC/MS SIM), a modification of EPA SW846 Method 8270. Surrogate compounds (Naphthalene$d 8$, Acenaphthene-d10, Phenanthrene-d10, and Benzo(a)pyrene-d12) were added to each sample to assess extraction efficiency. Matrix spiking solutions and matrix spike duplicate measurements were made to assess accuracy of measurement. A standard reference material, SRM HS-4, was analyzed in duplicate. A method blank was analyzed to detect potential contamination.

\subsubsection{Chlorinated pesticides and Polychlorinated Biphenyls (PCBS)}

Chlorinated pesticides and PCBs in sediments were quantified by Gas Chromatography/Electron Capture Detection (GC/ECD) following EPA SW846 Method 8080 (EPA 1986). Chlorinated pesticides and PC8s were extracted overnight using $\mathrm{MeCl}_{2}$ with solvent exchange to hexane for $\mathrm{GC} / E C D$ analysis. Dibutylchlorendate (DBC) was the surrogate compound added to each sample before extraction to assess extraction efficiency. The matrix spiking 
solution was also added to the appropriate samples before extraction. Matrix spike and matrix spike duplicate analyses were conducted to assess accuracy of measurement. One sample was analyzed in triplicate to assess analytical precision. A method blank was also analyzed. 


\subsection{RESULTS}

Sampling for the John F. Baldwin Ship Channel Phase II program was accomplished in mid-August 1990. At that time, samples for wetlands and uplands testing were shipped directly to WES, and samples for chemistry and geology from the new West Richmond stations were shipped to MSL. This section describes the results of field sampling for both WES and MSL, and the results of chemical and geologic analysis of the West Richmond core samples.

\section{I SEDIMENT SAMPLING FOR MSL ANALYSIS OF WEST RICHMOND CORES}

One core sample was collected from each of five new sites in the West Richmond reach of John $F$. Baldwin Ship Channel. All sampling was conducted on August 14, 1990, using the 4-in core sampler as described in Section 2.1.2. The new sampling sites (WR-A, WR-B, WR-C, WR-D, and WR-E) are shown on Figure 3.1, which also shows the Phase I stations for comparison. Complete sampling information is provided in Table 3.1. All sampling sites were shallower than $-47 \mathrm{ft}$ MLLW, so relocation of stations to shallower areas was not necessary.

TABLE 3.1. Sampling Information for Phase Il West Richmond Stations (4-in cores in Lexan tubes for geology and chemistry)

\begin{tabular}{|c|c|c|c|c|c|c|c|c|}
\hline STATION & REP & $\begin{array}{l}\text { CALIFORNI } \\
\text { STATE PLANE } \\
\text { Y (Northing) }\end{array}$ & $\begin{array}{l}\text { 2ONE III } \\
\text { COORDINATES } \\
\underline{X \text { (Easting) }}\end{array}$ & $\begin{array}{l}\text { DATE } \\
\text { SAMPLED } \\
\end{array}$ & $\begin{array}{r}\text { WATER } \\
\text { DEPTH } \\
\text { (ft MLLW) }\end{array}$ & $\begin{array}{c}\text { CORE } \\
\text { REOUIRED } \\
\text { (ft to } \\
-47 \mathrm{ft} \text { MLLW) } \\
\end{array}$ & $\begin{array}{c}\text { CORE } \\
\text { COLLECTED } \\
\text { (ft } t) \\
\end{array}$ & COHMENTS \\
\hline WR-A & 1 & 523,268 & $1,439,718$ & $08-14-90$ & 36.8 & 10.2 & 14 & \\
\hline UR-B & 1 & 521,019 & $1,440,107$ & $08-14-90$ & 34.8 & 12.2 & 17 & \\
\hline WR-C & 1 & 518,602 & $1,440,857$ & $08-14-90$ & 34.5 & 12.5 & 18.5 & 3 attempts \\
\hline WR -0 & 1 & 518,308 & $1,439,457$ & $08-14-90$ & 42.4 & 4.6 & 6.5 & \\
\hline$W R-E$ & 1 & 517,380 & $1,439,924$ & $08-14-90$ & 40.9 & 6.1 & 6.5 & \\
\hline
\end{tabular}




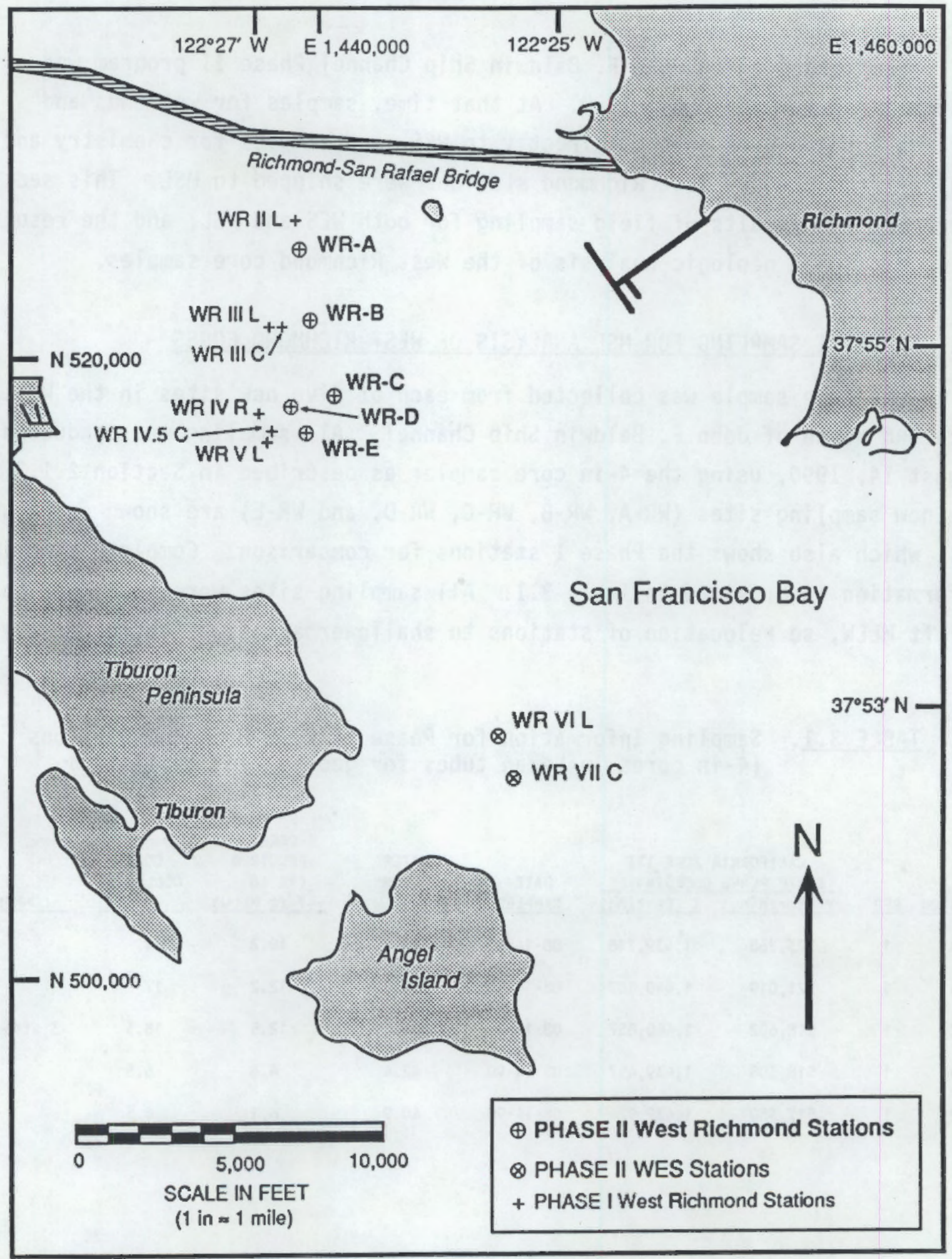

FIGURE 3.1. West Richmond Sampling Sites, John F. Baldwin Ship Channel, Showing Both Phase I and Phase II Stations 


\subsection{SEDIMENT SAMPLING FOR WES WETLANDS/UPLANDS TESTING}

Sediments from stations in both West Richmond and Pinole Shoal reaches of John F. Baldwin Ship Channel were collected for the WES Uplands testing program, while only Pinole Shoal stations were sampled for the Wetlands testing program. Sampling was conducted August 13,15, and 16, 1990, using the 12-in core sampler as described in Section 2.1.2. Sampling stations are shown in Figures 3.1 and 3.2. One station, P I C, had to be relocated to the northwest edge of the channel because the original site was already at project depth (-45 ft MLLW).

Sediments from multiple stations were added together to form Uplands Composite 1 (southern part of West Richmond reach), Wetlands Composite 2 (southwest Pinole Shoal), Wetlands Composite 3 (east Pinole Shoal), and Uplands Composite 4 (all Phase II Pinole Shoal stations). Fourteen 55-gal drums were needed for each uplands composite, while each wetlands composite required one 55-gal drum to be filled. To obtain the required volume of sediment, it was often necessary to collect replicate samples at some stations. The stations contributing to each composite, and the volume contributed, are listed in Table 3.2 along with other pertinent sampling information.

To accompany sediment for the WES Uplands testing program, 20 gal of water were obtained from the West Richmond and Pinole Shoal sampling areas. Surface water samples were collected using a clean 5-gal bucket to fill a labeled, epoxy-coated 30-gal barrel. West Richmond site water was collected between Stations WR VI L and WR VII $C$ on August 13. Pinole Shoal site water was collected near Station P IV R on August 16 . Both sediment and water samples were shipped via refrigerated truck from Vallejo, California, to Vicksburg, Mississippi, on August 17. 


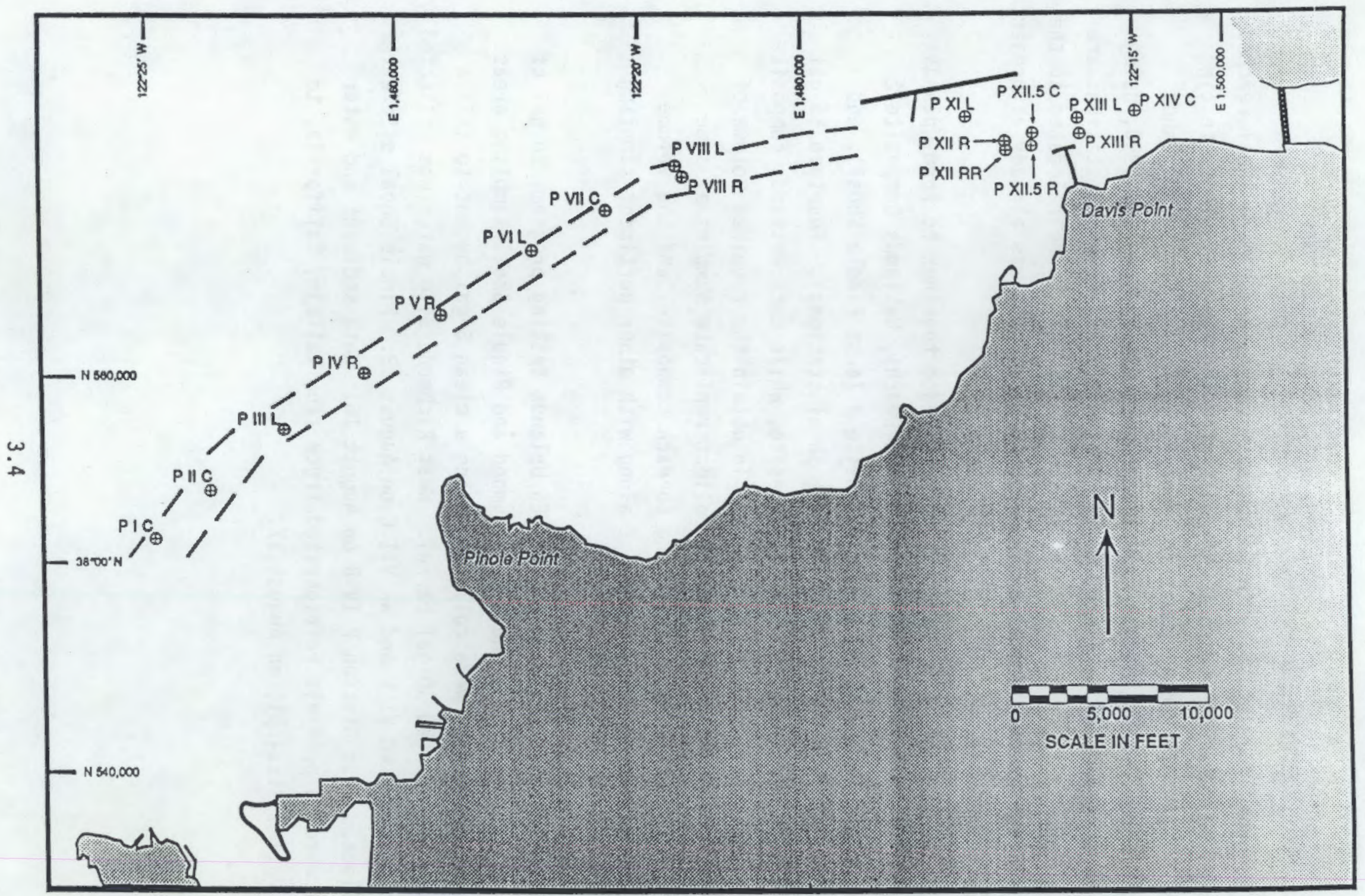

FIGURE 3.2. Pinole Shoal Sampling Sites, John F. Baldwin Ship Channel Phase II 
TABLE 3.2. West Richmond and Pinole Shoal Stations Sampled for WES Uplands and Wetlands Testing (using 12-in core sampler)

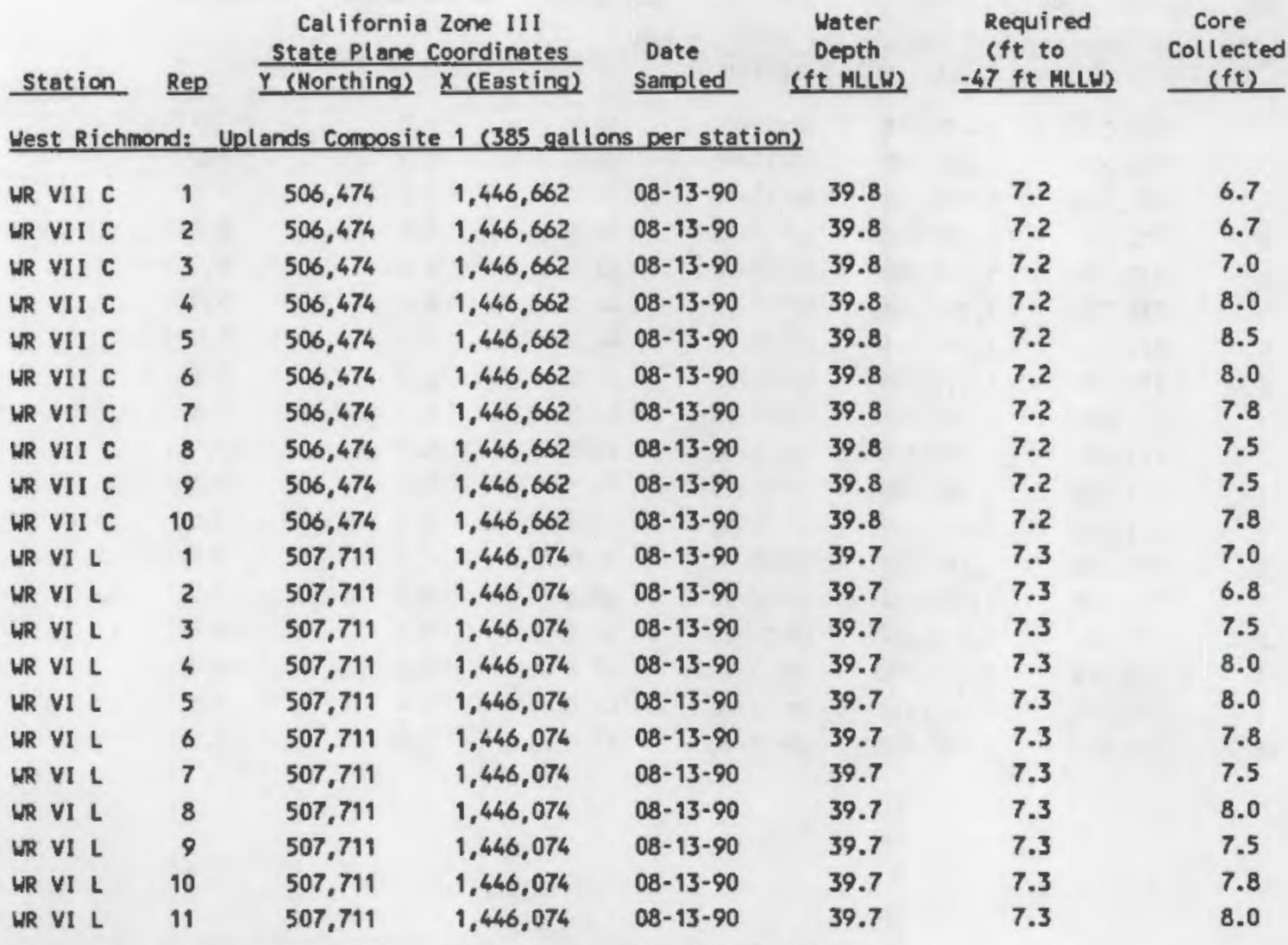

Pinole Shoal: Hetlands Composite 2 (6 gallons per station) and

\begin{tabular}{|c|c|c|c|c|c|c|c|}
\hline P VIII R & 1 & 569,815 & $1,473,806$ & $08-15-90$ & 36.2 & 10.8 & 14.0 \\
\hline P VIII L & 1 & 570,269 & $1,473,536$ & $08-15-90$ & 37.2 & 9.8 & 9.8 \\
\hline P VII C & 1 & 568,126 & $1,470,212$ & $08-15-90$ & 36.0 & 11.0 & 11.0 \\
\hline P VI L & 1 & 566,221 & $1,466,553$ & $08-16-90$ & 36.6 & 10.4 & 11.3 \\
\hline$P \vee R$ & 1 & 563,067 & $1,462,070$ & $08-16-90$ & 37.1 & 9.9 & 13.6 \\
\hline$P$ IV $R$ & 1 & 560,133 & $1,458,245$ & $08-16-90$ & 40.3 & 6.7 & 12.0 \\
\hline$P$ IV $R$ & 2 & 560,133 & $1,458,245$ & $08-16-90$ & 40.3 & 6.7 & 9.5 \\
\hline P $111 \mathrm{~L}$ & 1 & 557,301 & $1,454,275$ & $08-16-90$ & 42.8 & 4.2 & 5.7 \\
\hline P III L & 2 & 557,301 & $1,454,275$ & $08-16-90$ & 42.8 & 4.2 & 6.0 \\
\hline$P \| C$ & 1 & 554,046 & $1,450,790$ & $08-16-90$ & 41.8 & 5.2 & 6.8 \\
\hline PIIC & 2 & 554,046 & $1,450,790$ & $08-16-90$ & 41.8 & 5.2 & 8.5 \\
\hline$P$ I C & $N / A$ & 551,186 & $1,448,210$ & $08-16-90$ & 44.8 & $N / A$ & $N / A$ \\
\hline P I C & 1 & 551,713 & $1,448,049$ & $08-16-90$ & 43.8 & 3.2 & 4.5 \\
\hline$P \perp C$ & 2 & 551,713 & $1,448,049$ & $08-16-90$ & 43.8 & 3.2 & 6.0 \\
\hline$P \perp C$ & 3 & 551,713 & $1,448,049$ & $08-16-90$ & 43.8 & 3.2 & 4.5 \\
\hline
\end{tabular}




\section{TABLE 3.2. (Continued)}

\begin{tabular}{|c|c|c|c|c|c|c|c|}
\hline Station & Rep & $\begin{array}{r}\text { Californi } \\
\text { State Plane } \\
\text { Y Northing) }\end{array}$ & $\begin{array}{l}\text { Zone III } \\
\text { coordinates } \\
x \text { (Easting) }\end{array}$ & $\begin{array}{c}\text { Date } \\
\text { Sampled }\end{array}$ & $\begin{array}{c}\text { Water } \\
\text { Depth } \\
\text { (ft MLLU) } \\
\end{array}$ & 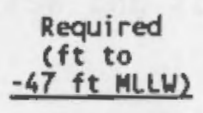 & $\begin{array}{c}\begin{array}{c}\text { Core } \\
\text { Collected } \\
(\mathrm{ft})\end{array} \\
\end{array}$ \\
\hline \multicolumn{8}{|c|}{$\frac{\text { Pinole Shoal: Hetlands Comoosite } 3 \text { (7 gallons per station) and }}{\text { Uplands Composite } 4 \text { (48 gallons per station) }}$} \\
\hline P XIV C & 1 & 573,019 & $1,495,878$ & $08-15-90$ & 40.8 & 6.2 & 7.0 \\
\hline P XIV C & 2 & 573,019 & $1,495,878$ & $08-15-90$ & 40.8 & 6.2 & 7.3 \\
\hline$P X I I I R$ & 1 & 571,966 & $1,493,161$ & $08-15-90$ & 37.7 & 9.3 & 9.8 \\
\hline P XIIIL & 1 & 572,705 & $1,493,026$ & $08-15-90$ & 46.4 & 2.6 & 2.6 \\
\hline P XIIIL $L$ & 2 & 572,705 & $1,493,026$ & $08-15-90$ & 44.4 & 2.6 & 7.0 \\
\hline$P X I 11 L$ & 3 & 572,705 & $1,493,026$ & $08-15-90$ & 44.4 & 2.6 & 5.0 \\
\hline$P X 111 L$ & 4 & 572,705 & $1,493,026$ & $08-15-90$ & 44.4 & 2.6 & 5.0 \\
\hline$P X I 11<$ & 5 & 572,705 & $1,493,026$ & $08-15-90$ & 44.4 & 2.6 & 5.0 \\
\hline P XI1.5 C & 1 & 571,871 & $1,490,811$ & $08-15-90$ & 41.9 & 5.1 & 7.6 \\
\hline$P \times 11.5 \mathrm{C}$ & 2 & 571,871 & $1,490,811$ & $08-15-90$ & 41.9 & 5.1 & 7.0 \\
\hline PXII.5 R & 1 & 571,343 & $1,490,800$ & $08-15 \cdot 90$ & 31.3 & 15.7 & 17.5 \\
\hline PXIIR & 1 & 571,422 & $1,489,561$ & $08-15-90$ & 38.9 & 8.1 & 9.5 \\
\hline P XIIR & 2 & 571,422 & $1,489,561$ & $08-15-90$ & 38.9 & 8.1 & 8.3 \\
\hline P XII RR & 1 & 571,160 & $1,489,564$ & $08-16-90$ & 38.8 & 8.2 & 8.5 \\
\hline P XII RR & 2 & 571,160 & $1,489,564$ & $08-16-90$ & 38.8 & 8.2 & 10.2 \\
\hline$P X I L$ & 1 & 572,673 & $1,487,592$ & $08-15-90$ & 43.6 & 3.4 & 4.5 \\
\hline P XI L & 2 & 572,673 & $1,487,592$ & $08-15-90$ & 43.6 & 3.4 & 4.5 \\
\hline P XI L & 3 & 572,673 & $1,487,592$ & $08-15-90$ & 43.6 & 3.4 & 6.3 \\
\hline
\end{tabular}




\subsection{ANALYSIS OF PHASE II WEST RICHMOND 4-IN CORES}

Following delivery to MSL, the 4-in cores from the new West Richmond stations were cut, homogenized, and subsampled for chemistry as described in Section 2.2. Initial core cutting and sample preparation occurred on August 21,1990 , and chemistry samples were shipped immediately to the analytical laboratory. The core halves for geologic description were stored in the walk-in cold room at the MSL until September when a geologist was available to perform the descriptions. A summary of the geologic descriptions and the results of chemical analysis are presented in the following sections.

\subsubsection{Geologic Description}

\section{Geology of John F. Baldwin Ship Channel}

In this section, the general geology of the John F. Baldwin Ship Channel sediments is described, followed by descriptions of the five new core samples collected in August 1990. Three geologic units are present in the John F. Baldwin Ship Channel study area: the 01der Bay Mud, Sand Deposits, and Younger Bay Mud (USACE 1975a). The oldest unit is the 0lder Bay Mud (OBM) which consists primarily of firm clay, silt, sand, and small gravels deposited during the last glacial period when sea level resided as much as $335 \mathrm{ft}$ below its present level (USACE 1975b, 1979). None of the cores collected during the most recent phase of coring penetrated to this OBM unit, therefore, no further discussion is presented here.

The Sand Deposits form a unit that lies between the underlying OBM and the overlying Younger Bay Mud (YBM); thickness of the Sand Deposits is not uniform throughout, being generally thicker along bay margins. The Sand Deposits are fine grained and mixed with considerable silt and clay; the unit is believed to represent alluvial fans formed by fluviatile current action during shoreline fluctuation in the Pleistocene (USACE 1975a). Although considerable amounts of fine sands are present in several cores, it is unlikely that they represent the Sand Deposit unit due to the shallow depths penetrated during core sampling.

The YBM consists of mostly soft, dark-colored sediments deposited in an estuarine environment. These deposits were laid down as sea level rose 
following the last ice age, which ended approximately 12,000 years ago (Barry 1983). The YBM unit appears to form a continuous blanket across the bay bottom. The YBM unit consists mostly of very soft to soft silty clays and clayey silts with minor amounts of organic material, fine sand and shell fragments (USACE 1975a). Soil colors range from dark gray to dark olive gray to black. Dark colors, in combination with the odor of rotten eggs (i.e., hydrogen sulfide), are indications of chemically reducing conditions. The USACE (1975a) subdivided the YBM unit into a Semi-Consolidated Bay Mud member overlain by Soft Bay Mud member. While the firmness of the cores from the study areas generally increases with depth, this appears to be a result of compaction from overlying sediments rather than the sudden, characteristic change in consistency which is considered the boundary between the Semi-Consolidated Bay Mud and Soft Bay Mud members (USACE 1979). The shallow nature of the sediment cores would suggest that the primary unit represented in the sampling areas is the Soft Bay Mud member of the YBM.

\section{Phase II West Richmond Cores}

A total of five cores, ranging in length from 4.7 to $12.8 \mathrm{ft}$, were characterized from the West Richmond reach of the John F. Baldwin Ship Channel. Detailed methods for the description of core logs are contained in Appendix A. A descriptive data $\log$ for each of the Phase II cores is contained in Appendix B. Only the YBM unit was represented in these cores.

Figure 3.3 shows a cross section along the northern portion of the West Richmond reach and includes the Phase I (September 1989) cores WR I R, WR II $L$, WR III $L$, WR IV R, WR IV.5 $C$, and WR V $L$ as well as the Phase II cores WR-A, WR-B, WR-C, WR-D, and WR-E. The cores sampled in September 1990 consist predominantly of dark olive-gray to very dark olive-gray sands with alternating layers of interstratified silt and/or clay. Most sediments entering the bay system were probably deposited during periods of high runoff and turbulence associated with winter storms. These storm deposits produced normally graded beds ranging from millimeters to several centimeters in thickness, depending on distance from the source and the amount of sediment in suspension. 


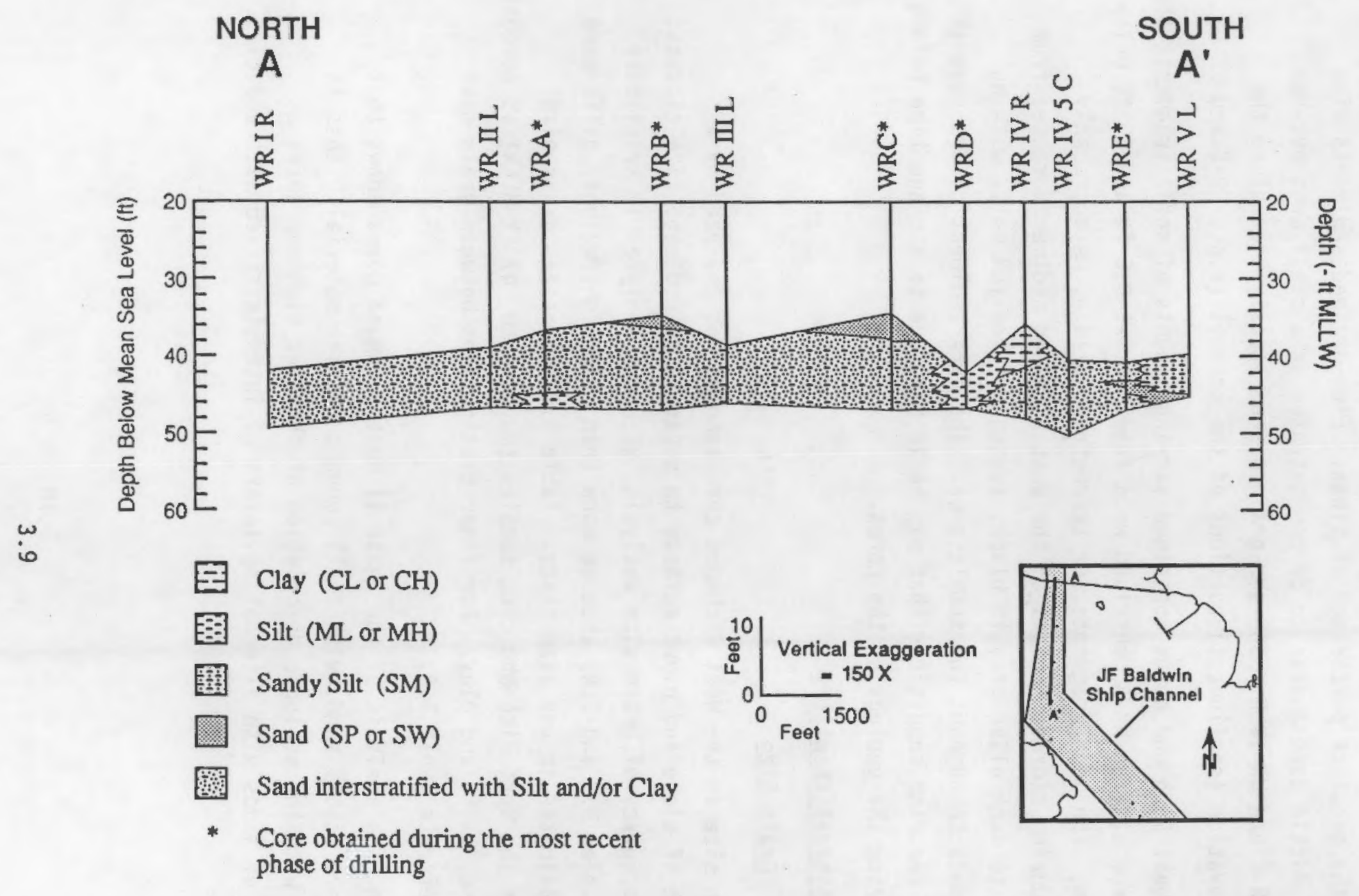

FIGURE 3.3. Sediment Lithology in the West Richmond Reach of John F. Baldwin Ship Channel 
The maximum particle size was very fine pebbles found interspersed in cores WR-C and WR-D. All cores had considerable amounts of finer material such as sand interstratifed with silt and clay. Of the new cores, core WR-D contained the greatest percentage of fines. Fine-grained sediments with relatively little sand appear to be concentrated in a small area between stations WR-C and WR IV R. Coarser-grained sand locally lies along the highest elevation (shallowest) portions of the channel (e.g., WR-B and WR-C).

All West Richmond cores contained varying amounts of shell fragments and one core from station WR-A contained wood fragments at $0.5 \mathrm{ft}$ and $10 \mathrm{ft}$ below the mudline. The wood fragments, of terrestrial origin, were probably deposited during storms. Colors of the West Richmond sediments ranged from olive gray to dark olive gray to black, typical of the YBM unit, with no overall trends throughout the sample area. The dark sediment colors suggest chemically reducing conditions that may be in part due to storage time before characterizing the geology of the cores.

\subsubsection{Analytical Chemistry}

Grain Size

Grain size in the West Richmond core samples was analyzed by a combination of sieve and pipet methods to separate 16 sediment size classes. To assess accuracy of grain size analysis, WR-E was analyzed in triplicate. Results (Tables 3.3 and 3.4) show no more than $1 \%$ (weight/weight) difference between replicates in any size class. Table 3.3 summarizes grain size analysis of the West Richmond core samples (mudline to $-47 \mathrm{ft}$ MLLW) as percent gravel, sand, silt, and clay. For finer distinctions between grain size classes, refer to Table 3.4 .

Grain size analysis of the Phase II West Richmond cores shows that sediments are mostly sand, with small amounts of fine material. This is consistent with the geologic description of the West Richmond cores as consisting of sands with alternating layers of interstratified silt and clay. 
TABLE 3.3. Summary of Grain Size Analys is, Phase II West Richmond Cores

\begin{tabular}{|c|c|c|c|c|}
\hline Station & $\begin{array}{c}\text { Percent } \\
\text { Gravel } \\
(\geq 2000 \mathrm{~mm})\end{array}$ & $\begin{array}{l}\text { Percent } \\
\text { Sand } \\
(62.5- \\
\left(2000_{\mu \mathrm{m}}\right)\end{array}$ & $\begin{array}{c}\text { Percent } \\
\text { Silt } \\
(3.9- \\
(62.5 \mu \mathrm{m})\end{array}$ & $\begin{array}{c}\text { Percent } \\
\text { Clay } \\
(<3.9 \mu \mathrm{m})\end{array}$ \\
\hline $\begin{array}{l}\text { WR-A } \\
\text { WR-B } \\
\text { WR-C } \\
\text { WR-D } \\
W R-E(a)\end{array}$ & $\begin{array}{ll}4 & \\
3 & \\
5 & \\
3 & \\
& 2\end{array}$ & $\begin{array}{l}67 \\
64 \\
72 \\
55 \\
\quad 72\end{array}$ & $\begin{array}{l}16 \\
18 \\
12 \\
23 \\
\\
\\
14\end{array}$ & $\begin{array}{l}13 \\
15 \\
11 \\
19\end{array}$ \\
\hline
\end{tabular}

Iriplicate Analysis

$\begin{array}{lllll}\text { WR-E rep 1 } & 2 & 72 & 14 & 12 \\ \text { WR-E rep 2 } & 1 & 73 & 14 & 12 \\ \text { WR-E rep 3 } & 2 & 72 & 14 & 12\end{array}$

(a) Mean of three replicates 
TABLE 3.4. Results of Grain Size Analys is, Phase II West Richmond Cores

Percent at Size Fraction

\begin{tabular}{|c|c|c|c|c|c|c|c|c|c|c|c|c|c|c|c|c|c|}
\hline \multirow[b]{2}{*}{$\begin{array}{l}\text { phi } \\
\text { un }\end{array}$} & \multicolumn{2}{|c|}{ Gravel } & \multicolumn{6}{|c|}{ Sand } & \multicolumn{4}{|c|}{ silt } & \multicolumn{5}{|c|}{ Clay } \\
\hline & $\begin{array}{r}-2.25 \\
\lcm{24759} \\
\end{array}$ & $\begin{array}{l}-1 \\
4750- \\
2000 \\
\end{array}$ & $\begin{array}{r}-6.25 \\
2600- \\
850 \\
\end{array}$ & $\begin{array}{l}1.25 \\
858- \\
425 \\
\end{array}$ & $\begin{array}{l}2 \\
425- \\
250 \\
\end{array}$ & $\begin{array}{l}3.25 \\
256- \\
196 \\
\end{array}$ & $\begin{array}{c}3.75 \\
106- \\
75 \\
\end{array}$ & $\begin{array}{l}4 \\
75- \\
62.5 \\
\end{array}$ & $\begin{array}{l}5 \\
62.5- \\
31.2 \\
\end{array}$ & $\begin{array}{l}6 \\
31.2- \\
15.8 \\
\end{array}$ & $\begin{array}{l}7 \\
15.0- \\
7.8 \\
\end{array}$ & $\begin{array}{l}8 \\
7.8- \\
3.9 \\
\end{array}$ & $\begin{array}{l}9 \\
3.9- \\
1.9 \\
\end{array}$ & $\begin{array}{l}10 \\
1.9- \\
0.9 \\
\end{array}$ & $\begin{array}{l}11 \\
0.9- \\
0.4 \\
\end{array}$ & $\begin{array}{l}12 \\
9.4- \\
0.2 \\
\end{array}$ & $\langle 0.2$ \\
\hline
\end{tabular}

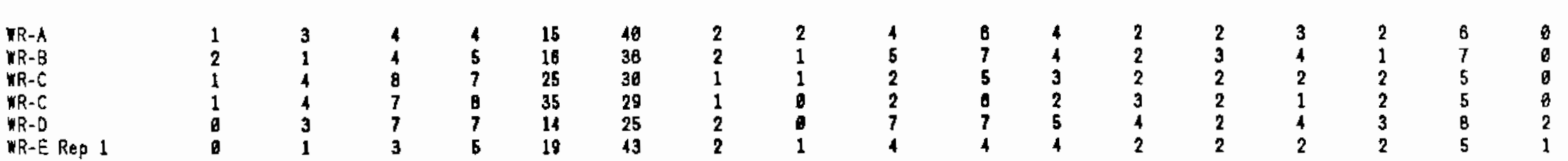

\section{Analytical Replicate Analyses}

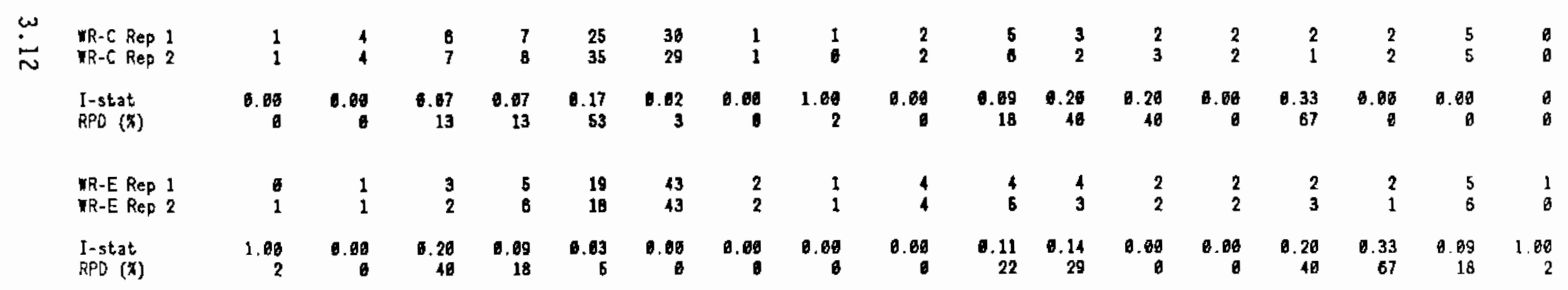


Iotal Volatile Solids (TVS), Total Organic Carbon (TOC), Oil and Grease, and Total Petroleum Hydrocarbons (TPH).

Quality control results (Table 3.5 ) showed that detection limits were met for each of the conventional parameters TVS, TOC, 0 il and grease, and TPH. Acceptable comparisons occurred between replicates in the triplicate analyses of WR-C (TOC) and WR-E (TVS, $0 i 1$ and grease, TPH). Coefficients of variation (CV) for the measurements ranged from 8.2 to 11.5 for TOC, TVS, and TPH replicate measurements. The most variable measurement was oil and grease, with a $\mathrm{CV}$ of $35.6 \%$.

A matrix spike (MS) and a matrix spike duplicate (MSD) were analyzed for TOC with measured recoveries of 113 and $96 \%$. Matrix spikes and matrix spike duplicates were not performed for volatile solids because they are inappropriate for that parameter. Recoveries for the TPH MS and MSD were 13\% and $56 \%$ respectively. The low recovery of one of the TPH spikes was attributed to loss of solvent during the extraction procedure, the other spike had acceptable recovery. Recoveries of the MS and MSD for oil and grease were $42 \%$ and $107 \%$, respectively, which were acceptable. No analytes were detected in either the TPH or 0 il and grease method blanks. The concentrations of these conventional measures in the West Richmond samples were low.

\section{Metals}

Eleven metals were analyzed in each of the five West Richmond core sediments, following the methods described in Section 2.3.2. Quality control measures (Table 3.6) included triplicate analysis of one sample to assess analytical precision, and matrix spikes and/or standard reference materials (SRMs) to assess accuracy. Target detection limits were met for all metals analyses.

Matrix spikes to assess accuracy of GFAA and CVAA analysis of Ag, Cd, $\mathrm{Hg}$, Se, and $\mathrm{Tl}$ all showed excellent recoveries of greater than 95\%. Analysis of SRMs to assess accuracy of both XRF and AA results showed that the analytes in NRCC MESS-1 (As, $\mathrm{Cd}, \mathrm{Cr}, \mathrm{Cu}, \mathrm{Ni}, \mathrm{Pb}, \mathrm{Se}$, and $\mathrm{Zn}$ ) were found within the certified range of the SRM except for $\mathrm{Ni}$. Ni exceeded the certified reference value by approximatley $2 \%$. The analytes in SRM NBS-1646 (As, $\mathrm{Cd}, \mathrm{Cr}, \mathrm{Cu}, \mathrm{Hg}$, $\mathrm{Ni}, \mathrm{Pb}$, and $\mathrm{Zn}$ ) were within certified vaiues except for $\mathrm{As}, \mathrm{Cr}$, and $\mathrm{Hg}$. 
IABLE 3.5. Total Volatile Solids (TVS), Total Organic Carbon (TOC), 0 il and Grease, Total Petroleum Hydrocarbons (TPH), and Petroleum Fraction as a Percentage of $0 i 1$ and Grease in West Richmond Sediment $(U=$ undetected above given detection 1 imit; $N / A=$ not applicable $)$

\begin{tabular}{|c|c|c|c|c|c|}
\hline Sample & $\begin{array}{c}\text { TVS } \\
\text { (X dry wt) }\end{array}$ & $\begin{array}{l}\operatorname{TOC} \\
(x \quad d r y+t)\end{array}$ & $\begin{array}{l}\text { oil and Grease } \\
(\mu g / \mathrm{kg} d r y \text { wt) }\end{array}$ & $\begin{array}{c}\text { TPH } \\
(\mu g / \mathrm{kg} d r y \quad u t)\end{array}$ & $\begin{array}{l}\text { Petroleum } \\
\text { Fraction }\end{array}$ \\
\hline Method Blank & $N / A$ & $M / A$ & $0.7 \mathrm{U}$ & $0.7 \mathrm{U}$ & N/A \\
\hline Wh-A & 5.11 & 0.53 & 17.0 & 14.0 & $82 x$ \\
\hline$W R-B$ & 5.58 & 0.62 & 8.8 & 9.9 & $100 x$ \\
\hline LR $-\mathrm{C}$ & 5.43 & $1.17(b)$ & 4.3 & $0.7 \mathrm{U}$ & $<16 x$ \\
\hline WR -0 & 6.29 & 0.86 & 18.0 & 1.7 & $9.4 \mathrm{x}$ \\
\hline WR-E & $4.79(\theta)$ & 0.71 & $17.2(c)$ & $4.3(d)$ & $25 x$ \\
\hline \multicolumn{6}{|l|}{ Iriplicate Analysis } \\
\hline Re-C Rep 1 & $M / A$ & 1.12 & $N / A$ & $N / A$ & $H / A$ \\
\hline WR-C Rep 2 & N/A & 1.30 & $N / A$ & $N / A$ & $M / A$ \\
\hline WR-C Rep 3 & $M / A$ & 1.10 & $\mathbf{H} / \mathbf{A}$ & $N / A$ & $\mathrm{H} / \mathrm{A}$ \\
\hline WR-E ReP 1 & 5.17 & $\mathbf{N} / \mathbf{A}$ & 24.0 & $0.7 \mathrm{U}$ & $<3 x$ \\
\hline WR $-E$ Rep 2 & 4.81 & $N / A$ & 15.3 & 3.9 & $25 x$ \\
\hline WR-E Rep 3 & 4.39 & $n / A$ & 12.2 & 4.6 & $38 x$ \\
\hline Matrix Spike & & $L R \cdot C$ & $L R-D$ & WR $=0 ?$ & \\
\hline Amount Spiked & $N / A$ & 1.10 & 55.7 & 56.0 & $N / A$ \\
\hline Amount Recovered & $\mathrm{N} / \mathrm{A}$ & 2.36 & 41.2 & 9.2 & $N / A$ \\
\hline Anount in saaple & $N / A$ & 1.12 & 18.0 & 1.7 & $N / A$ \\
\hline Percent Recovery & $N / A$ & $113 x$ & $42 x$ & $13 x$ & $M / A$ \\
\hline Matrix Soike Duplicate & & $w R-C$ & $W R=0$ & $\underline{R}-\mathrm{D} ?$ & \\
\hline Anount Spiked & $M / A$ & 1.00 & $\infty .1$ & 60.0 & $\mathrm{H} / \mathrm{A}$ \\
\hline Amount Recovered & $M / A$ & 2.08 & 82.2 & 35.0 & $N / A$ \\
\hline Mount in Sample & $N / A$ & 1.12 & 18.0 & 1.7 & $N / A$ \\
\hline Percent Recovery & $\mathrm{H} / \mathrm{A}$ & $96 x$ & $107 x$ & $56 x$ & $N / A$ \\
\hline
\end{tabular}

(a) Mean of three replicates, $s d=0.39$

(b) Mean of three repl icates, od=0.11

(c) Mean of three repl icates, sd=6.1

(d) Mean of two replicates where $T P H$ detected, $s d=0.49, R P D=16 x$ 
IABLE 3.6. Qualfty Control Data for Metals Anatysis, Phase II West Richmond Cores

Metal Concentration ( $\mathrm{mg} / \mathrm{kg}$ dry weight)

sample

Iriplicate Analysis

UR-E
HR-E
WR-E
Standard Deviation
Coefficient of Variation $(x)$

\section{Matrix Spike (UR-D)}

\section{Amount Recovered}

Amount in Sample

Anount Spiked

Recovery

\section{Standerd Reference Materials}

NRCC MESS- 1
Certified value
of MESS- 1

NBS - 1646

Certified Value of NBS-1646

\begin{tabular}{|c|c|c|c|c|c|c|c|c|c|c|}
\hline Ag & As & Cd & $\mathrm{Cr}$ & $\mathrm{Cu}$ & $\mathrm{Hg}$ & $\mathrm{NH}$ & $\mathrm{Pb}$ & Se & Il & $2 n$ \\
\hline
\end{tabular}

0.055

0.051

$\begin{array}{ll}11.2 & 0.12 \\ 10.2 & 0.11\end{array}$

$\begin{array}{lll}217.0 & 20.6 & 0.047\end{array}$

20.6
18.3
19.9

0.047
0.027
0.027

86.9

6.2

6.6
9.1

$0.15<0.12$

0.15

0.12

$<0.12$

64.5

0.002

$0.7 \quad 0.006$

16.7

$\begin{array}{ll}1.2 & 0.012 \\ 6.0 & 34\end{array}$

3.2
3.8

1.6
21.5

0.00

0.00
0.0

$\mathbf{H} / \mathbf{A}$

65.4

\subsection{2}

M/A

$\begin{array}{lll}N / A & 1.31 & 2.91\end{array}$

$+0.12$

1.00

$104 x$

$N / A$

$N / A$

N/A
0.058

0.500

$97 x$

$\begin{array}{lr}W / A & 1.11 \\ N / A & 0.16 \\ N / A & 1.00 \\ N / A & 95\end{array}$

N/A

MC

$10.6 \quad 0.59$

$+1.2 \geq 0.01$

80.0

71.0
+11

24.0

25.1

$+3.8$

NC

N/A

$\begin{array}{rr}0.9 & 0.32 \\ 11.6 & 0.36 \\ +1.3 & \geq 0.07\end{array}$

69.0

$18.2 \quad 0.077$

$18.0 \quad 0.063$

$\pm 3$

$+0.012$

76.0
$\times 3$

$\pm$

$\begin{array}{ll}W / A & 0.526 \\ W / A & 0.031 \\ N / A & 0.500\end{array}$

$N / A=$ not apolicsble

$N C=$ not certified 
While measured values of $A$ s and $C r$ were within the certified ranges for SRM MESS-1, they were slightly out of the certified range for the SRM NBS-1646. As and $\mathrm{Cr}$ were measured at slightly lower concentrations (13\% and 5\%, respectively) than the certified range of NBS-1646. Hg was measured at $3 \%$ higher than the certified range of NBS-1646.

These slight differences should not affect the accuracy of the sample measurements, given the accurate values measured for the other SRM (NRCC MESS1) and the accurate $\mathrm{Hg}$ matrix spike. Triplicate analysis of WR-E showed very good precision with all coefficients of variation (standard deviation/mean) less than $10 \%$ except $\mathrm{Hg}, \mathrm{Cr}$, and $\mathrm{Pb}$. For each of these metals, the variation was due to one high replicate (Table 3.6 ). Such variation within a sample of sediment is not unusual given metal concentrations as low as those measured in West Richmond sediments.

The results of metals analysis in the five Phase II West Richmond core samples are shown in Table 3.7. All of the metal concentrations measured in the new West Richmond cores were comparable to the low end of the concentration range of West Richmond sediments sampled during Phase I of the John $F$. Baldwin project. In no case were there higher metals concentrations from sediments collected during Phase II. 
TABLE 3.7. Metals in Phase II West Richmond Cores

\begin{tabular}{|c|c|c|c|c|c|c|c|c|c|c|c|}
\hline Sample & $\underline{A g}$ & $\underline{\Delta s}$ & cd & $\underline{\mathrm{C} r}$ & $\underline{\underline{S u}}$ & $\underline{\mathrm{kg}}$ & Ni & $\underline{\text { p }}$ & $\underline{\mathrm{se}}$ & II & $\underline{2 n}$ \\
\hline$U R-A$ & 0.055 & 7.0 & 0.10 & 196.0 & 20.7 & 0.027 & 76.3 & 8.8 & 0.23 & $<0.12$ & 63.6 \\
\hline WR -8 & 0.061 & 10.4 & 0.12 & 216.0 & 21.8 & 0.027 & $B 0.5$ & 7.1 & 0.19 & $<0.12$ & 64.7 \\
\hline$W R-C$ & 0.055 & 15.0 & 0.13 & 208.0 & 20.2 & 0.033 & 86.3 & 4.1 & 0.27 & $<0.12$ & 62.3 \\
\hline$H R \cdot D$ & 0.058 & 12.8 & 0.16 & 145.0 & 21.6 & 0.031 & 72.9 & 5.4 & 0.27 & $<0.12$ & 60.5 \\
\hline$W R-E^{(a)}$ & 0.054 & 10.4 & 0.11 & 199.0 & 19.6 & 0.034 & 83.3 & 7.3 & 0.15 & $<0.12$ & 65.5 \\
\hline
\end{tabular}

(a) Mean of three replicates, standard deviations reported beneath triplicate values in table 3.6 


\section{Butyltins}

Butyltin compounds were analyzed using gas chromatography with flame photometric detection (GC-FPD) following the methods of Unger et al. (1986), detailed in Section 2.3.3. Butylt in results and quality control data are shown in Table 3.8. Surrogate recoveries for the samples ranged from $29 \%$ to $41 \%$. Although the majority of these recoveries fall below the control limit of $40 \%$, the data are found to be acceptable. Recent data indicate that the surrogate compound used during analyses of these samples does not accurately reflect the behavior of the monobutylt in (MBT), dibutyltin (DBT), and tributyltin (TBT) compounds. A new surrogate is currently being used in conjunction with the propyltin, and although recoveries of the original propyltin surrogate are still low, the recoveries of the new surrogate are acceptable with recoveries from $70-100 \%$.

Matrix spike recoveries for TBT and DBT were acceptable at $55 \%$ and 68\% respectively (note the propyltin surrogate recovery for the spike sample was comparable to those of the samples at 27\%). Low levels of TBT and MBT $(0.9$ and $0.6 \mu \mathrm{g} / \mathrm{kg}$ respectively) were detected in the method b] ank. Compared to the SRM measurement of accuracy, the measured values of SRM PACS showed good agreement with the certified values. It is important to note that the PACS results are corrected for the propyltin surrogate recovery. Although the surrogate used has been found to be inadequate for accurate quantitation of the butyltins, the original certification of PACS was performed by numerous laboratories using the propyltin surrogate as an internal standard, thus, the original certified values may be biased.

Butyltin compounds were found only at very low concentrations in West Richmond sediments, with less than $2 \mu \mathrm{g} / \mathrm{kg}$ total butyltins at all stations. These levels are comparable to or lower than the results of the John F. Baldwin Ship Channel Phase I butyltin analyses of West Richmond sediments. 
TABLE 3.8. Butyltins in West Richmond Sediment $(U=$ undetected above given detection limit; $N / A=$ not applicable)

\begin{tabular}{|c|c|c|c|c|c|}
\hline \multirow[b]{2}{*}{ Sample } & \multirow{2}{*}{$\begin{array}{l}\text { Propyltin } \\
\text { Surrogate } \\
\text { Recovery }\end{array}$} & \multicolumn{4}{|c|}{ Butyltin Concentration $(\mu \mathrm{g} / \mathrm{kg}$ dry weight) } \\
\hline & & Tri- & $\mathrm{Di}-$ & Mono- & TOTAL \\
\hline Method Blank & $19.7 \%$ & 0.9 & $0.6 \mathrm{U}$ & 0.6 & 1.5 \\
\hline $\begin{array}{l}\text { WR-A } \\
\text { WR-B } \\
\text { WR-C } \\
\text { WR-D } \\
\text { WR-E Rep 1 } \\
\text { WR-E Rep 2 }\end{array}$ & $\begin{array}{l}29.3 \% \\
41.8 \% \\
35.2 \% \\
33.7 \% \\
35.9 \% \\
36.0 \%\end{array}$ & $\begin{array}{l}0.5 \\
0.8 \\
0.6 \\
0.9 \\
0.9 \\
0.8\end{array}$ & $\begin{array}{l}0.4 \\
0.8 \\
0.5 \mathrm{U} \\
0.4 \mathrm{U} \\
0.5 \mathrm{U} \\
0.5 \mathrm{U}\end{array}$ & $\begin{array}{l}0.4 \mathrm{U} \\
0.4 \mathrm{U} \\
0.4 \mathrm{U} \\
0.4 \mathrm{U} \\
0.6 \\
0.5 \mathrm{U}\end{array}$ & $\begin{array}{l}0.9 \\
1.6 \\
0.6 \\
0.9 \\
1.5 \\
0.8\end{array}$ \\
\hline \multicolumn{6}{|l|}{ Matrix Spike (WR-E) } \\
\hline $\begin{array}{l}\text { Amount Recovered } \\
\text { Amount in Sample } \\
\text { Amount Spiked } \\
\text { Recovery }\end{array}$ & $27.1 \%$ & $\begin{array}{c}71.8 \\
0.8 \\
130 \\
55 \%\end{array}$ & $\begin{array}{c}88.2 \\
0.5 \mathrm{U} \\
130 \\
68 \%\end{array}$ & $\begin{array}{c}38.5 \\
0.5 \mathrm{U} \\
130 \\
30 \%\end{array}$ & $\begin{array}{l}\text { N/A } \\
\text { N/A } \\
\text { N/A } \\
\text { N/A }\end{array}$ \\
\hline \multicolumn{6}{|c|}{ Standard Reference Material } \\
\hline $\operatorname{PACS}(a)$ & $39.8 \%$ & 1348 & 1250 & 445 & 3043 \\
\hline $\begin{array}{l}\text { Certified Value } \\
\text { of PACS }\end{array}$ & & $\begin{array}{r}1270 \\
\pm 220\end{array}$ & $\begin{array}{r}1160 \\
\pm 180\end{array}$ & $\begin{array}{r}280 \\
+170\end{array}$ & $N / A$ \\
\hline
\end{tabular}

(a) PACS certified values are corrected for surrogate recovery, therefore, PACS sample concentrations are reported corrected for the $39.8 \%$ surrogate recovery. 


\section{Polychiorinated Biphenyls (PCBs) and Pesticides}

PCBs and chlorinated pesticides were extracted and analyzed according to Method 8080 in EPA Test Methods for Evaluating Sol id Wastes: Physical/Chemical Methods, SW-846 (USEPA 1986), as detailed in Section 2.3.5. For both PCBs (Table 3.9) and pesticides (Table 3.10), the achieved detection limits were acceptabiy low, and there were no analytes found in the method blanks. Quality control results show acceptable comparison of triplicate analyses and acceptable matrix spike/spike duplicate recoveries (Tables 3.9 and 3.11 ).

PCB aroclors and chlorinated pesticides were not detected in any of the samples, indicating that the West Richmond sample area is uncontaminated with respect to these compounds. This was also the case for the West Richmond samples analyzed during Phase $I$ of the John F. Baldwin Ship Channel project. It is reasonable to expect that PCBs and pesticides would not accumulate in West Richmond sediments because of the high-energy environment, lack of fine particles, and lack of organic carbon. 
TABLE 3.9. Polychlorinated Biphenyls (PCBs) in west Richmond Sediment $(U=$ undectected above given detection limit)

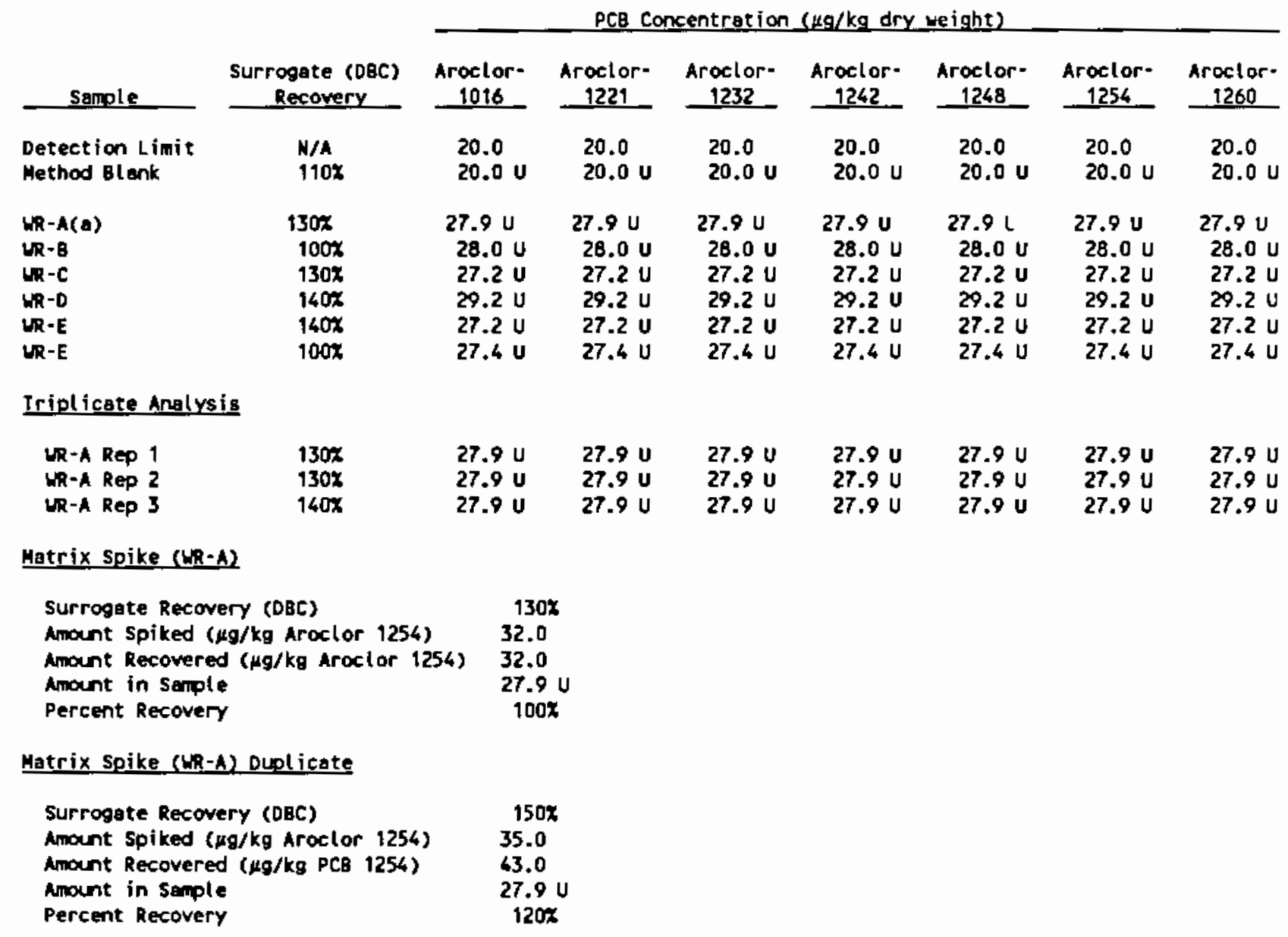

(a) Mean of three replicates, sd=0.0 (compounds belou detection in all samples) 
IABLE 3.10. Pesticides in Phase II West Richmond Cores (U=undetected above given detection limit)

Pesticide (ug/kg dry weight)

\begin{tabular}{|c|c|c|c|c|c|c|c|c|c|c|}
\hline \multirow[b]{2}{*}{ Sample } & \multirow[b]{2}{*}{ Recoyery } & & & & & & & & & \\
\hline & & Aldrin & A-BHC & $\mathrm{B}-\mathrm{BHC}$ & $\mathrm{D}-\mathrm{BHC}$ & Chlordane & $44^{\prime} 000$ & $4,4^{\prime} \mathrm{ODE}$ & $4,4^{\prime} \mathrm{DOT}$ & Dieldein \\
\hline $\begin{array}{l}\text { Detection Linit } \\
\text { Method } 8 \text { lank }\end{array}$ & $\begin{array}{r}N / A \\
116 x\end{array}$ & $2.0 \mathrm{U}$ & $\begin{array}{l}2.0 \\
2.8 \mathrm{U}\end{array}$ & $\begin{array}{l}2.8 \\
2.60\end{array}$ & $\begin{array}{l}2.6 \\
2.6 \mathrm{U}\end{array}$ & $2.0 \mathrm{U}$ & $\begin{array}{l}2.0 \\
2.6 \mathrm{U}\end{array}$ & $\begin{array}{l}2.6 \\
2.6 \mathrm{U}\end{array}$ & $\begin{array}{l}2.0 \\
2.00\end{array}$ & $\begin{array}{l}2.9 \\
2.0 \mathrm{U}\end{array}$ \\
\hline $\begin{array}{l}W R-\lambda(a) \\
W R-B \\
W R-C \\
W R-D \\
W R-E\end{array}$ & $\begin{array}{l}136 x \\
100 x \\
130 x \\
146 x \\
140 x\end{array}$ & $\begin{array}{l}2.8 \mathrm{U} \\
2.8 \mathrm{U} \\
2.7 \mathrm{U} \\
2.9 \mathrm{U} \\
2.7 \mathrm{U}\end{array}$ & $\begin{array}{l}2.8 \mathrm{U} \\
2.8 \mathrm{U} \\
2.7 \mathrm{U} \\
2.9 \mathrm{U} \\
2.7 \mathrm{U}\end{array}$ & $\begin{array}{l}2.8 \mathrm{U} \\
2.8 \mathrm{U} \\
2.7 \mathrm{U} \\
2.9 \mathrm{U} \\
2.7 \mathrm{U}\end{array}$ & $\begin{array}{l}2.8 \mathrm{U} \\
2.8 \mathrm{U} \\
2.7 \mathrm{U} \\
2.9 \mathrm{U} \\
2.7 \mathrm{U}\end{array}$ & $\begin{array}{l}2.8 \mathrm{U} \\
2.8 \mathrm{U} \\
2.7 \mathrm{U} \\
2.9 \mathrm{U} \\
2.7 \mathrm{U}\end{array}$ & $\begin{array}{l}2.8 \mathrm{U} \\
2.8 \mathrm{U} \\
2.7 \mathrm{U} \\
2.9 \mathrm{U} \\
2.7 \mathrm{U}\end{array}$ & $\begin{array}{l}2.8 \mathrm{U} \\
2.8 \mathrm{U} \\
2.7 \mathrm{U} \\
2.9 \mathrm{U} \\
2.7 \mathrm{U}\end{array}$ & $\begin{array}{l}2.8 \mathrm{U} \\
2.8 \mathrm{U} \\
2.7 \mathrm{U} \\
2.9 \mathrm{U} \\
2.7 \mathrm{U}\end{array}$ & $\begin{array}{l}2.8 U \\
2.8 U \\
2.7 U \\
2.9 U \\
2.7 U\end{array}$ \\
\hline \multicolumn{11}{|c|}{ Triplicate Analysis } \\
\hline $\begin{array}{ll}W R-A & R e p \\
\text { WR-A Rep } 2 \\
\text { WR-A Rep } 3\end{array}$ & $\begin{array}{l}190 x \\
190 x \\
146 x\end{array}$ & $\begin{array}{l}2.8 \mathrm{U} \\
2.8 \mathrm{U} \\
2.8 \mathrm{U}\end{array}$ & $\begin{array}{l}2.8 \mathrm{U} \\
2.8 \mathrm{U} \\
2.8 \mathrm{U}\end{array}$ & $\begin{array}{l}2.8 \mathrm{U} \\
2.8 \mathrm{U} \\
2.8 \mathrm{U}\end{array}$ & $\begin{array}{l}2.8 \mathrm{U} \\
2.8 \mathrm{U} \\
2.8 \mathrm{U}\end{array}$ & $\begin{array}{l}2.8 \mathrm{U} \\
2.8 \mathrm{U} \\
2.8 \mathrm{U}\end{array}$ & $\begin{array}{l}2.8 \mathrm{U} \\
2.8 \mathrm{U} \\
2.8 \mathrm{U}\end{array}$ & $\begin{array}{l}2.8 \mathrm{U} \\
2.8 \mathrm{U} \\
2.8 \mathrm{U}\end{array}$ & $\begin{array}{l}2.8 \mathrm{U} \\
2.8 \mathrm{U} \\
2.8 \mathrm{U}\end{array}$ & $\begin{array}{l}2.8 \mathrm{U} \\
2.8 \mathrm{U} \\
2.8 \mathrm{U}\end{array}$ \\
\hline
\end{tabular}

in

\begin{tabular}{|c|c|c|c|c|c|c|c|c|c|c|c|}
\hline \multirow[b]{2}{*}{ Sanple } & \multicolumn{11}{|c|}{ Pesticide (ug/kg dry reight) } \\
\hline & $\begin{array}{c}\text { Endosulfan } \\
\text { I }\end{array}$ & $\begin{array}{c}\text { Endosulfan } \\
\text { II }\end{array}$ & $\begin{array}{l}\text { Endesulfan } \\
\text { Sulfate } \\
\end{array}$ & Endrin & $\begin{array}{l}\text { Endrin } \\
\text { Aldehyde }\end{array}$ & Keptachlor & $\begin{array}{l}\text { Heptachlor } \\
\text { Epoxide }\end{array}$ & $\begin{array}{l}\text { Lindane } \\
(G-B M C) \\
\end{array}$ & $\begin{array}{l}\text { Wethoxy- } \\
\text { chlor }\end{array}$ & $\begin{array}{l}\text { Endrin } \\
\text { Ketone }\end{array}$ & Toxaphene \\
\hline $\begin{array}{l}\text { Detect ion Linit } \\
\text { Method Blank }\end{array}$ & $2.8 \mathrm{U}$ & 2.84 & $\begin{array}{l}2.0 \\
2.00\end{array}$ & $\begin{array}{l}2.8 \\
2.8 U\end{array}$ & $\begin{array}{l}2.0 \\
2.0 \mathrm{U}\end{array}$ & $\begin{array}{l}2.0 \\
2.80\end{array}$ & 2.00 & $\begin{array}{l}2.0 \\
2.6 \mathrm{U}\end{array}$ & $\begin{array}{l}4.0 \\
4.00\end{array}$ & $\begin{array}{l}2.0 \\
2.0 \mathrm{U}\end{array}$ & $\begin{array}{l}20.8 \\
20.8 \mathrm{U}\end{array}$ \\
\hline $\begin{array}{l}\mathbb{R} R-A(a) \\
R R-B \\
R R-C \\
R R-D \\
R R-E\end{array}$ & $\begin{array}{l}2.8 \mathrm{U} \\
2.8 \mathrm{U} \\
2.7 \mathrm{U} \\
2.9 \mathrm{U} \\
2.7 \mathrm{U}\end{array}$ & $\begin{array}{l}2.8 \mathrm{U} \\
2.8 \mathrm{U} \\
2.7 \mathrm{U} \\
2.9 \mathrm{U} \\
2.7 \mathrm{U}\end{array}$ & $\begin{array}{l}2.8 \mathrm{U} \\
2.8 \mathrm{U} \\
2.7 \mathrm{U} \\
2.9 \mathrm{U} \\
2.7 \mathrm{U}\end{array}$ & $\begin{array}{l}2.8 \mathrm{U} \\
2.8 \mathrm{U} \\
2.7 \mathrm{U} \\
2.9 \mathrm{U} \\
2.7 \mathrm{U}\end{array}$ & $\begin{array}{l}2.8 \mathrm{U} \\
2.8 \mathrm{U} \\
2.7 \mathrm{U} \\
2.9 \mathrm{U} \\
2.7 \mathrm{U}\end{array}$ & $\begin{array}{l}2.8 \mathrm{U} \\
2.8 \mathrm{U} \\
2.7 \mathrm{U} \\
2.9 \mathrm{U} \\
2.7 \mathrm{U}\end{array}$ & $\begin{array}{l}2.8 \mathrm{U} \\
2.8 \mathrm{U} \\
2.7 \mathrm{U} \\
2.9 \mathrm{U} \\
2.7 \mathrm{U}\end{array}$ & $\begin{array}{l}2.8 \mathrm{U} \\
2.8 \mathrm{U} \\
2.7 \mathrm{U} \\
2.9 \mathrm{U} \\
2.7 \mathrm{U}\end{array}$ & $\begin{array}{l}5.8 U \\
5.6 U \\
5.5 U \\
5.8 U \\
5.4 U\end{array}$ & $\begin{array}{l}2.8 U \\
2.8 U \\
2.8 U \\
2.9 U \\
2.7 U\end{array}$ & $\begin{array}{l}27.9 \mathrm{U} \\
28.0 \mathrm{U} \\
27.3 \mathrm{U} \\
29.2 \mathrm{U} \\
27.2 \mathrm{U}\end{array}$ \\
\hline \multicolumn{12}{|c|}{ Iriplicate Analysi } \\
\hline $\begin{array}{l}R R-\lambda \text { rep } 1 \\
R-\Lambda \text { rep } 2 \\
R-\lambda \text { rep } 3\end{array}$ & $\begin{array}{l}2.8 \mathrm{U} \\
2.8 \mathrm{U} \\
2.8 \mathrm{U}\end{array}$ & $\begin{array}{l}2.8 \mathrm{U} \\
2.8 \mathrm{U} \\
2.8 \mathrm{U}\end{array}$ & $\begin{array}{l}2.8 \mathrm{U} \\
2.8 \mathrm{U} \\
2.8 \mathrm{U}\end{array}$ & $\begin{array}{l}2.8 \mathrm{U} \\
2.8 \mathrm{U} \\
2.8 \mathrm{U}\end{array}$ & $\begin{array}{l}2.8 U \\
2.8 U \\
2.8 U\end{array}$ & $\begin{array}{l}2.8 \mathrm{U} \\
2.8 \mathrm{U} \\
2.8 \mathrm{U}\end{array}$ & $\begin{array}{l}2.8 \mathrm{U} \\
2.8 \mathrm{U} \\
2.8 \mathrm{U}\end{array}$ & $\begin{array}{l}2.8 \mathrm{U} \\
2.8 \mathrm{U} \\
2.8 \mathrm{U}\end{array}$ & $\begin{array}{l}5.6 \mathrm{U} \\
5.6 \mathrm{U} \\
2.8 \mathrm{U}\end{array}$ & $\begin{array}{l}2.8 \mathrm{U} \\
2.8 \mathrm{U} \\
2.8 \mathrm{U}\end{array}$ & $\begin{array}{l}27.9 \mathrm{U} \\
27.9 \mathrm{U} \\
27.9 \mathrm{U}\end{array}$ \\
\hline
\end{tabular}

(a) Wean of three replicates, $s d=6.9$ (compounds belor detection in all samples) 
TABLE 3.11. Results of Pesticide Matrix Spikes ( $U=$ undetected above given detection 1 imit; $N / A=$ not applicable)

Sample

Matrix spike (HR-A)

Anount Spiked $(\mu g / \mathrm{kg})$

Anount Recovered ( $\mu g / \mathrm{kg}$ )

Anount in Sample

Percent Recovery

Matrix Spike (WR-A) Duplicate

Anount Spiked $(\mathrm{kg} / \mathrm{kg})$

Anount Recovered $(\mu g / k g)$

Anount in Semple

Percent Recovery
Pesticide

Aldrin $4.4^{\prime}$ DOT Dieldrin Endrin Heptachlor SG-BHC) $\begin{aligned} & \text { Lindane Surrogate } \\ & \text { Recovery }\end{aligned}$

\begin{tabular}{|c|c|c|c|c|c|c|}
\hline $\begin{array}{c}22.0 \\
29.0 \\
2.8 \mathrm{U} \\
130 \mathrm{x}\end{array}$ & $\begin{array}{c}22.0 \\
26.0 \\
2.8 \mathrm{U} \\
120 \mathrm{x}\end{array}$ & $\begin{array}{c}22.0 \\
24.0 \\
2.8 \mathrm{U} \\
110 \%\end{array}$ & $\begin{array}{l}22.0 \\
21.0 \\
2.8 \mathrm{U} \\
99 \%\end{array}$ & $\begin{array}{l}22.0 \\
21.0 \\
2.8 \mathrm{U} \\
935\end{array}$ & $\begin{array}{c}22.0 \\
24.0 \\
2.8 \mathrm{U} \\
110 x\end{array}$ & $\begin{array}{l}N / A \\
H / A \\
N / A \\
110 X\end{array}$ \\
\hline
\end{tabular}

$\begin{array}{ccccccc}24.0 & 24.0 & 26.0 & 26.0 & 24.0 & 24.0 & \mathrm{H} / \mathrm{A} \\ 46.0 & 46.0 & 26.0 & 36.0 & 22.0 & 26.0 & \mathrm{~N} / \mathrm{A} \\ 2.8 \mathrm{U} & 2.8 \mathrm{U} & 2.8 \mathrm{U} & 2.8 \mathrm{U} & 2.8 \mathrm{U} & 2.8 \mathrm{U} & \mathrm{H} / \mathrm{A} \\ 200 \mathrm{X} & 117 \mathrm{X} & 110 \mathrm{X} & 160 \mathrm{X} & 98 \mathrm{X} & 110 \mathrm{X} & 110 \mathrm{X}\end{array}$


Polynuclear Aromatic Hydrocarbons (PAH)

Sixteen PAH compounds were extracted and analyzed following Method 8270 in EPA Test Methods for Evaluating Solid Wastes: Physical/Chemical Methods, SW-846 (USEPA 1986). PAH results and quality control data for the Phase II West Richmond core samples are presented in Tables 3.12, 3.13, and 3.14. The achieved detection limits were acceptably low, no analytes were detected in the method blank, and recoveries for surrogate compounds were very good, ranging from 60 to $100 \%$. No PAH compounds were detected in any of the five Phase II West Richmond core samples.

TABLE 3.12. Polynuclear Aromatic Hydrocarbons in Phase II West Richmond Cores ( $U$ = undetected above given concentration)

CONCENTRATION ( $\mu \mathrm{g} / \mathrm{kg}$ dry weight)

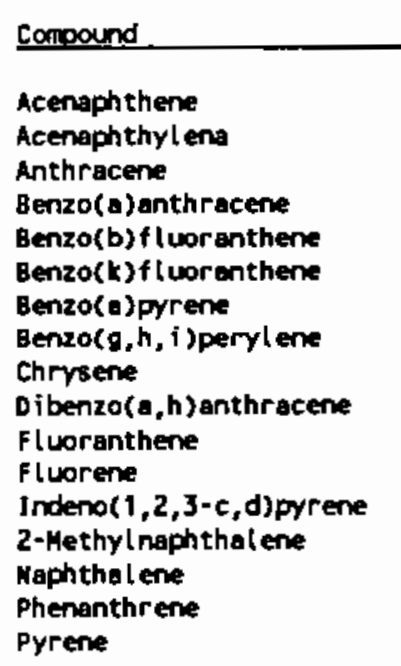

Surrogate Recovery ( $\mathbf{X})$

Naph thal ene-da

Acenaphthene-d10

Phenanthrene-d10

Benzo(a)pyrene-d12

\begin{tabular}{|c|c|c|c|c|c|c|}
\hline $\begin{array}{l}\text { Detection } \\
\text { Limit }\end{array}$ & $\begin{array}{l}\text { Method } \\
\text { Blank }\end{array}$ & $\mathbf{G} \cdot \mathbf{A}$ & $w R+B$ & $G R-C$ & $M R-0$ & $\mathrm{WR}-\mathrm{E}$ \\
\hline 10 & $10 U$ & $10 \mathrm{U}$ & $10 \mathrm{U}$ & $10 \mathrm{U}$ & $10 \mathrm{U}$ & $10 \mathrm{U}$ \\
\hline 10 & $10 \mathrm{U}$ & $10 \mathrm{U}$ & $10 \mathrm{U}$ & $10 \mathrm{U}$ & $10 \mathrm{U}$ & to U \\
\hline 10 & $10 \mathrm{U}$ & $10 U$ & $10 \mathrm{U}$ & $10 \mathrm{U}$ & $10 \mathrm{U}$ & $10 \mathrm{U}$ \\
\hline 10 & $10 \mathrm{U}$ & $10 \mathrm{U}$ & $10 \mathrm{U}$ & $10 \mathrm{U}$ & $10 \mathrm{U}$ & $10 \mathrm{U}$ \\
\hline 10 & $10 \mathrm{U}$ & $10 \mathrm{U}$ & $10 \mathrm{U}$ & $10 \mathrm{U}$ & $10 \mathrm{U}$ & $10 \mathrm{U}$ \\
\hline 10 & $10 \mathrm{U}$ & $10 \mathrm{U}$ & $10 \mathrm{U}$ & $10 \mathrm{U}$ & $10 \mathrm{U}$ & $10 \mathrm{U}$ \\
\hline 10 & $10 \mathrm{U}$ & $10 \mathrm{U}$ & $10 \mathrm{U}$ & $10 \mathrm{U}$ & $10 \mathrm{U}$ & $10 \mathrm{U}$ \\
\hline 10 & $10 \mathrm{U}$ & $10 \mathrm{U}$ & $10 \mathrm{U}$ & $10 \mathrm{U}$ & $10 \mathrm{U}$ & $10 \mathrm{U}$ \\
\hline 10 & $10 \mathrm{U}$ & $10 \mathrm{U}$ & $10 \mathrm{U}$ & $10 u$ & $10 \mathrm{U}$ & $10 \mathrm{U}$ \\
\hline 10 & $10 \mathrm{U}$ & $10 \mathrm{U}$ & $10 \mathrm{U}$ & $10 \mathrm{U}$ & $10 \mathrm{U}$ & $10 \mathrm{U}$ \\
\hline 10 & $10 \mathrm{U}$ & $10 \mathrm{U}$ & $10 \mathrm{U}$ & $10 \mathrm{U}$ & $10 \mathrm{U}$ & $10 \mathrm{U}$ \\
\hline 10 & $10 \mathrm{U}$ & $10 \mathrm{U}$ & $10 \mathrm{U}$ & $10 \mathrm{U}$ & $10 \mathrm{U}$ & $10 \mathrm{U}$ \\
\hline 10 & $10 \mathrm{U}$ & $10 U$ & $10 \mathrm{~V}$ & $10 \mathrm{U}$ & $10 \mathrm{U}$ & $10 \mathrm{U}$ \\
\hline 20 & $20 \mathrm{U}$ & $20 \mathrm{U}$ & $20 \mathrm{U}$ & $20 \mathrm{U}$ & $20 \mathrm{U}$ & $20 \mathrm{U}$ \\
\hline 20 & $20 \mathrm{U}$ & $20 \mathrm{U}$ & $20 \mathrm{U}$ & $20 \mathrm{U}$ & $20 \mathrm{U}$ & $20 \mathrm{U}$ \\
\hline 10 & $10 \mathrm{U}$ & $10 \mathrm{U}$ & $10 \mathrm{U}$ & $10 \mathrm{U}$ & $90 \mathrm{U}$ & $10 U$ \\
\hline 10 & $10 \mathrm{U}$ & $10 \mathrm{U}$ & $10 \mathrm{U}$ & $10 \mathrm{U}$ & $10 \mathrm{U}$ & $10 \mathrm{U}$ \\
\hline
\end{tabular}

$\begin{array}{lrrrrrr}\text { W/A } & 83 & 89 & 82 & 84 & 85 & 60 \\ \text { W/A } & 78 & 77 & 75 & 78 & 76 & 71 \\ \text { W/A } & 81 & 79 & 78 & 79 & 75 & 75 \\ \text { W/A } & 100 & 100 & 100 & 100 & 95 & 96\end{array}$


IABLE 3.13. Matrix Spike Data for PAH Analysis (Concentrations in $\mu \mathrm{g} / \mathrm{kg}$ dry weight; $U=$ undetected above given concentration; $N / A=$ not applicable)

\begin{tabular}{|c|c|c|c|c|c|c|c|c|}
\hline \multirow[b]{2}{*}{ Compound } & \multirow[b]{2}{*}{$\begin{array}{l}\text { Detection } \\
\text { Limit }\end{array}$} & \multirow[b]{2}{*}{$\begin{array}{l}\text { Amount } \\
\text { Spiked }\end{array}$} & \multirow[b]{2}{*}{$\begin{array}{c}\text { Anount } \\
\text { in Sample }\end{array}$} & \multicolumn{2}{|c|}{ Matrix Spike(a) } & \multicolumn{2}{|c|}{ Matrix Spike Duplicate ${ }^{(a)}$} & \multirow{2}{*}{$\begin{array}{l}\text { MS/MSD } \\
\text { Relative Percent } \\
\text { Difference (RPD) }(D)\end{array}$} \\
\hline & & & & $\begin{array}{c}\text { Amount } \\
\text { Recovered }\end{array}$ & $\begin{array}{c}\text { Spike } \\
\text { Recovery (x) }\end{array}$ & $\begin{array}{l}\text { Amount } \\
\text { Recovered }\end{array}$ & $\begin{array}{c}\text { Spike } \\
\text { Recovery }(x)\end{array}$ & \\
\hline Acenaph thene & 5 & 100 & U 5 & 120 & 120 & 120 & 120 & 0 \\
\hline Acenaphthylene & 5 & 100 & u 5 & 120 & 120 & 120 & 120 & 0 \\
\hline Anthracene & 5 & 100 & 7 & 127 & 120 & 147 & 160 & 15 \\
\hline Benzo(a) anthracene & 5 & 100 & 12 & 122 & 110 & 142 & 130 & 17 \\
\hline Benzo(b) flusronthene & 5 & 100 & 18 & 128 & 110 & 188 & 170 & 43 \\
\hline Oenzo(k) fiuorenthene & 5 & 100 & 14 & 124 & 110 & 154 & 140 & 24 \\
\hline Benzo(a)pyrene & 5 & 100 & 19 & 119 & 100 & 159 & 140 & 33 \\
\hline Benzo(g, $h, i)$ perylene & 5 & 100 & 22 & 109 & $B 7$ & 132 & 110 & 23 \\
\hline Chrysene & 5 & 100 & 14 & 124 & 110 & 164 & 150 & 31 \\
\hline Dibenzo $(a, h)$ anthracene & 5 & 100 & U 5 & 140 & 140 & 140 & 140 & 0 \\
\hline Fluoranthene & 5 & 100 & 18 & 128 & 110 & 138 & 120 & 9 \\
\hline Fluorene & 5 & 100 & $\cup 5$ & 130 & 130 & 120 & 120 & 8 \\
\hline Indeno $(1,2,3-c, d)$ pyrene & 5 & 100 & 19 & $\$ 19$ & 100 & 159 & $\$ 40$ & 33 \\
\hline Naphtholene & 10 & 100 & บ 5 & 150 & 150 & 160 & 160 & 6 \\
\hline Phenanthrene & 5 & 100 & 12 & 122 & 110 & 132 & 120 & 9 \\
\hline Pyrene & 5 & 100 & 42 & 134 & 92 & 152 & 110 & 18 \\
\hline \multicolumn{9}{|l|}{ Surrogates } \\
\hline Naph thalene-da & N/A & 500 & $99^{(c)}$ & $\mathrm{N} / \mathrm{A}$ & $87^{(c)}$ & $\omega / \AA$ & $100^{(c)}$ & $\mathrm{H} / \mathrm{A}$ \\
\hline Acenaph thene-d10 & $\mathrm{H} / \mathrm{A}$ & 500 & 89 & $\mathrm{H} / \mathrm{A}$ & 80 & $N / A$ & 88 & H/A \\
\hline Phenanthrene-d10 & $N / A$ & 500 & 81 & $N / A$ & 80 & $N / A$ & 81 & $\mathrm{~N} / \mathrm{A}$ \\
\hline Benzo(a)pyrene-d12 & $\mathrm{H} / \mathrm{A}$ & 500 & 110 & $\mathrm{~N} / \mathrm{A}$ & 120 & $N / A$ & 120 & N/A \\
\hline
\end{tabular}

(a) Matrix spike sample was not sediment from John $F$. Boldwin Phase II program but was anblyzed by the same laboratory at the same time

(b) $R P D=($ difference between replicates $) /($ mean of replicates) $\times 100$

(c) Volues are percent recovery of surrogates 
IABLE 3.14. Standard Reference Material PAH Results (Concentrations in $\mu \mathrm{g} / \mathrm{kg}$ dry weight; $U=$ undetected above given concentration; $N C=$ SRM not certified for compound; $N / A=$ not applicable)

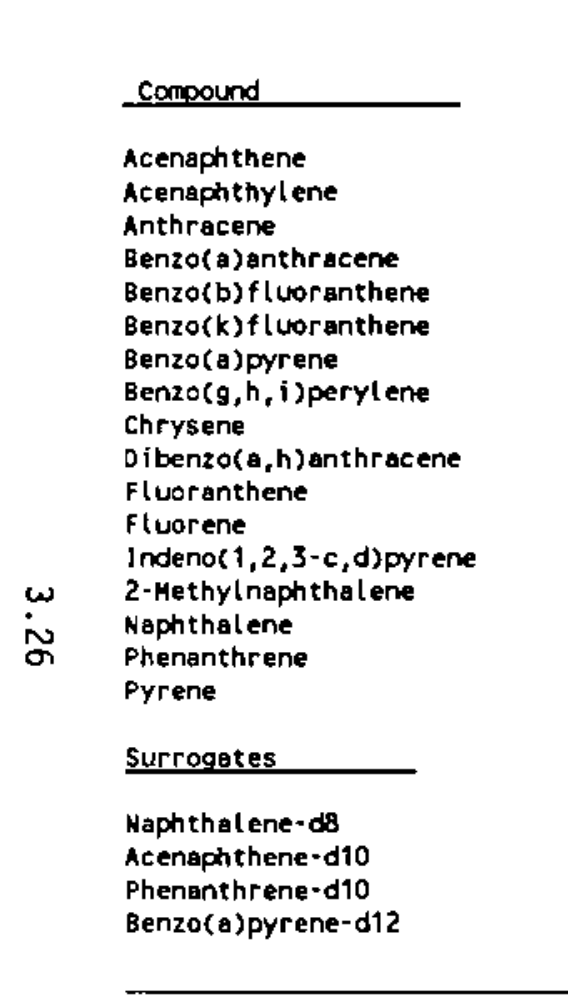

\begin{tabular}{|c|c|}
\hline $\begin{array}{c}\text { Detection } \\
\text { Limft } \\
\end{array}$ & $\begin{array}{c}\text { SRM HS-4 } \\
\text { Certified } \\
\text { Range } \\
\end{array}$ \\
\hline $\begin{array}{l}5.0 \\
5.0 \\
5.0 \\
5.0 \\
5.0 \\
5.0 \\
5.0 \\
5.0 \\
5.0 \\
5.0 \\
5.0 \\
5.0 \\
5.0 \\
10 \\
10 \\
5.0 \\
5.0\end{array}$ & $\begin{array}{rl}U & 150 \\
U & 150 \\
140 & \pm 70 \\
530 & \pm 50 \\
700 & \pm 150 \\
360 & \pm 50 \\
650 & \pm 80 \\
580 & \pm 220 \\
650 & \pm 80 \\
120 & \pm 50 \\
1250 & \pm 100 \\
U & 150 \\
510 & \pm 150 \\
& N C \\
U & 150 \\
680 & \pm 80 \\
940 & \pm 120\end{array}$ \\
\hline
\end{tabular}

\begin{tabular}{|c|c|}
\hline Conc, & $\begin{array}{l}\text { In/out of } \\
\text { Range }\end{array}$ \\
\hline 33 & in \\
\hline 150 & In \\
\hline 230 & out $+10 x$ \\
\hline 520 & In \\
\hline 570 & In \\
\hline 510 & Out $+24 x$ \\
\hline 520 & Out $-9 x$ \\
\hline 390 & $\ln$ \\
\hline 620 & $\ln$ \\
\hline 130 & $\ln$ \\
\hline 870 & Out $-25 x$ \\
\hline 42 & In \\
\hline 480 & In \\
\hline 110 & $N / A$ \\
\hline 78 & In \\
\hline 550 & Out $=8 x$ \\
\hline 720 & out $-12 x$ \\
\hline
\end{tabular}

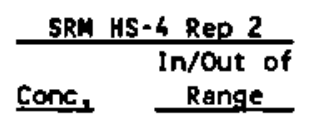

30

150

220

500

570

480

510
350

350

140

850

40

40
440

110

78

out $-8 x$

out $-12 x$

$\begin{array}{ll}88^{(b)} & N / A \\ 93 & N / A \\ 84 & N / A \\ 110 & N / A\end{array}$

Relative Percent

Difference (RPO) (a)

Between Replicates.

10
0
4
4
0
6
2
11
3
7
2
5
9
0
0
2
6

(a) RPD = (|difference between replicates $\mid) /($ mean of replicates) $\times 100$

(b) values are percent recovery for surrogates 


\subsection{DISCUSSION}

The five sites sampled during Phase Il of the John F. Baldwin Ship Channel Program were located just outside and to the east of the existing channel, while the John F. Baldwin Phase I stations were inside the existing channel. The Phase II West Richmond cores were characterized as geologicaliy and chemically very similar to the nearest Phase I cores. Compared to Phase I samples, Phase II sediments showed comparable or lower concentrations of oil and grease, petroleum hydrocarbons, metals, and butyltins. Pesticides and PCBs were not detected in either Phase I or Phase II West Richmond sediments.

The most noticeable difference was in the PAH values of sediment cores from the central part of the West Richmond reach of the channel, where the upchannel direction changes from northwest to north (refer to Figure 3.1). No PAHs were detected in any Phase II West Richmond sediments, while PAH leve]s of $1-3 \mathrm{mg} / \mathrm{kg}(\mathrm{ppm})$ were measured at the three nearest Phase I stations (WR IV R, WR IV.5 C, and WR V L) (Word and Kohn 1990). Phase II stations WR-D and WR-E were located approximately $1000 \mathrm{ft}$ east of those Phase I stations; Phase II station WR-C was approximately $2000 \mathrm{ft}$ east.

Concentrations of PAH, total organic carbon, and percent clay for Phase II stations and nearby Phase I stations are compared in Table 4.1. It appears that detection of PAH in WR IV R, WR IV.5 C, and WR V L may be correlated with a higher proportion of fine-grained sediments (clay). The relationship of PAH to organic carbon shows no such correlation, as Phase II samples showed TOC values as high as those Phase I samples where PAH was detected. Further north in the channel, PAHs were undetected in both Phase I and Phase II stations (WR III L, WR III C, WR II $L$, WR-A, and WR-B). While there is no reason to expect adverse biological effects due to $P A H$ in sediment removed from the Phase II sampling area, there may be increased potential for transport of PAH into the area once it is dredged, if the source of PAH to the Phase I sites is still active. 
TABLE 4.1. Comparison of PAH, Core Length, Percent Clay, and TOC in West Richmond Sediments, John F. Baldwin Phases I and II ( $M W=$ molecular weight; $N D=$ not detected)

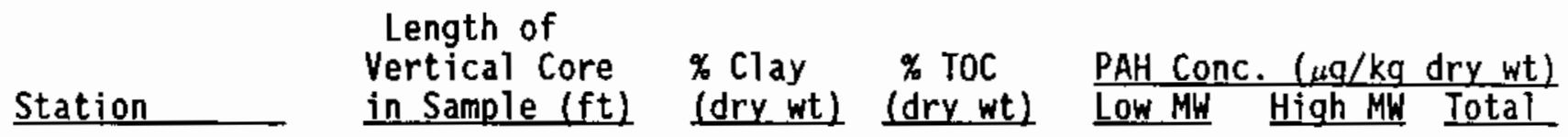

\section{Phase II}

WR-A

WR $-B$

WR-C

WR-D

WR-D

Phase I

WR II L $\left(0-6.9^{\prime}\right)$

WR III $C\left(0-6.4^{\prime}\right)$

WR III L $\left(0-6.6^{\prime}\right)$

WR IV R $\left(0-6^{\prime}\right)$

WR IV R (6-11.5')

WR IV.5 C $\left(0-4^{\prime}\right)$

WR V L $\left(0-6^{\prime}\right)$
10.2

12.2

12.5

4.6

6.1

6.9

6.4

6.6

6.0

5.5

4.0

6.0
13

15

11

19

12
0.53

0.62

1.17

0.86

0.71

0.49

0.44

0.46

0.92

0.40

0.76

$\begin{array}{lllll}32 & 1.05 & 709 & 2366 & 3075\end{array}$

ND

ND

ND

ND

ND

$\begin{array}{ll}\text { ND } & \text { ND } \\ \text { ND } & \text { ND } \\ \text { ND } & \text { ND } \\ \text { ND } & \text { ND } \\ \text { ND } & \text { ND }\end{array}$

ND

$\begin{array}{lllll}26 & 0.76 & 371 & 1412 & 1783\end{array}$




\subsection{REFERENCES}

American Society for Testing and Materials (ASTM). 1972. Standard Method for Particle-Size Analysis of Soils (with the substitution of the No. 100 sieve for the No. 140 sieve). 0422, American Society for Testing and Materials, Philadelphia, Pennsylvania.

American Society for Testing and Materials (ASTM). 1978. Standard Method for Dry Preparation of Soil Samples for Particle-size Analysis and Determination of Soil Constants. D421, American Society for Testing and Materials, Philadelphia, Pennsylvania.

American Society for Testing and Materials (ASTM). 1984. Standard Practice for Description and Identification of Soils. D 2488-84, American Society for Testing and Materials, Philadeiphia, Pennsylvania, pp. 293-302.

Barry, R.G. 1983. Late-Pleistocene Climatology: Late Quaternary Environments of the United States, Vol. 1, Wright, H. E., ed., pp. 390-407, University of Minnesota Press, Minneapolis, Minnesota.

Bloom,. N.S., and E.A. Crecelius. 1983. "Determination of Mercury in Seawater at Sub-Nanogram per Liter Levels." Marine Chemistry 14:49-59.

Bloom, N.S., and E.A. Crecelius. 1984. "Distribution of Silver, Mercury, Lead, Copper and Cadium in Central Puget Sound Sediments." Marine Chemistry $21: 377-390$.

Nielson, K.K., and R.W. Sanders, 1983. "Multielement Analys is of Unweighed Biological and Geological Samples Using Backscatter and Fundamental

Parameters." Adv. X-Ray Anal. 26:385-390.

Puget Sound Estuary Program (PSEP). 1986, Recommended for Measuring Selected Environmental Variables in Puget Sound. Final Report. TC-3991-04. Prepared by Tetra Tech, Inc., for the U.S. Environmental Protection Agency, Seattle, Washington.

Unger, M.A., W.G. Macintyre, J. Greaves, and R.J. Huggett. 1986. "GC Determination of Butyltins in Natural Waters by Flame Photometric Detection of Hexyl Derivatives with Mass Spectrometric Confirmation." Chemosphere $15(4): 461-470$.

U.S. Army Corps of Engineers (USACE). 1975a. Maintenance Oredging: Existing Navigation Projects, San Francisco Bay Region, California. Final Composite Environmental Statement. U.S. Army Corps of Engineers, San Francisco District. July 1975.

U.S. Army Corps of Engineers (USACE). 1975b. Dredqe Disposal Study: San Francisco Bay and Estuary. Appendix F: Crystall ine Matrix. U.S. Army Corps of Engineers, San Francisco District. July 1975. 
U.S. Army Corps of Engineers (USACE). 1979. Dredge Disposal Study: San

Francisco Bay and Estuary. Appendix B: Pollutant Distribution. May, 1979.

U.S. Environmental Protection Agency (EPA). 1979. Test Methods for

Evaluating Solid Waste: Physical/Chemical Methods. EPA-600 4-79-020 Methods 413.2, 418.1, Environmenta] Monitoring and Support Laboratory, Cincinnati, Ohio.

U.S. Environmental Protection Agency (EPA). 1986. Test Methods for Evaluating Solid Waste: Physical/Chemical Methods. SW-846, U.S. Document No. 955-001-00000, Washington, D.C.

Word, J.Q., J.A. Ward, J.A. Strand, and E.A. Crecelius. 1990. Ecological Evaluation of Proposed Discharge of Dredged Material from Oakl and Harbor into Ocean Waters (Phase II of -42 Foot Project). PNL-7483. Prepared for the U.S. Army Corps of Engineers by Battelle/Marine Sciences Laboratory, Sequim, Washington.

Word, J.Q., and N.P. Kohn. 1990. Chemical Evaluations of John F. Baldwin Ship Channel Sediment. PNL-7486, Battelle/Marine Sciences Laboratory, Sequim, Washington. 


\section{APPENDIX A}

MATERIALS AND METHODS USED FOR THE DESCRIPTION OF SEDIMENT CORES 
APPENDIX A

MATERIALS AND METHODS USED FOR

THE DESCRIPIION OF SEDIMENT CORES

\section{A.1 MATERIALS}

The following is a checklist of items and materials useful for the examination and description of sediment cores.

- ASTM Procedure D 2488-84

- Stainless-steel knife

- Hand lens (10X magnification)

- $\quad 10 \mathrm{~N}$ Hydrochloric acid (HCl)

- Ruler (scaled in 0.1-foot increments)

- Blank log forms (see Figure A.1)

- Clipboard

- AGI Data Sheets

- Munsell Color Charts

In addition, the charts and/or reference materials listed in Table A.l, and included in this appendix, are useful in the description of specific sediment characteristics.

\section{A.2 METHODS}

Descriptions of the physical, chemical, and biological features preserved in sediments aid in the interpretation of the types of geologic processes active both during and after the sediment was deposited. A total of 17 sediment characteristics, outlined in ASTM (1984), are commonly used to describe inorganic soils. These are listed in Table A.2.

Moisture condition was not routinely logged because of the saturated nature of the sediments. Furthermore, since particles were rarely larger than coarse sand, neither were angularity, particle shape, range in particle size, and hardness logged. For this reason, these sediment characteristics were not included in the $\log$ form used for the description of John $F$. Baldwin sediments (Figure A.1). However, in the few instances where these characteristics did apply, they were described under the "COMMENTS" column. 
Core Data Log

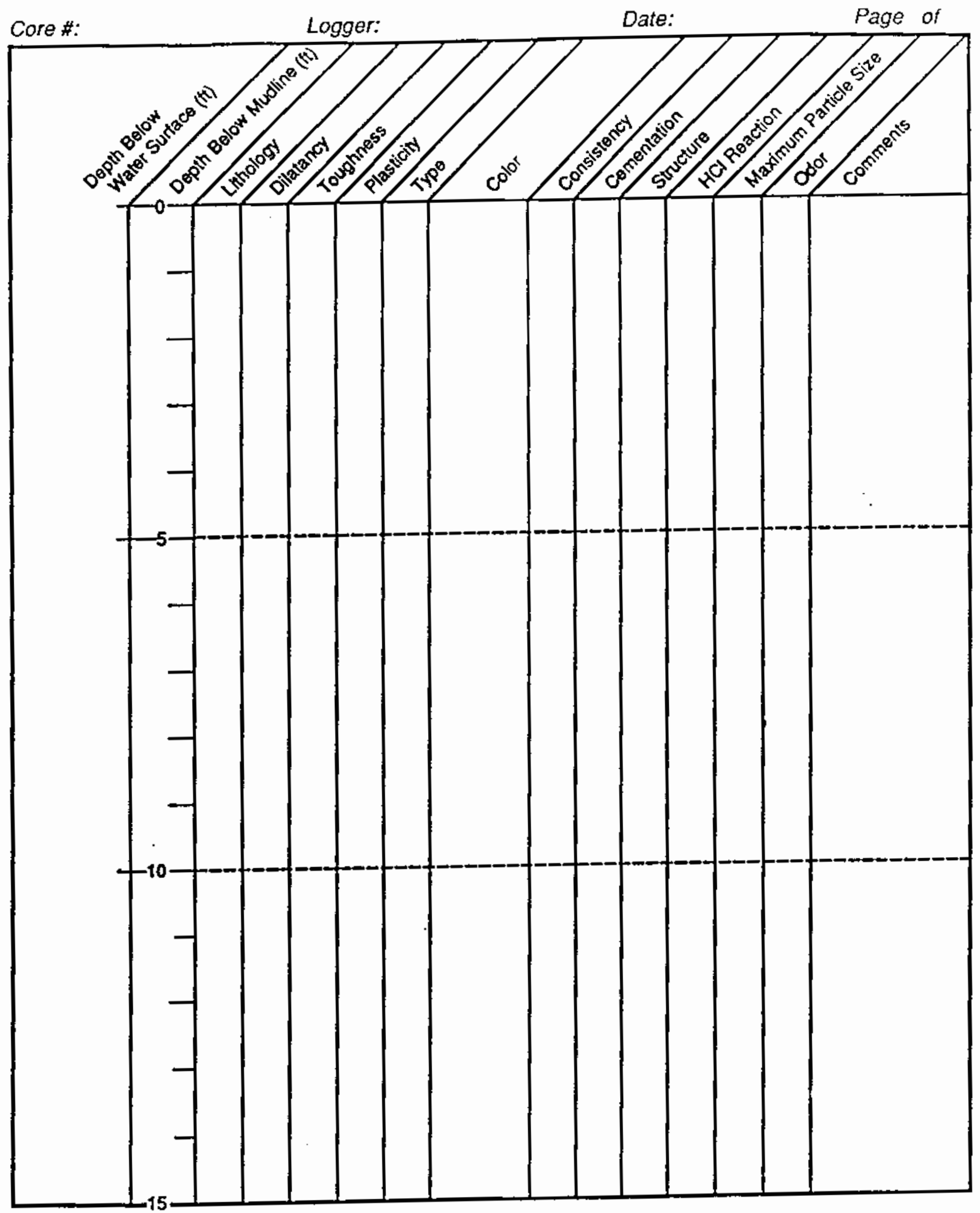

FIGURE A.1. Log Form Used to Record Sediment Descriptions 
IABLE A.1. Charts and Other Reference Materials Used to Provide Standardized Descriptions of Sediment Characteristics.

CHART/REFERENCE

- Percentage Estimate Chart

- Roundness Scale

- Sorting Chart

- Particle Shape

- Munsell Soil Color Charts

- Unified Soil Classification System

- Grain-size Scales

- Lithologic Symbols
PURPOSE

FIGURE \#

Estimate percentage of individual particles or constituents

Roundness of sand and coarser particles

Estimate of grading

Reference to describe particle shape

Soil color

Method for designating sediment type

Range of particle sizes; maximum particle size

Graphic patterns for lithologic log
A. 3B

A. 5

A. 6, A. 7

A. 2

A. 3 A

A. 4

A. 8, A. 9

A.10, A.11

TABLE A.2. Sediment characteristics identified in ASTM Procedure 02488-84.

1) angularity *

2) particle shape *

3) color

4) odor

5) moisture condition

6) $\mathrm{HCl}$ reaction

7) consistency (i.e., firmness)

8) cementation *

9) structure
10) sediment classification type (i.e., lithology)

11) range of particle sizes *

12) maximum particle size

13) hardness *

14) dry strength $\star *$

15) dilatancy **

16) toughness $* *$

17) plasticity **

* Applies to coarse-grained sediment (sand and larger particles) ** Applies to fine-grained sediment of mostly silt and/or clay Features not generally logged for this study are underlined 
The definition of "soil" from the engineers standpoint (ASTM, 1984), includes any unconsolidated sediment. The geologic definition of soil is slightly different and restricts soils to those sedimentary deposits that have undergone alteration near the land's surface by either physical, chemical, and/or biological processes; therefore, in a strict sense, not all sediments are soils. For the purposes of this discussion, however, "soils" and "sediments" will be used synonymously.

It is sometimes helpful to provide an estimate of the relative proportions of different constituents in sediments (e.g. light-versus dark-colored minerals). This is made easier and more accurate by using a percentage estimate chart, which provides a graphic reference with varying concentrations of a particular constituent (Figure A.2).

The criteria used to describe each of the 17 sediment characteristics identified in ASTM (1984) are discussed below.

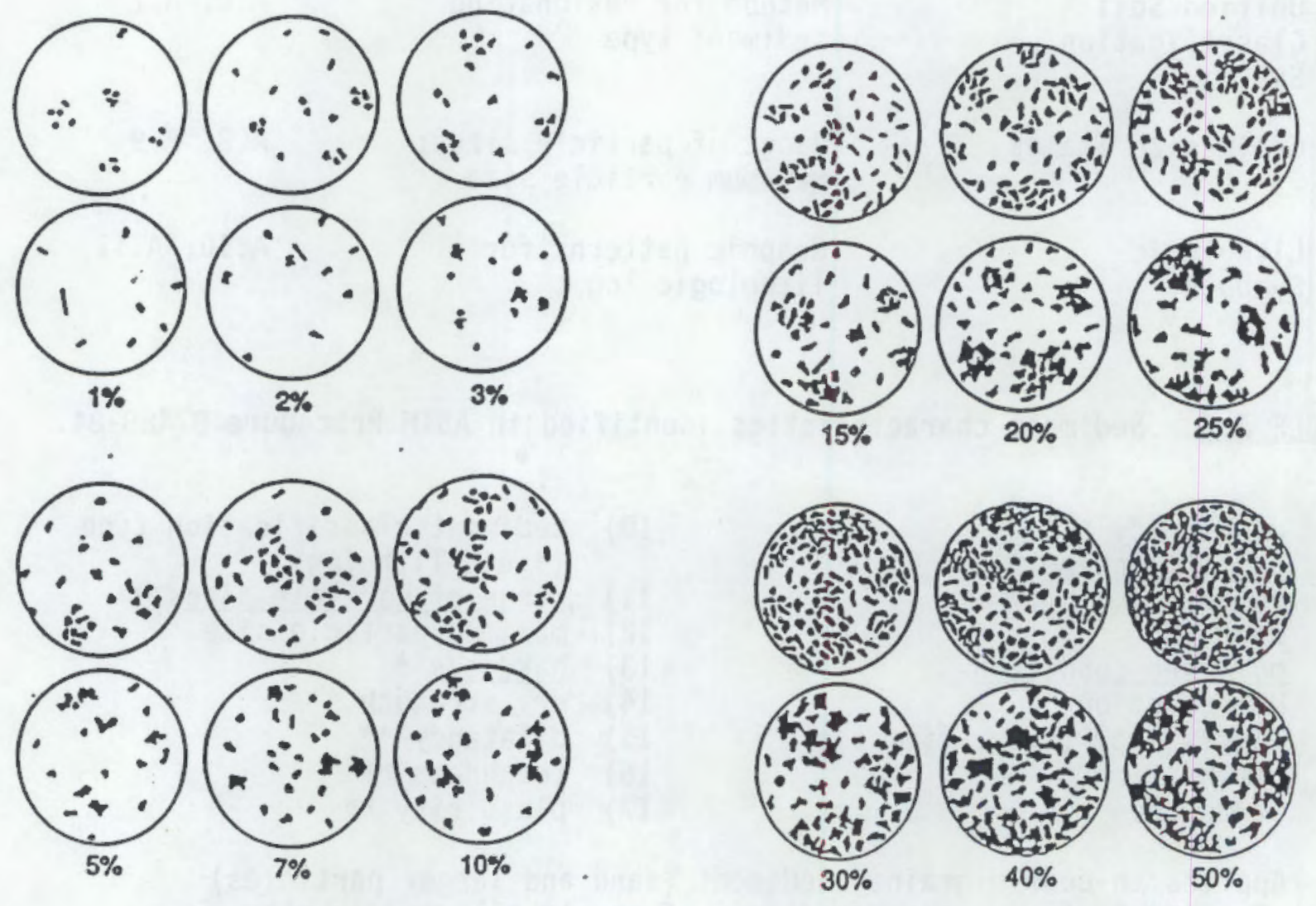

FIGURE A.2. Comparison Chart Used to Estimate the Percentages of Constituents (from AGI 1982) 
A

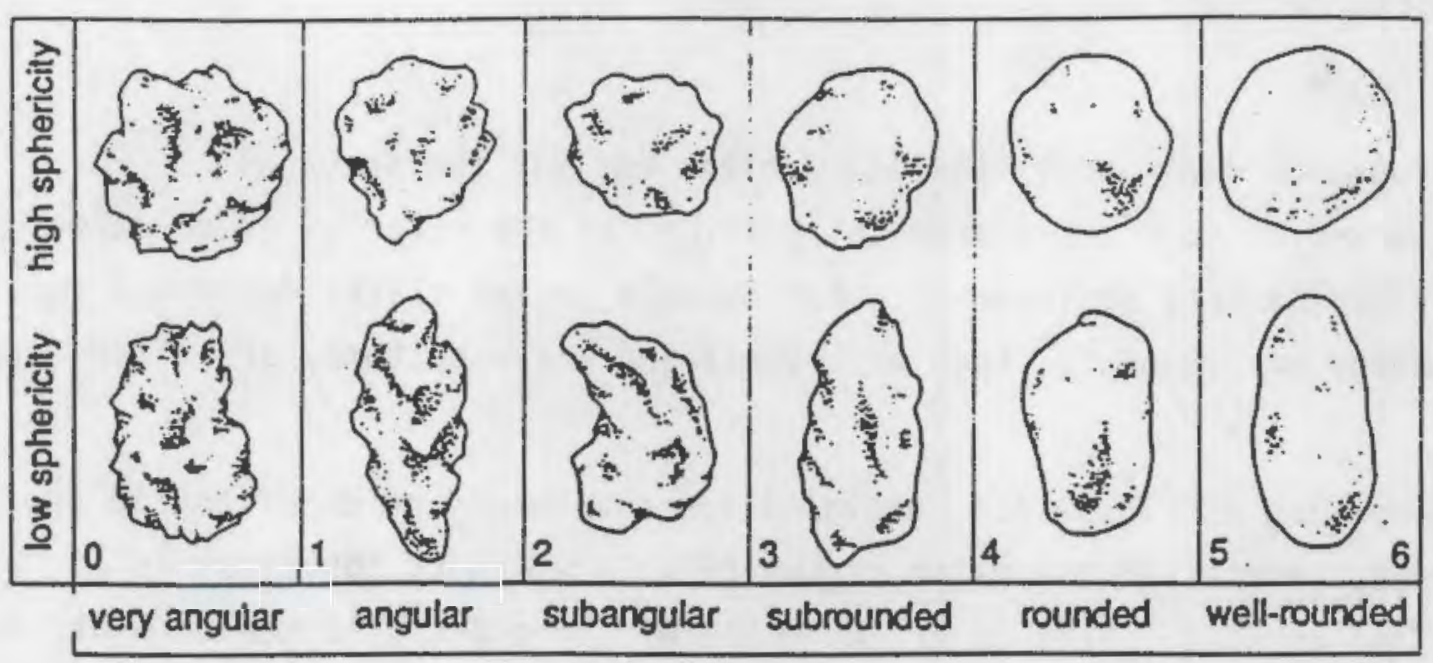

B

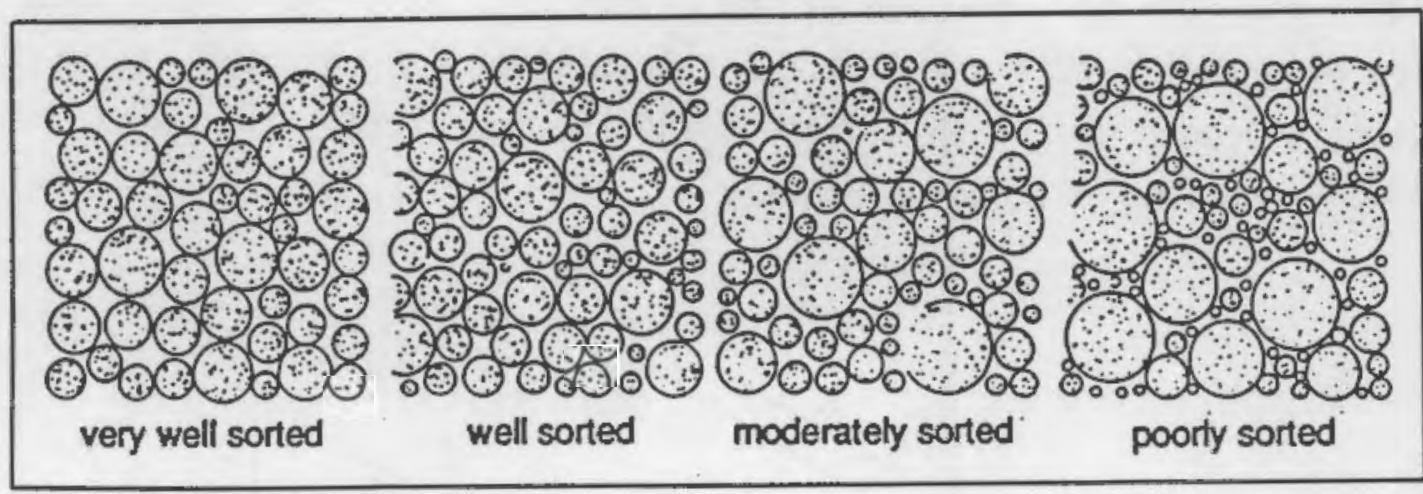

Poorty

Well

Graded

Graded

FIGURE A.3. Charts Used to Visually Estimate (A) Roundness/Sphericity and (B) Sorting/Grading 


\section{A.2.1 Angularity}

The angularity of sedimentary particles is a reflection of the sedimentary environment and the amount of time that has elapsed before deposition and burial. A chart showing how to classify the angularity of sedimentary particles is presented in Figure A.3A. A range of angularity may be stated, such as: subrounded to rounded.

\section{A.2.2 Shape}

Shapes of sedimentary particles often reflect the internal characteristics (e.g., preferential parting) of the material or sometimes the type of sedimentary environment. For example gravel clasts deposited in high-energy environments, such as beaches and river bottoms, are often worn flat.

According to Figure A.4, gravel-sized clasts may be described in one of four ways. First, if the ratio of the clast's width to thickness is $>3$, it is classified as flat. Second, if the ratio of the clast's length to width is $>3$, the clast is elongate. Third, if both criteria apply the clast is both flat and elongate. And last, if none of the criteria apply, then shape is not mentioned. Indicate the fraction of the clasts that have the shape, such as: one-third of gravel clasts are flat. Particle shape did not apply to most of the sediments logged during this project and the few pebbles that were observed were neither flat nor elongate.

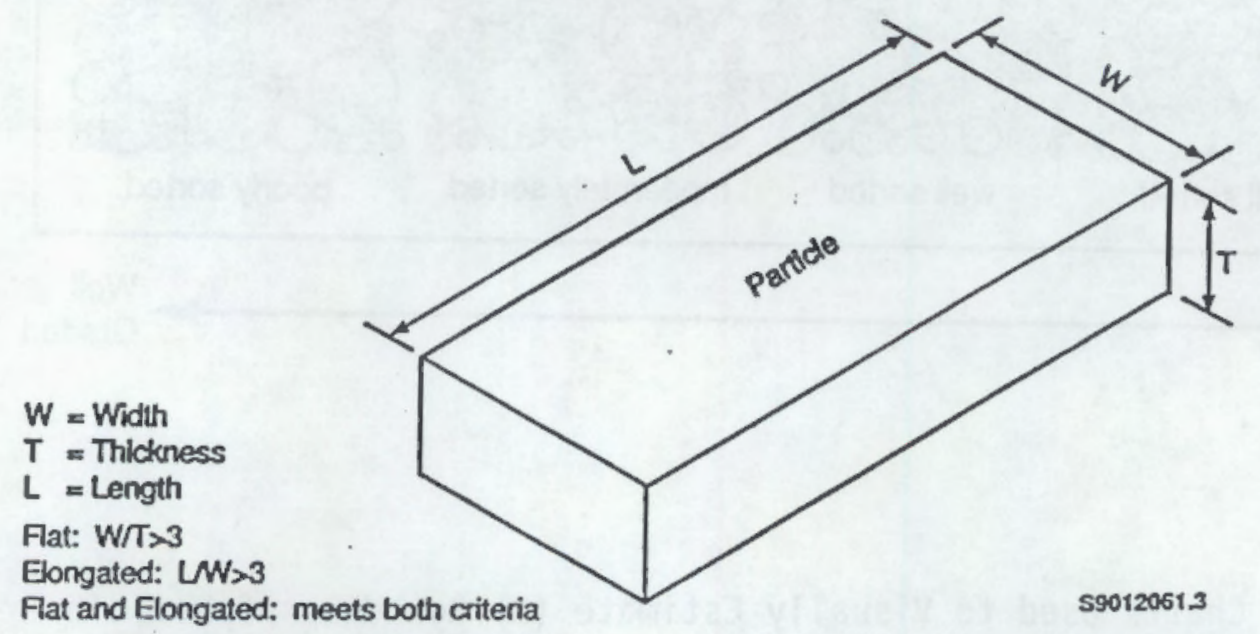

FIGURE A.4. Criteria Used to Describe Particle Shape of Pebbles and Large Gravels (From ASTM 1984) 


\section{A.2.3 Color}

Color may be useful in identifying materials of similar geologic origin. For example, color was often a useful criteria for differentiating Younger Bay Mud from 01der Bay Mud. Sediment color was determined by comparing the wet sediment with standard sediment colors given in Munsell (1975). The advantage to using the Munsell soil color system is that it provides a consistent, standardized method for describing color and subjectivity is minimized.

The Munsell color notation consists of three simple variables that combine to describe all colors known in the Munsell soil color system. The three variables are: hue, value, and chroma (Figure A.5). The hue notation indicates the relation of the sediment color with respect to red, yellow, green, blue and purple; the value notation indicates its lightness, and the chroma notation indicates its strength (i.e., intensity).

Color can be described either by the Munsell notation (e.g., 5YR 5/3; hue $=5 Y R$, value $=5$, chroma $=3$ ) or by its equivalent color name (e.g., reddish brown). Both the color name and Munsell notation were recorded on core logs (see Appendix B). Only rarely was there not a reasonable match between the true color of the core sediment and one of the colors on a Munsell color chart.

\section{A.2.4 $\underline{\text { Odor }}$}

Odors may indicate the presence of contaminants or be the result of the geochemical environment. Odors most frequently noted were that of petroleum hydrocarbons and the smell of rotten eggs (an indication of the presence of hydrogen sulfide). Both of these odors were restricted to the Younger Bay Mud unit. Petroleum odors may be the result of contamination of the sediments by shipping spills or industrial waste, or perhaps is derived from the abundant decaying organic matter present in these sediments. Hydrogen sulfide is a common natural by-product in chemically reducing environments such as the Richmond Harbor estuary. 

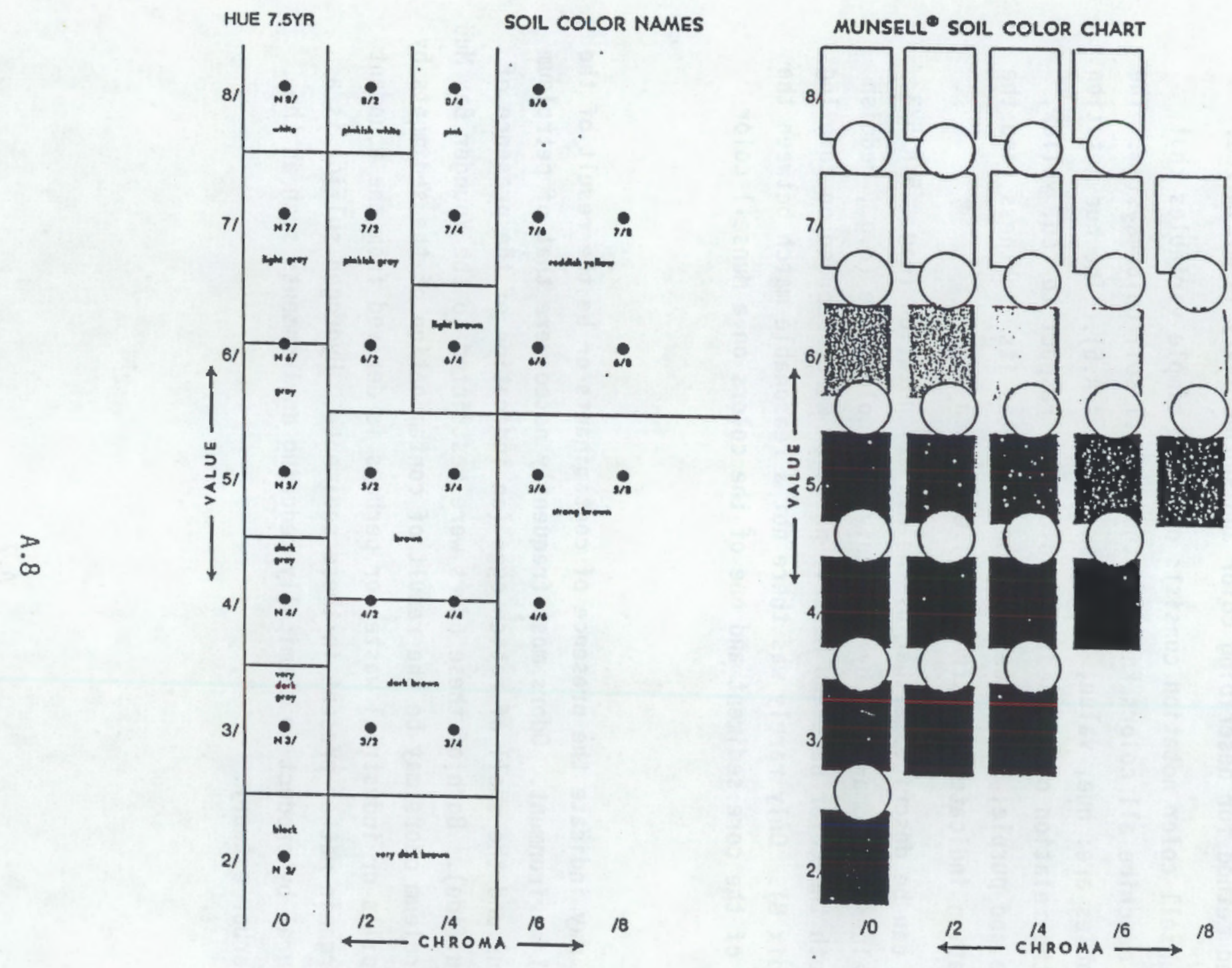

7.5YA

FIGURE A.5. Example of a Page from the Munsell Soil Color for Hue 7.5YR 


\section{A.2.5 Moisture Condition}

Moisture condition is described as either dry, moist, or wet according to the following criteria:

DRY Absence of moisture, dry to the touch

MOIST Damp but no visible water

WET Visible free water, usually soil is below water table (i.e., saturated)

All the sediments logged for this project were taken from below sea level and did not lose any significant moisture between the time they were drilled and logged. Therefore, they are all classified as wet.

\section{A.2.6 HCl Reaction}

The reaction (i.e., effervescence) of sedimentary material, as a result of adding dilute hydrochloric acid, is an indication of the presence of calcium carbonate. Calcium carbonate in sediments may be derived from a variety of sources including: 1) physical disintegration of preexisting carbonate rocks (e.g., limestone, marble), 2) biogenic precipitation (e.g., shell, bone), and 3) soil development. In the last example, calcium carbonate concentrations, often referred to as caliche or calcrete, may accumulate over time near the land's surface in arid climates. Where calcium carbonate concentrations occur in combination with other evidence for soil development, such as root traces and oxidation, then a pedogenic (soil forming) origin is favored. Criteria for describing the reaction with $10 \mathrm{~N} \mathrm{HCl}$ are as follows:

NONE No visible reaction

WEAK Some reaction, with bubbles forming slowly

STRONG Violent reaction, with bubbles forming immediately

A solution of $10 \mathrm{~N} \mathrm{HCl}$ is obtained by slowly adding one part of concentrated hydrochloric acid to three parts of distilled water. (To avoid a violent exothermic reaction never add water to acid). 


\section{A.2.7 Consistency}

Consistency is a measure of the firmness or consolidation of sedimentary material. In general, there is a direct relationship between consistency and age of the deposit (i.e., older deposits are usually more firm because of compaction and/or cementation). Consistency is most applicable to fine-grained sediments and least applicable on sediments that contain significant amounts of gravel. The criteria used to determine consistency are as follows:

VERY SOFT Penetrometer penetrates soil greater than $4 \mathrm{~cm}$

SOFT Penetrometer penetrates soil 2.0 to $4.0 \mathrm{~cm}$

FIRM Penetrometer penetrates soil 0.25 to $2.0 \mathrm{~cm}$

HARD Penetrometer penetrates soil less than $0.25 \mathrm{~cm}$

The penetrometer used for sediment core descriptions consists of a 6-in . nail spike attached to a clay brick for a total mass of $2.0 \mathrm{~kg}$; the nail spike is marked in centimeter increments to quantify the amount of soil penetration.

\section{A.2.8 Cementation}

Often sedimentary particles are held together with a binding cement. Three common natural cements are calcium carbonate ( 1 ime), silica, and iron-oxide compounds. Particles cemented with calcium carbonate effervesce in the presence of hydrochloric acid (see Section A.2.6 above). Sediments cemented with iron oxide are usually some shade of red, yellow, or brown. Usually there is a relationship between consistency (Section A.2.7) and cementation, in that strongly cemented deposits are also hard to very hard. Criteria used to describe the degree of cementation are:

WEAK Crumbles or breaks with handling or light finger pressure

MODERATE Crumbles or breaks with considerable finger pressure

STRONG Will not crumble or break with finger pressure

\section{A.2.9 Structure}

Structures are features that originate within the layers of sediment or at the sediment/water interface in response to various physical, biologic 
and/or chemical processes. Structures may be classified into two categories: primary and secondary. Primary structures form as the sediment is being deposited (e.g., lamination, stratification). Secondary structures form after deposition, often as a result of compaction or other stresses (e.g., fissured, slickensided), biologic activity (e.g., root traces, mottling), and soil development (e.g., homogeneous, blocky, mottled). The following are some common structures observed in sedimentary deposits. PRIMARY STRUCTURES

STRATIFIED Alternating layers of varying material or color with layers at least $6 \mathrm{~mm}$ thick

LAMINATED Alternating layers of varying material or color with the layers less than $6 \mathrm{~mm}$ thick

LENSED Inclusion of small pockets of different sediment type, such as small lenses of sand scattered through a mass of clay. (This type of structure may also be secondary).

SECONDARY STRUCTURES

FISSURED Breaks along definite planes of fracture with little resistance to fracturing

SLICKENSIDED Fracture planes appear polished or glossy, sometimes striated

BLOCKY Cohesive soil that can be broken down into small angular lumps which resist further breakdown

MOTTLED Variation in color of sediments as represented by localized spots or blotches of color or shades of color

HOMOGENEOUS Same color and appearance throughout

\section{A.2.10 Sediment Classification Type}

The classification method used in this study is the Unified Soil Classification System, which consists of a two-letter designation for most soils (i.e., unconsolidated sediments). A simplified version of the Unified Soil Classification System is presented in Figure A.6, while a more-detailed breakdown is presented in Figure A.7. 


\begin{tabular}{|c|c|c|c|c|}
\hline \multicolumn{3}{|c|}{ Major Divisions } & $\mid \begin{array}{c}\text { Group } \\
\text { Symbols }\end{array}$ & Description \\
\hline \multirow{8}{*}{ 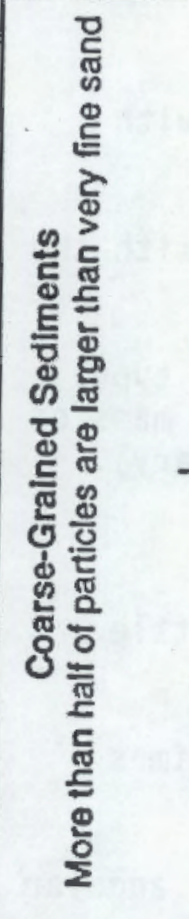 } & \multirow{4}{*}{$250 \%$ Gravel } & \multirow{2}{*}{$\begin{array}{c}\text { Clean } \\
\text { Gravels }\end{array}$} & GW & $\begin{array}{l}\text { Well-graded (i.e., poorly sorted) gravels. } \\
\text { gravel-sand mixtures, little or no fines }\end{array}$ \\
\hline & & & GP & $\begin{array}{l}\text { Poorly graded (i.e., well sorted) gravels, } \\
\text { gravel-sand mixtures, little or no fines }\end{array}$ \\
\hline & & \multirow{2}{*}{$\begin{array}{c}\text { Gravels } \\
\text { with } \\
\text { Fines }\end{array}$} & GM & Silty gravels, gravel-sand-silt mixtures \\
\hline & & & GC & Clayey gravels, gravel-sand-clay mixtures \\
\hline & \multirow{4}{*}{$250 \%$ Gravel } & \multirow{2}{*}{$\begin{array}{l}\text { Clean } \\
\text { Sands }\end{array}$} & SW & Well-graded sands, gravelly sands, little or no fines \\
\hline & & & SP & Poorly graded sands, gravelly sands, little or no fines \\
\hline & & \multirow{2}{*}{$\begin{array}{c}\text { Sands } \\
\text { with } \\
\text { Fines }\end{array}$} & SM & Silty sands, sand-sitt mixtures \\
\hline & & & SC & Clayey sands, sand-clay mixtures \\
\hline \multirow{4}{*}{ 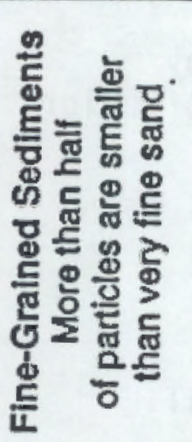 } & \multirow{4}{*}{$\begin{array}{l}\text { Silts and } \\
\text { Clays }\end{array}$} & \multirow{2}{*}{$\begin{array}{l}\text { Low } \\
\text { Liquid } \\
\text { Limit }\end{array}$} & ML & $\begin{array}{l}\text { Silts and very fine sands, silty or clayey fine sands, } \\
\text { or clayey silts, with slight plasticity }\end{array}$ \\
\hline & & & CL & $\begin{array}{l}\text { Clays of low to medium plasticity, gravelly clays, } \\
\text { sandy clays, silty clays, lean clays }\end{array}$ \\
\hline & & \multirow{2}{*}{$\begin{array}{l}\text { High } \\
\text { Liquid } \\
\text { Limit }\end{array}$} & MH & Silts or fine sandy silts with moderate plasticity \\
\hline & & & $\mathrm{CH}$ & Clays of high plasticity, fat clays \\
\hline
\end{tabular}

S9012061.1

FIGURE A.6. Abbreviated Form of the Unified Soil Classification System (From AGI 1982) 

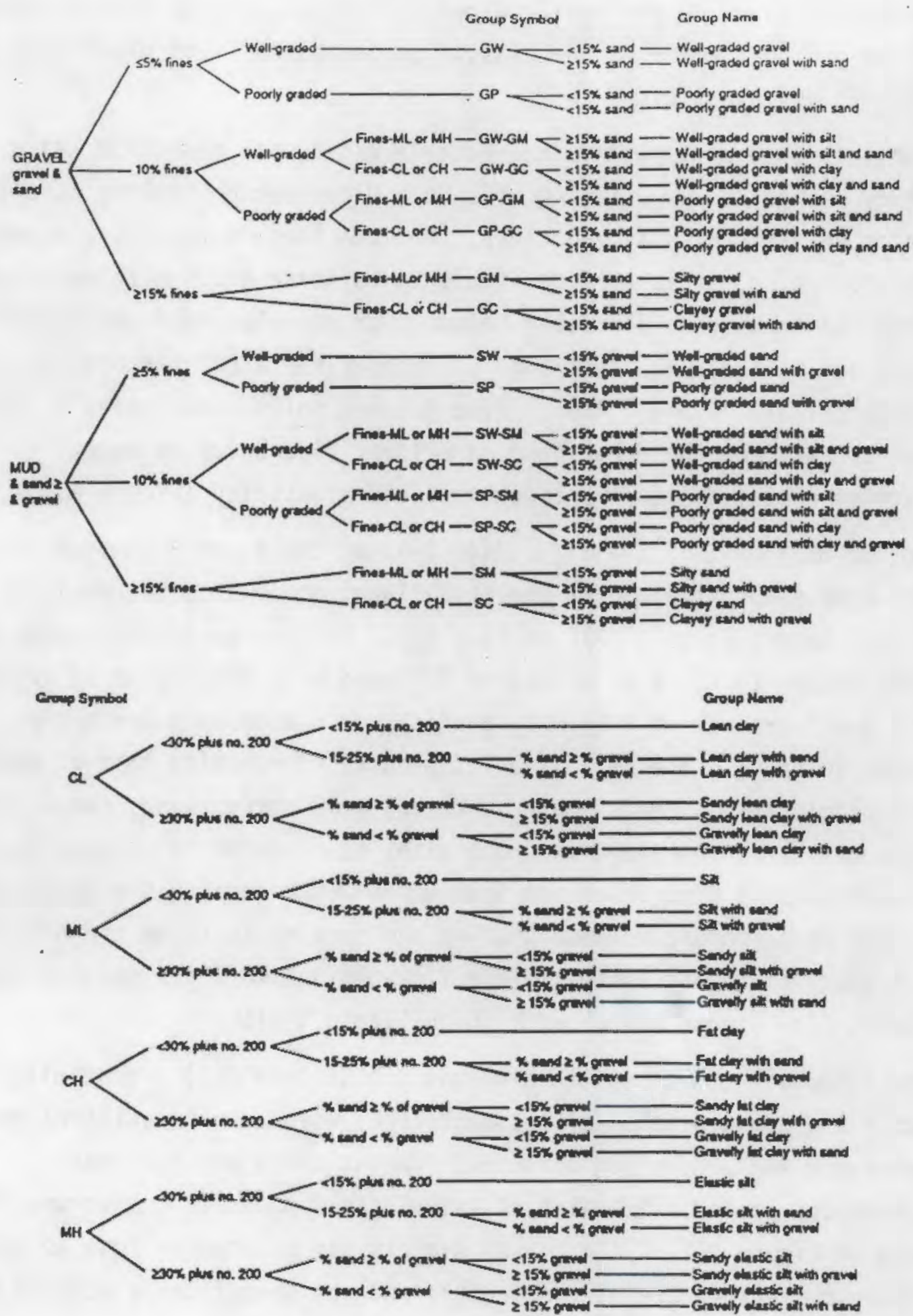

FIGURE A.7. Detailed Flow Chart For the Classification of Coarse- and FineGrained Soils Using the Unified Soil Classification System 
According to the Unified Soil Classification System, coarse-grained sediments are classified based on grain-size distribution and grading (i.e., sorting), while fine-grained sediments are classified on the basis of grain size and liquid limit vs. plasticity.

Particle-size distribution may be determined with precision using laboratory methods (e.g., sieving of sand and coarser particles; pipette or hydrometer analysis of silt and clay). Because these methods are expensive and time-consuming, it is more desirable to estimate grain size using rapid visual-manual techniques described below. For example, sand and coarser particles are most easily identified via comparison with standard charts of grain size (Figures A.8 and A.9). Fine-grained soils, consisting of mostly silt and/or clay, on the other hand, are identified based on manual tests of their dry strength, dilatancy, toughness, and plasticity (Figure A.10).

In the Unified Soil Classification System, the first letter of the sediment-type symbol represents the predominant grain-size interval, be it gravel (G), sand (S), silt (M), or clay (C). For coarse-grained sediments, the first letter (i.e., G or S) may be followed by a descriptor of grading, either W (well graded) or $P$ (poorly graded), or a secondary grain-size descriptor $(M$ or $C)$. The definition of grading is opposite that of sorting, a common geologic term. For example, a clean, well-sorted sand, consisting of particles over a narrow range in grain size, is referred to as poorly graded in the Unified Soil Classification System and would receive the designation "SP". The relationship between grading and sorting is shown graphically in Figure A.3B. The second letter in the fine-grained soil designation consists of either L (low liquid limit) or $H$ (high liquid limit).

The lithology column on the geologic log (Figure A.1) essentially represents a graphic display of sediment type, which can be utilized for quick easy reference and comparison between different cores and thus make interpretations easier. Examples of lithologic symbols in common use are presented in Figure A.11. Additional symbols may be used as long as they are graphically representative of the feature and are specifically defined and identified in a key that accompanies lithologic logs. 


\begin{tabular}{|c|c|c|c|c|c|c|c|}
\hline \multicolumn{3}{|c|}{ Grade Limits } & \multirow[b]{2}{*}{ inches } & \multirow{2}{*}{$\begin{array}{c}\text { U.S. } \\
\text { Standard } \\
\text { Sieve Series }\end{array}$} & \multirow{2}{*}{\multicolumn{3}{|c|}{ Grade Name }} \\
\hline phi & $\mathrm{mm}$ & $\mathrm{mm}$ & & & & & \\
\hline-12 & 4096 - & $-\quad-$ & 161.3 & $-\quad-$ & very large & & \multirow{11}{*}{ GRAVEL } \\
\hline-11 & $2048-$ & $-\quad-$ & 80.6 & $-\quad-\quad-$ & $\overline{\text { large }}-\overline{-}$ & & \\
\hline-10 & $1024-$ & $-\quad-$ & 40.3 & $-\quad--$ & $\overline{m e d i u m}^{-}-$ & Boulders & \\
\hline-9 & $512-$ & $-\quad-$ & 20.2 & $-\quad-$ & smail & & \\
\hline-8 & $256-$ & $-\quad-$ & 10.1 & --- & large & & \\
\hline-7 & $128-$ & $-\quad-$ & 5.0 & $-\quad-$ & $-\overline{\text { small }}-$ & Cobbles & \\
\hline-6 & $64-$ & - & 2.52 & & very coarse & \multirow{5}{*}{ Pebbles } & \\
\hline-5 & $32-$ & $-\quad-$ & 1.26 & $31.5 \mathrm{~mm}$ & $-\overline{c o a r s e}-$ & & \\
\hline-4 & $16-$ & $-\quad-$ & 0.63 & $16 \mathrm{~mm}-$ & modium & & \\
\hline-3 & 8- & $-\quad-$ & 0.32 & $8 \mathrm{~mm}-$ & $\overline{r i n e}^{-}-$ & & \\
\hline-2 & $4-$ & $-\quad-$ & 0.16 & No. 5 - & $\bar{v}^{-}-{ }^{-}-$ & & \\
\hline \multicolumn{3}{|l|}{$-1-$} & \multirow{2}{*}{$\begin{array}{l}0.08 \\
0.04\end{array}$} & No. $10-$ & \multirow{2}{*}{$\begin{array}{l}\text { very coarse } \\
-\quad- \\
\text { coarse }\end{array}$} & \multirow{5}{*}{ Sand } & \multirow{5}{*}{ SAND } \\
\hline 0 & $1-$ & $-\quad-$ & & No. 18 - & & & \\
\hline+1 & $1 / 2-$ & $0.500-$ & - & No. 35 - & $\overline{m e d i u m}^{-}$ & & \\
\hline+2 & $1 / 4$ & $0.250-$ & -- & №. 60 - & $\overline{f l i n e}^{-}-$ & & \\
\hline+3 & $1 / 8-$ & $0.125-$ & $-\quad-$ & No. 120 & ${ }^{-}{ }^{-}{ }^{-}-$ & & \\
\hline$+4-$ & $1 / 1 / 6$ & 0.062 & & $-N o .230-$ & coarse & \multirow{4}{*}{ Silt } & \multirow{8}{*}{ MUD } \\
\hline+5 & $1 / 32-$ & $0.031-$ & -- & $-\cdot-$ & medium & & \\
\hline+6 & $1 / 64-$ & $0.016-$ & $-\quad-$ & $-\quad-$ & fine $^{-}-$ & & \\
\hline+7 & $1 / 128-$ & $0.008-$ & -- & --- & - very fine & & \\
\hline+8 & $1 / 256-$ & $0.004-$ & -- & $-\quad-$ & coarse & \multirow{4}{*}{ Clay Size } & \\
\hline+9 & $1 / 512-$ & $0.002-$ & -- & --- & $\overline{\text { medium }}^{-}-$ & & \\
\hline+10 & $1 / 1024$ & $0.001-$ & -- & --- & $\overline{\text { fine }}^{-}-$ & & \\
\hline+11 & $1 / 2048$ & $0.0005-$ & $-\quad-$ & $-\cdot-$ & - very fine & & \\
\hline+12 & $-1 / 4096$ & -0.00025 & & & & & \\
\hline
\end{tabular}

FIGURE A.8. Grain-size Scale Used to Determine Sedimentary Particle Size 


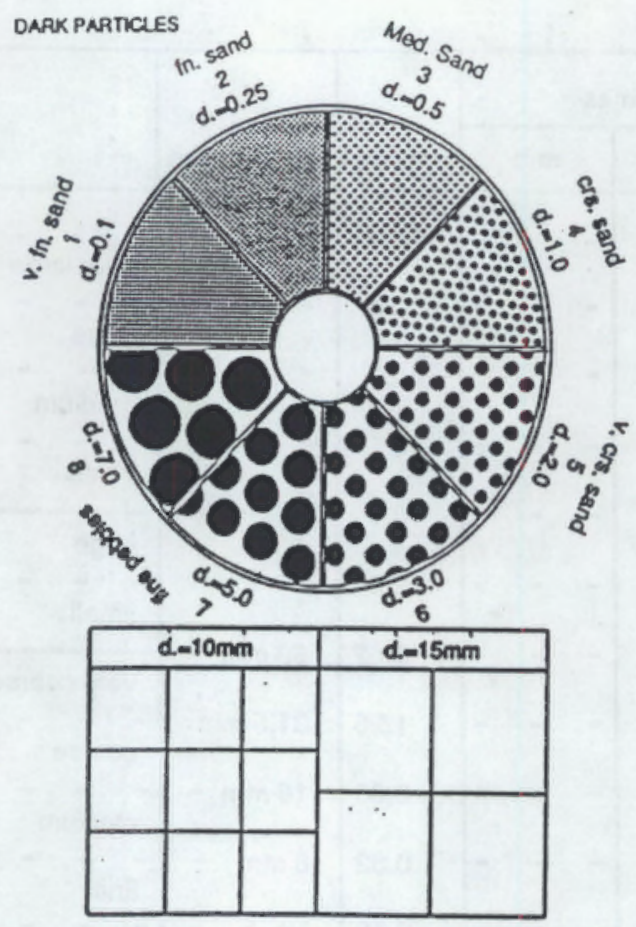

FIGURE A.9. Comparison Chart Used to Distinguish Among Sand to Pebble-size Particles (From AGI 1982). For larger particles, refer to Figure A.8; for smaller particles, refer to Sections A.2.13 and A.2.16 in this Appendix

\begin{tabular}{|c|c|c|c|c|}
\hline \multirow{2}{*}{$\begin{array}{l}\text { Sediment } \\
\text { Type }\end{array}$} & Dry Strength & Dilatancy & Toughness & Plasticity \\
\hline & 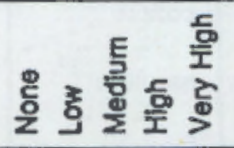 & 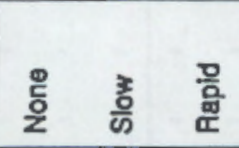 & 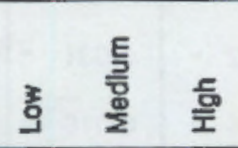 & 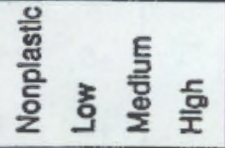 \\
\hline $\begin{array}{l}\text { ML } \\
\text { (Siti) }\end{array}$ & & & & \\
\hline $\begin{array}{c}\text { MH } \\
\text { (Elastle Silt) }\end{array}$ & & & & \\
\hline$\underset{\text { (Lean Clay) }}{\mathrm{CL}}$ & & & & \\
\hline$\underset{\text { (Fat Clay) }}{\mathrm{CH}}$ & & & & \\
\hline
\end{tabular}

FIGURE A.10. Identification of Inorganic Fine-grained Soils From Manual Tests 


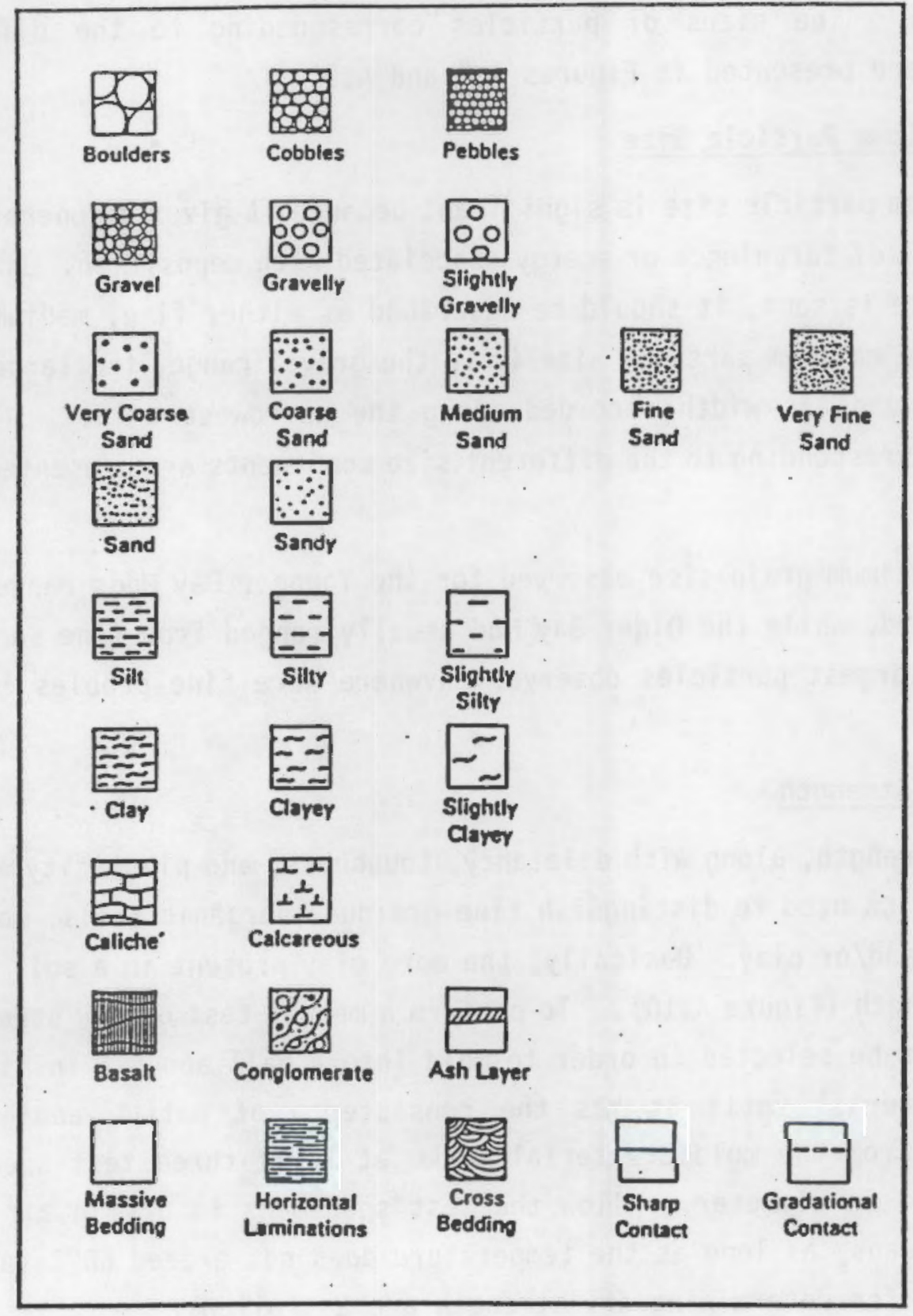

FIGURE A.11. Lithologic Symbols Used on Core Log Forms 


\section{A.2.11 Range of Particle Sizes}

For gravel- and sand-sized particles, the range of particle sizes within each component is defined. For example, $20 \%$ fine to coarse gravel, $40 \%$ fine to coarse sand. The sizes of particles corresponding to the different size components are presented in Figures A.8 and A.9.

\section{A.2.12 Maximum Particle Size}

Maximum particle size is significant because it gives a general indication of the amount of turbulence or energy associated with deposition. If the maximum particle size is sand, it should be described as either fine, medium, or coarse sand. If the maximum particle size is in the gravel range, the largest particle is measured and its width recorded along the narrowest axis. The sizes of particles corresponding to the different size components are presented in Figures A.8 and A.9.

The maximum grain size observed for the Younger Bay Muds ranged from silt to medium sand, while the 0lder Bay Mud usually ranged from fine sand to coarse sand. The largest particles observed anywhere were fine pebbles in the 01der Bay Mud unit.

\section{A.2.13 Dry Strength}

Dry strength, along with dilatancy, toughness, and plasticity are physical characteristics used to distinguish fine-grained inorganic soils, consisting of mostly silt and/or clay. Basically, the more clay present in a soil the greater its dry strength (Figure A.10). To perform a manual test of dry strength enough material must be selected in order to mold into a ball about 1 in. in diameter. Mold the material until it has the consistency of putty, adding water if necessary. From the molded material, make at least three test specimens each about $1 / 2$ in. in diameter. Allow the test specimens to dry in air, sun or by artificial means, as long as the temperature does not exceed $60^{\circ} \mathrm{C}$ (ASTM, 1984). The criteria for determining dry strength are as follows:

NONE The dry specimen crumbles into powder with mere pressure of handling

LOW The dry specimen crumbles into powder with light finger pressure 
MEDIUM The dry specimen breaks into pieces or crumbles with considerable finger pressure

HIGH The dry specimen cannot be broken with finger pressure. Specimen will break into pieces between thumb and a hard surface

VERY HIGH The dry specimen cannot be broken between the thumb and a hard surface

Dry strength was determined for John $F$. Baldwin cores by sampling selected intervals and allowing the samples to air dry overnight. Dry strength was determined the next day and noted in the comments column of the geologic log.

\section{A.2.14 Dilatancy}

Dilatancy is a measure of how easily a soil gives up water when shaken. For example, some clays have the ability to absorb and retain large amounts of water into their crystal lattice. "Fat" clays tend to retain their water even under stress whereas "lean" clays and silt tend to release water when shaken.

To test for dilatancy select enough material to mold into a ball about $1 / 2$ in. in diameter. Mold the material, adding water if necessary, until it has a soft, but not sticky consistency. Smooth the soil ball in the palm of the hand with a blade of a knife or small spatula. Shake horizontally, striking the side of the hand vigorously against the other several times. Note the reaction of water appearing on the surface of the soil. Squeeze the sample by closing the hand or pinching the soil between the fingers, and note the reaction. Specimens with high dilatancy will quickly yield water when shaken and absorb water when squeezed. The criteria for describing dilatancy are:

NONE No visible change in the specimen

SLOW Water appears slowly on the surface of the specimen during shaking and does not disappear or disappears slowly upon squeezing

RAPID Water appears quickly on the surface of the specimen during shaking and disappears quickly upon squeezing 
The range of dilatancy for the different fine-grained sediment types is shown in Figure A.10. From this figure it is apparent that dilatancy decreases with decreasing grain size.

\section{A.2.15 Toughness}

After completion of the dilatancy test, shape the same specimen into an elongated pat and roll by hand on a smooth surface or between the palms into a thread about $1 / 8 \mathrm{in.} \mathrm{(} 3 \mathrm{~mm}$ ) in diameter. (If the sample is too wet to roll easily, it should be spread into a thin layer and allowed to lose some water by evaporation.) Fold the sample threads and reroll repeatedly until the thread crumbles at a diameter of about $1 / 8 \mathrm{in}$. The thread will crumble at a diameter of $1 / 8 \mathrm{in}$. When the soil is near the plastic limit. Note the pressure required to roll the thread near the plastic limit. Also, note the strength of the thread. After the thread crumbles, the pieces should be lumped together and kneaded until the lump crumbles. Note the toughness of the material during kneading and classify into one of the following categories.

Low Only slight pressure is required to roll the thread near the plastic limit. The thread and lump are weak and soft

MEDIUM Medium pressure is required to roll the thread to near the plastic limit. The thread and lump have medium stiffness.

HIGH Considerable pressure is required to roll the thread to near the plastic limit. The thread and the lump have very high stiffness.

The range of toughness for the different fine-grained sediment types is shown in Figure A.10. From this figure it is apparent that toughness increases with a decrease in particle size.

\section{A.2.16 Plasticity}

On the basis of observations made during the toughness test, describe the plasticity of the material according to the following criteria:

NONPLASTIC

A $1 / 8$ in. thread cannot be rolled at any water content

LOW The thread can barely be rolled and the lump cannot be formed when drier than the plastic limit. 
MEDIUM

The thread is easy to roll and not much time is required to reach the plastic limit. The thread cannot be rerolled after reaching the plastic limit. The lump crumbles when drier than the plastic limit.

$\mathrm{HIGH} \quad$ It takes considerable time rolling and kneading to reach the plastic limit. The thread can be rerolled several times after reaching the plastic limit. The lump can be formed without crumbiing when drier than the plastic limit.

The range of plasticity for the different fine-grained sediment types is shown in Figure A.10. From this figure it is apparent that an increase in plasticity accompanies a decrease in grain size. 


\section{A.3 REFERENCES}

American Geological Institute. 1982. AGI Data Sheets for Geology in the Field, Laboratory, and Office. American Geological Institute, Falls Church, Virginia.

American Society for Testing and Materials. 1984. Stnadard Practice for Description and Identification of Soils (Visual-manual procedure): Procedure D 2488-84, American Society for testing and Materials, Philadelphia, Pennsylvania, p. 293-302.

Munse11. 1975. Munsell Soil Color Charts. Macbeth, a division of Kollmorgen Co., Baltimore, Maryland, 7 charts. 


\section{APPENDIX B}

JOHN F. BALDWIN SHIP CHANNEL PHASE II GEOLOGICAL CORE LOGS OF WEST RICHMOND CORES 


\section{John F. Baldwin}

Key to Core Data Logs (After ASTM Procedure D2488-84)

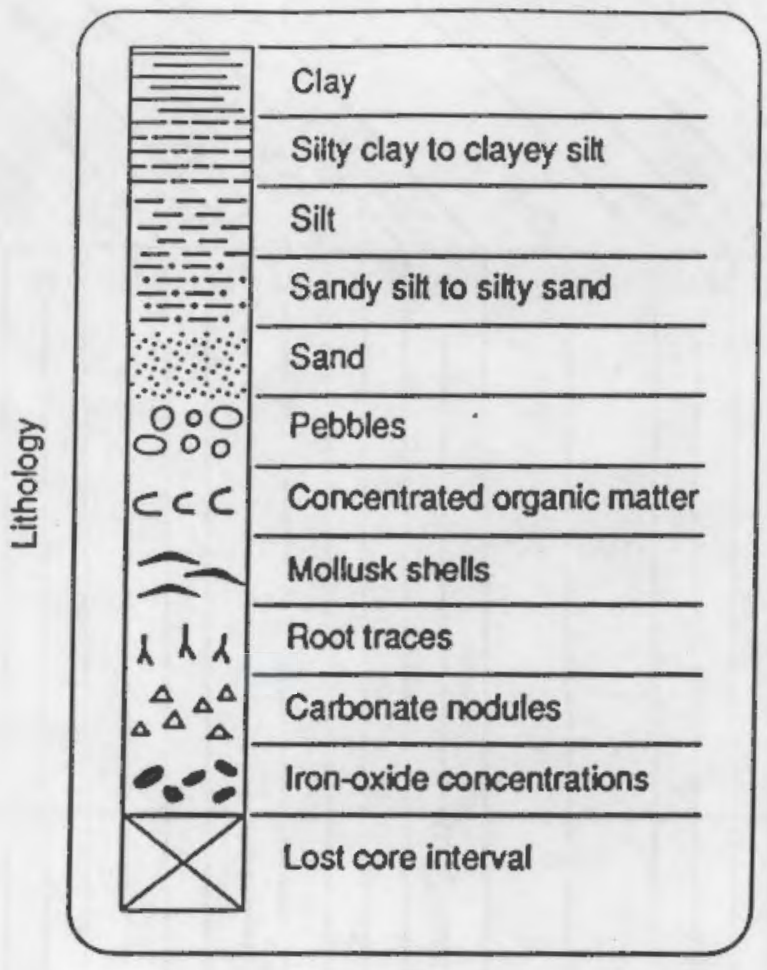

Type:

See soil group classification in ASTM D2488-84

\section{Color (wet):}

Selected from Munsell Soil

Color Chart

$$
\begin{aligned}
& \text { Consistency: } \\
& <0.25 \mathrm{~cm}=\text { hard } \\
& 0.25-2.0 \mathrm{~cm}=\text { firm } \\
& 2.0=4.0 \mathrm{~cm}=\text { soft } \\
& >4.0 \mathrm{~cm}=\text { very soft } \\
& \text { Cementation: } \\
& N=\text { not cemented } \\
& W=\text { weakly cemented } \\
& M=\text { moderately cemented } \\
& S=\text { strongly cemented }
\end{aligned}
$$

Dilatancy:

$\mathrm{N}=$ none

$\mathrm{S}=$ slow

$R=$ rapid

Toughness:

$\mathrm{L}=$ low

$M=$ medium

$\mathrm{H}=$ high

Plasticity:

$N=$ none

$\mathrm{L}=$ low

$M=$ medium

$H=$ high

Structure:

$S=$ stratified

$\mathrm{L}=$ laminated

$F=$ fissured

$\mathrm{SI}=$ slickensided

Ln $=$ lensed

$\mathrm{BI}=$ blocky

$M=$ mottled

$H=$ homogeneous

HCl Reaction:

$$
\begin{aligned}
& N=\text { none } \\
& W=\text { weak } \\
& S=\text { strong }
\end{aligned}
$$

Maximum Particle Size:

VCP $=$ very coarse pebble

CS = coarse sand

MS = medium sand

FS = fine sand

Odor: .

$\mathrm{N}=$ none

$\mathrm{S}=$ sulfide

$\mathrm{P}=$ petroleum

$\mathrm{O}=$ other 


\section{Core Data Log}

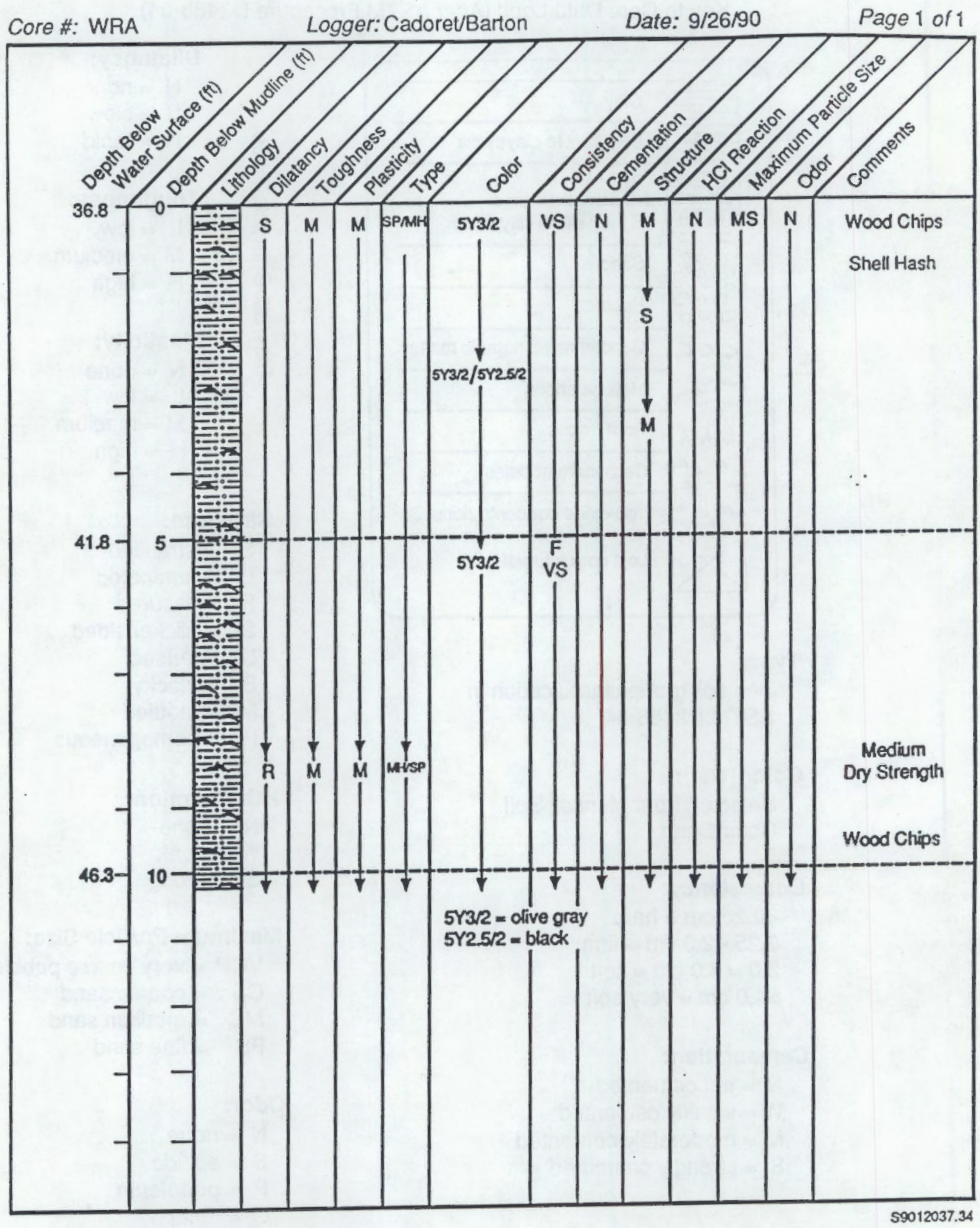

B.2 
Core Data Log

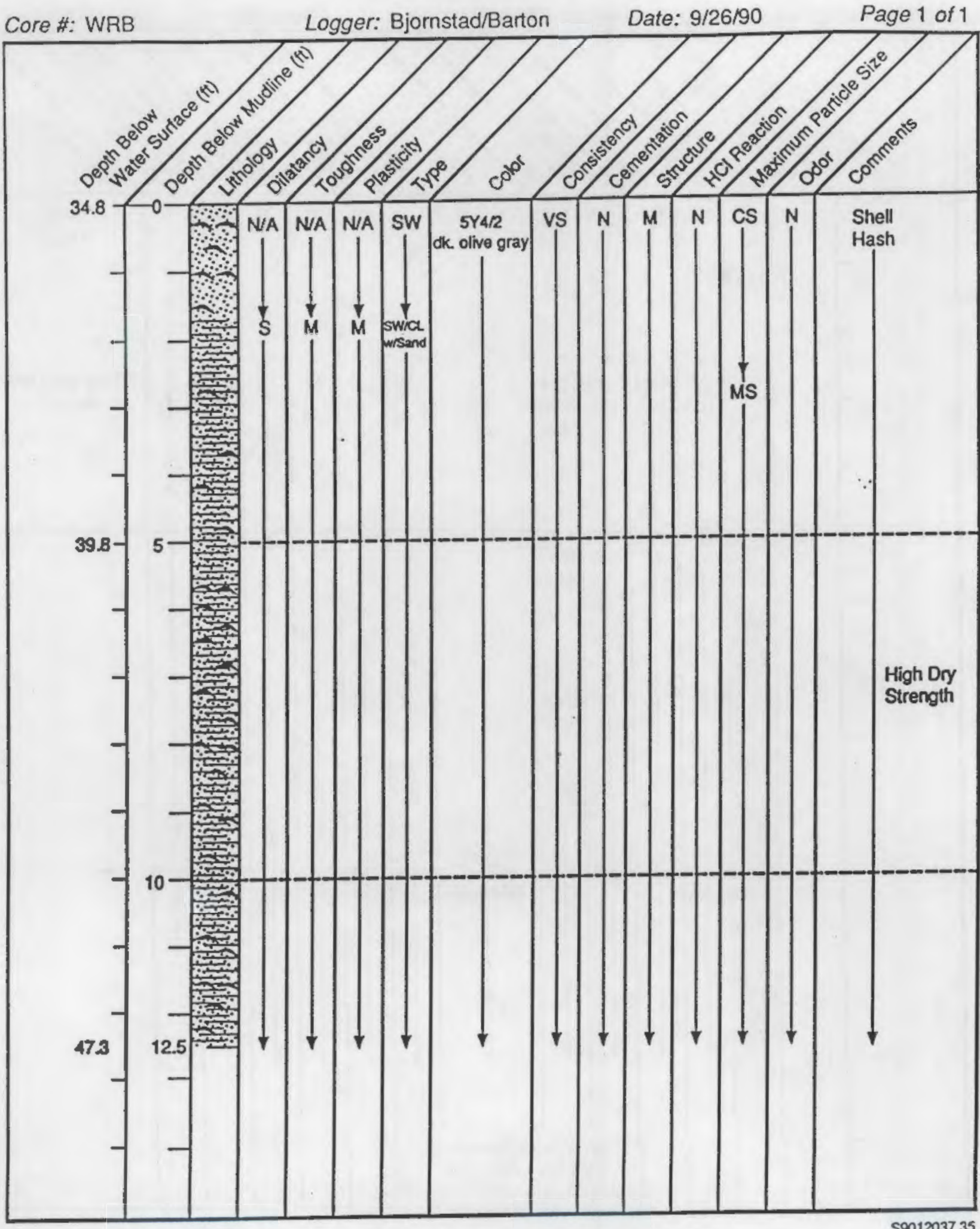

B. 3 


\section{Core Data Log}

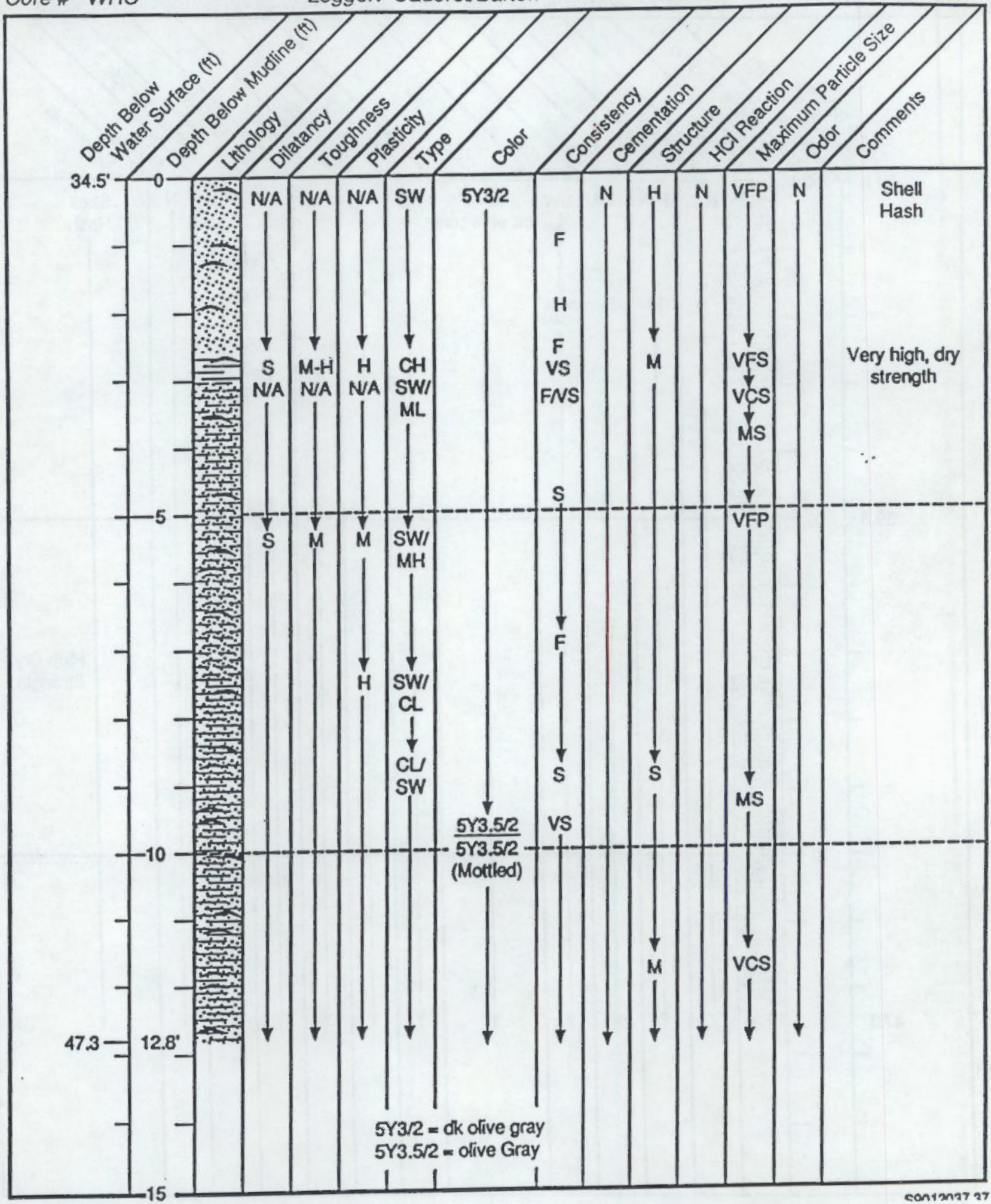

B. 4 


\section{Core Data Log}

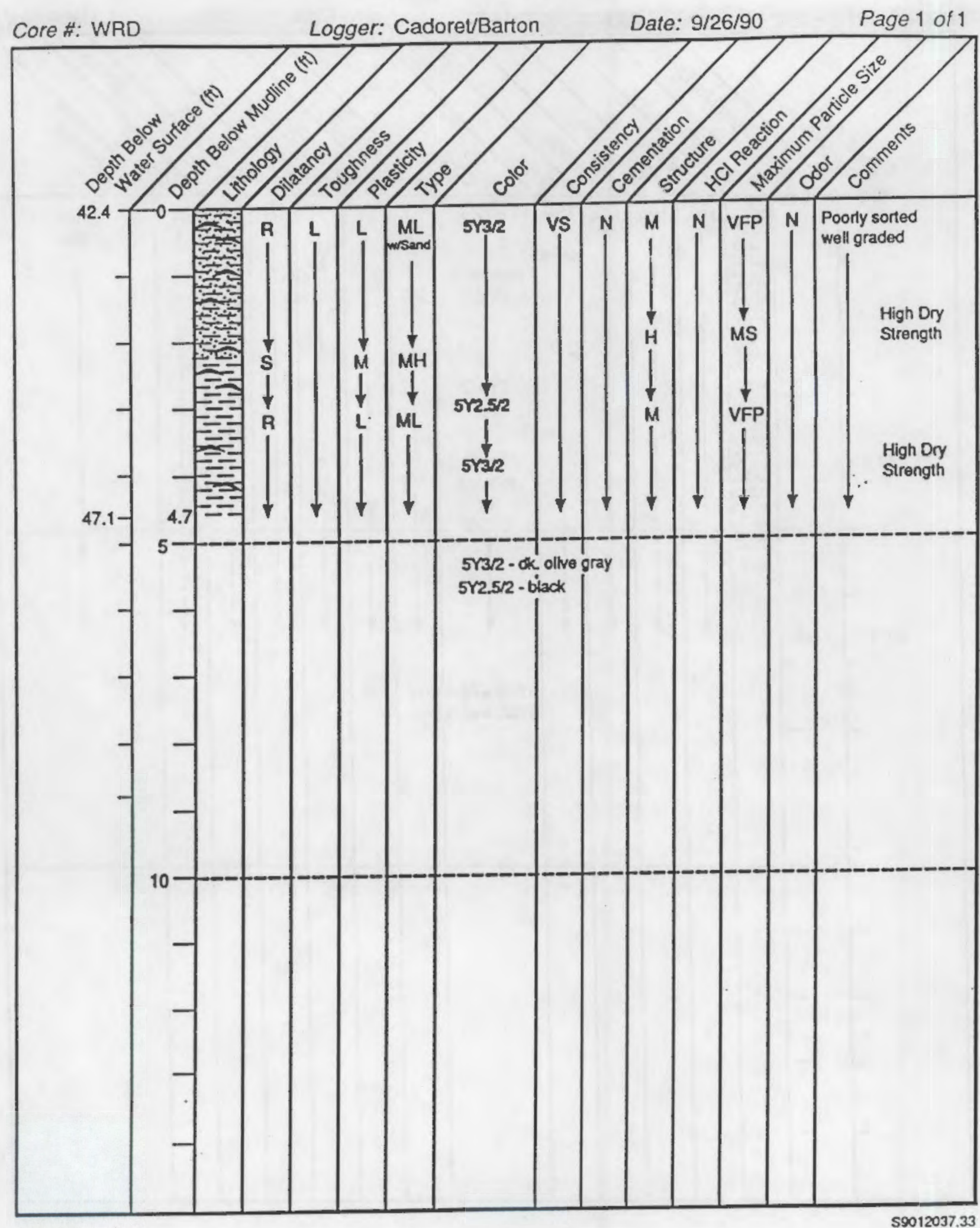


Core Data Log

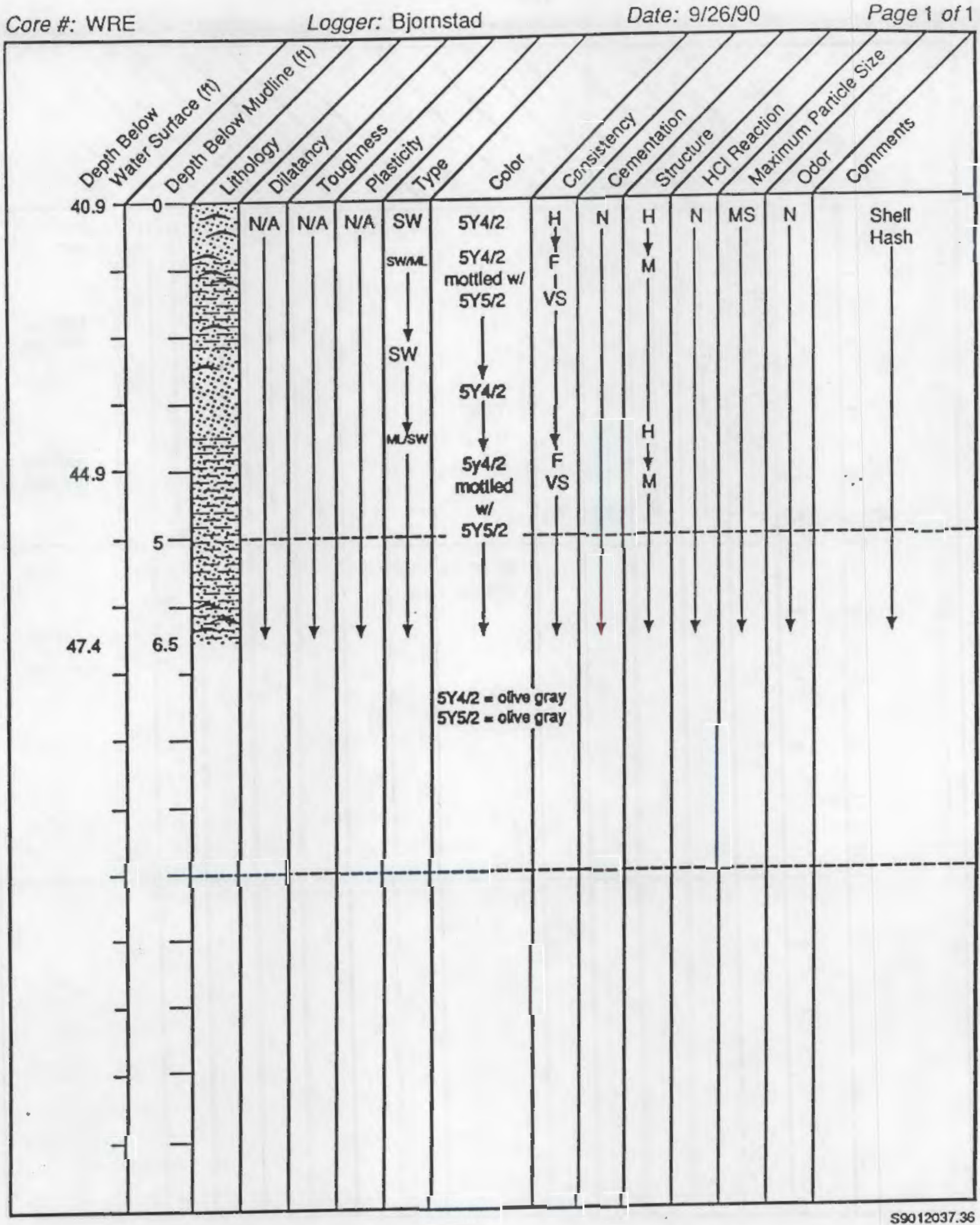

B. 6 


\section{DISTRIBUTION}

No. of

Copies

OFFSITE

2 DOE/Office Scientific and Technical Information

5 S. Lemlich

U. S. Army Corps of Engineers

San Francisco District

211 Main Street

San Francisco, CA 94105-1905

R. Chisholm

U. S. Army Corps of Engineers San Francisco District

211 Main Street

San Francisco, CA 94105-1905
No. of

Copies

ONSITE

31 Pacific Northwest Laboratory

K. 0. Barton

E. A. Crecelius

R. M. Ecker

R. Cuello

J. W. Falco

M. R. Finney

P. C. Hays

N. P. Kohn (5)

L. F. Lefkovitz (2)

G. P. O'Connor

M. R. Pinza

R. M. Thom

J. A. Trelstad (2)

J. A. Ward

J. Q. Word (5)

Publishing Coordination

Technical Report Files 
